Portland State University

PDXScholar

Spring 7-10-2019

\title{
Regional Modeling of the Glaciers of the North Cascades Mountains, Washington, USA
}

Christina Eileen Gray

Portland State University

Follow this and additional works at: https://pdxscholar.library.pdx.edu/open_access_etds

Part of the Geology Commons

Let us know how access to this document benefits you.

\section{Recommended Citation}

Gray, Christina Eileen, "Regional Modeling of the Glaciers of the North Cascades Mountains, Washington, USA" (2019). Dissertations and Theses. Paper 5037.

https://doi.org/10.15760/etd.6913

This Thesis is brought to you for free and open access. It has been accepted for inclusion in Dissertations and Theses by an authorized administrator of PDXScholar. Please contact us if we can make this document more accessible: pdxscholar@pdx.edu. 
Regional Modeling of the Glaciers of the North Cascades Mountains, Washington, USA

by

Christina Eileen Gray

A thesis submitted in partial fulfillment of the requirements of the degree of

\author{
Master of Science \\ In \\ Geology
}

\author{
Thesis Committee \\ Andrew G. Fountain \\ Brian Menounos \\ Adam Booth \\ Paul Loikith
}

Portland State University

2019 


\begin{abstract}
Glaciers in the North Cascades store winter snowfall as ice and release it in late summer as melt, providing an important regional source of water and hydroelectric energy. The future of glaciers in the North Cascades, Washington, were evaluated using a regional glaciation model driven by the Community Climate System Model 4 global climate model. The climate model was coupled with three Representative Concentration Pathways (RCPs), 2.6, 4.5, and 8.5. These RCPs provide a business-as-usual scenario (RCP 8.5), which assumes society makes little to no efforts to reduce greenhouse gas emissions, a best-case scenario (RCP 2.6) with strong attempts to mitigate greenhouse gas emissions, and a moderate scenario (RCP 4.5). Spun up from 850 C.E., modeled glacier area for 1970 was $96-102 \%$ of observed. By 2100 the predicted area relative to the total observed area in 1900 was $42 \%$ for RCP $2.6,16 \%$ for RCP 45 , and $5 \%$ for RCP 8.5. By 2100 only glaciers on high peaks, such as Mt. Baker and Glacier Peak, will remain $\left(145.98 \mathrm{~km}^{2}, \mathrm{RCP} 2.6 ; 70.49 \mathrm{~km}^{2}, \mathrm{RCP} 4.5 ; 16.82 \mathrm{~km}^{2}, \mathrm{RCP} 8.5\right)$ and entirely gone by 2200 in any of the three climate scenarios.
\end{abstract}




\section{Acknowledgements}

I would like to thank thesis advisor, Dr. Andrew G. Fountain of the Geology Department at Portland State University. He always was available whenever I ran into trouble and would point me in the right direction to figure out the answer, pushing me to make my thesis better than I ever could alone.

I would also like to thank Brian Menounos, Paul Loikith, and Adam Booth for being on my thesis committee. They were always available when I had questions about aspects of my thesis outside of my expertise, as well as reading my work.

Finally, I am grateful to the Portland State Glacier Research Team, Bryce Glenn, Luna Brett, Felix Zamora, and Julian Cross for being there to bounce ideas off, discuss glaciers in general and to commiserate, as well as the support of my fellow graduate student, my parents, sister, and boyfriend for supporting me throughout my years of study, research, and thesis writing. This would not have been possible without them. 


\section{Table of Contents}

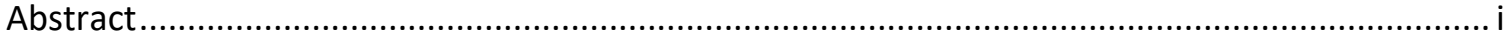

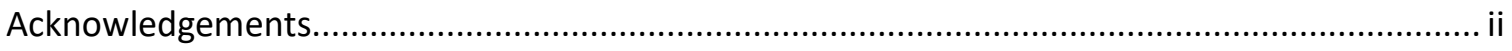

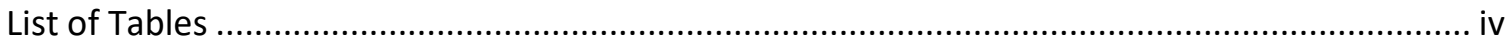

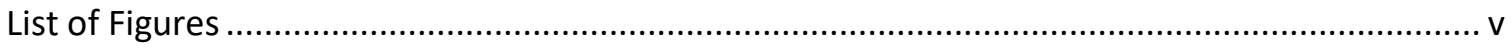

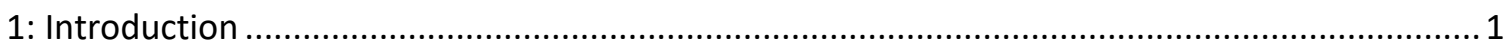

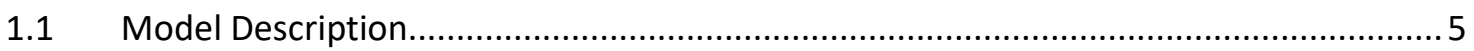

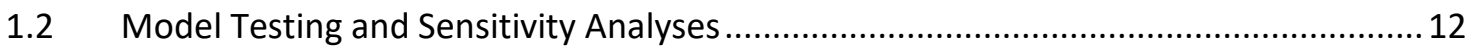

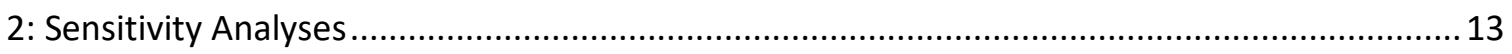

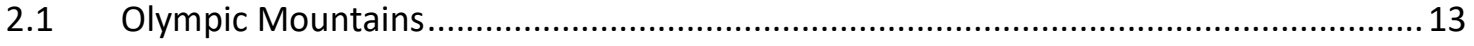

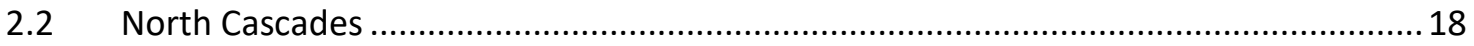

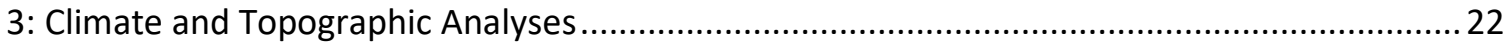

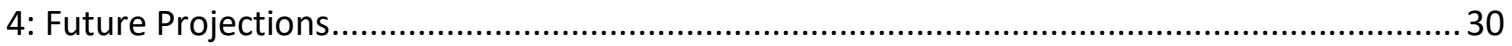

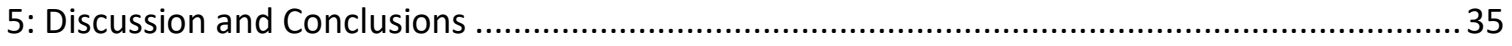

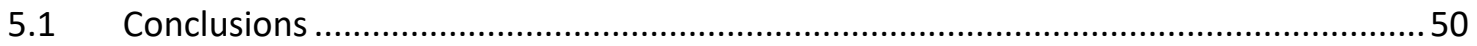

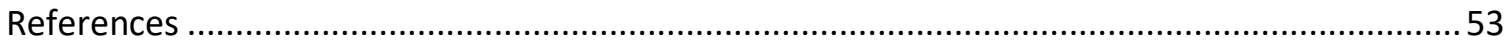

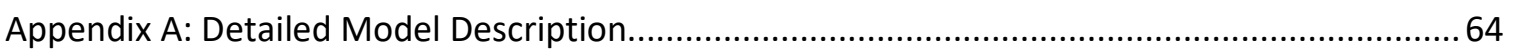

Appendix B: Olympics Sensitivity Analysis and Justification ...........................................................73

Appendix C: North Cascades Sensitivity Analysis ...........................................................................

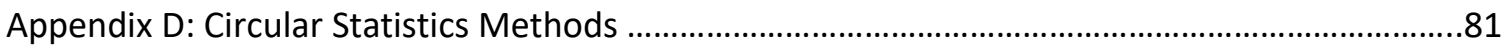

Appendix E: Final Model Climate Analyses: RCP 8.5 and 2.6 and Seasonal Trends for RCP 4.5.....83

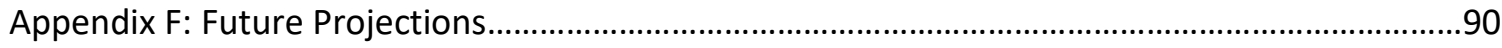




\section{List of Tables}

Table 2.1: Summary of sensitivity analyses for the Olympics using RCP 4.5 and their effects on the glacier area and the distribution of glaciers with topography.

Table 2.2: Comparison of the parameters used to model the North Cascades and their accuracy

Table 3.1: Statistical tests compare the location of correctly modeled glaciers and missing glaciers relative to climate and topography in the North Cascades..... .26

Table 5.1: Comparison of the final parameters of all final model applications. ... 36 Table 5.2: Table of the total area and Fractional Area Change (FAC) with respect to the modeled glacier area...... 46 


\section{List of Figures}

Figure 1.1: North Cascades region is picture here with the Randolph Glacier Inventory.

Figure 1.2: Comparison of different Representative Concentration Pathways (RCP) for future global climate change

Figure 2.1: Figure of the location misfit of the application the intermediate model in the Olympic Mountains. (

Figure 2.2: Distribution of modeled glaciers using RCP 4.5 as compared to 1970 observed glaciers extents in the North Cascades.

Figure 3.1: Monthly PRISM averages of mean precipitation and temperature from 1961-1970 over the North Cascades.

Figure 3.2: Map of two climate/glacier profiles though the North Cascades.............................23 Figure 3.3: Distribution of summer air-temperature, winter precipitation, and average annual insolation over modeled glaciers and missing glaciers from the application of the final model to the North Cascades.

Figure 3.4: Comparison of the distribution of correctly modeled glaciers and missing glaciers with both summer air-temperature and winter precipitation in the North Cascades.

Figure 3.5: Histograms for glacier area with location misfit category.

Figure 3.6: Comparison of historic output with estimated North Cascades glacier extents from LIA ( 1900), 1958, 1970, 1983, 1990, 1998, and 2009 (.

Figure 4.1: Area with respect to 1900 North Cascades modeled glacier area for all RCPs. ......... 31 Figure 4.2: Change in glacier distribution with topography over time in the North Cascades, with RCP 4.5 .

Figure 4.3: Change in glacier area with winter precipitation over time for the application of the final model to the North Cascades, with RCP 4.5.....

Figure 5.1: Change in volume over time in the North Cascades for each RCP

Figure 5.2: The amount of glacier discharge from fossil water, which is water stored as ice in the glacier, for RCP 4.5 . 


\section{1: Introduction}

Glacier change affects global sea level, which in turn can affect coastline cities and industries (Meier, 1984; Radic and Hock, 2001). Glaciers can also be used to infer climate history (Haeberli and Hoelzle, 1995; Thackery, 2001) and are agents of long-term erosion of mountains (Mitchell and Montgomery, 2006; Bennett and Glasser, 2009). The glaciers of the North Cascade Mountains are a large source of alpine stream flow and runoff, affecting its seasonal variation and late season water flow, which supplies water and hydroelectric energy to the surrounding localities (Fountain and Tangborn, 1985; Pelto, 1993). Quantifying the variability of glacier response to climate change will thus aid in predicting water runoff for ecological and anthropogenic needs (Brown et al., 2007; Grah and Beaulieu, 2013). Also, understanding the spectrum of glacier responses to the same regional climate forcing will provide uncertainty bounds on inferences of regional paleo-glacier change derived from investigations that focus on a single glacier. North Cascade glaciers have been retreating since the end of the Little Ice Age (LIA) (Pelto, 2008a) with a hiatus between 1944 and 1976 where glaciers stabilized and, in some cases, advanced (Dick, 2013). Retreat of most glaciers by the mid-1980's most glaciers was initiated by a shift to a warm phase of the Pacific Decadal Oscillation (PDO) in 1976/77 (Pelto, 1993; Hodge et al., 1998; Dick, 2013; Mote et al., 2018). Between 1958 and 1998, the glaciers in the North Cascades National Park Complex lost $~ 7 \%$ of their area and $\sim 8 \%$ of their volume (Granshaw and Fountain, 2006). This rate of retreat is similar to glaciers in many other regions around the globe (Paul et al., 2005; Radic and 
Hock, 2011; Radic et al., 2014; Beedle et al., 2015; Huss and Fischer, 2016) and is expected to continue. However, it is important to note that in some observational studies based on aerial photography retreat, while still present, may be inflated due to the inclusion of seasonal snow in the glacier inventory (Beedle et al., 2015). In the future the glaciers are expected to continue to retreat based on modeling results in neighboring British Columbia, Canada (Clarke et al., 2015). Glaciers in British Columbia are predicted to lose $70 \pm 10 \%$ of their volume by 2100 relative to 2005 (Clarke et al., 2015) and the North Cascades, a few $100 \mathrm{~km}$ south, are expected to react similarly

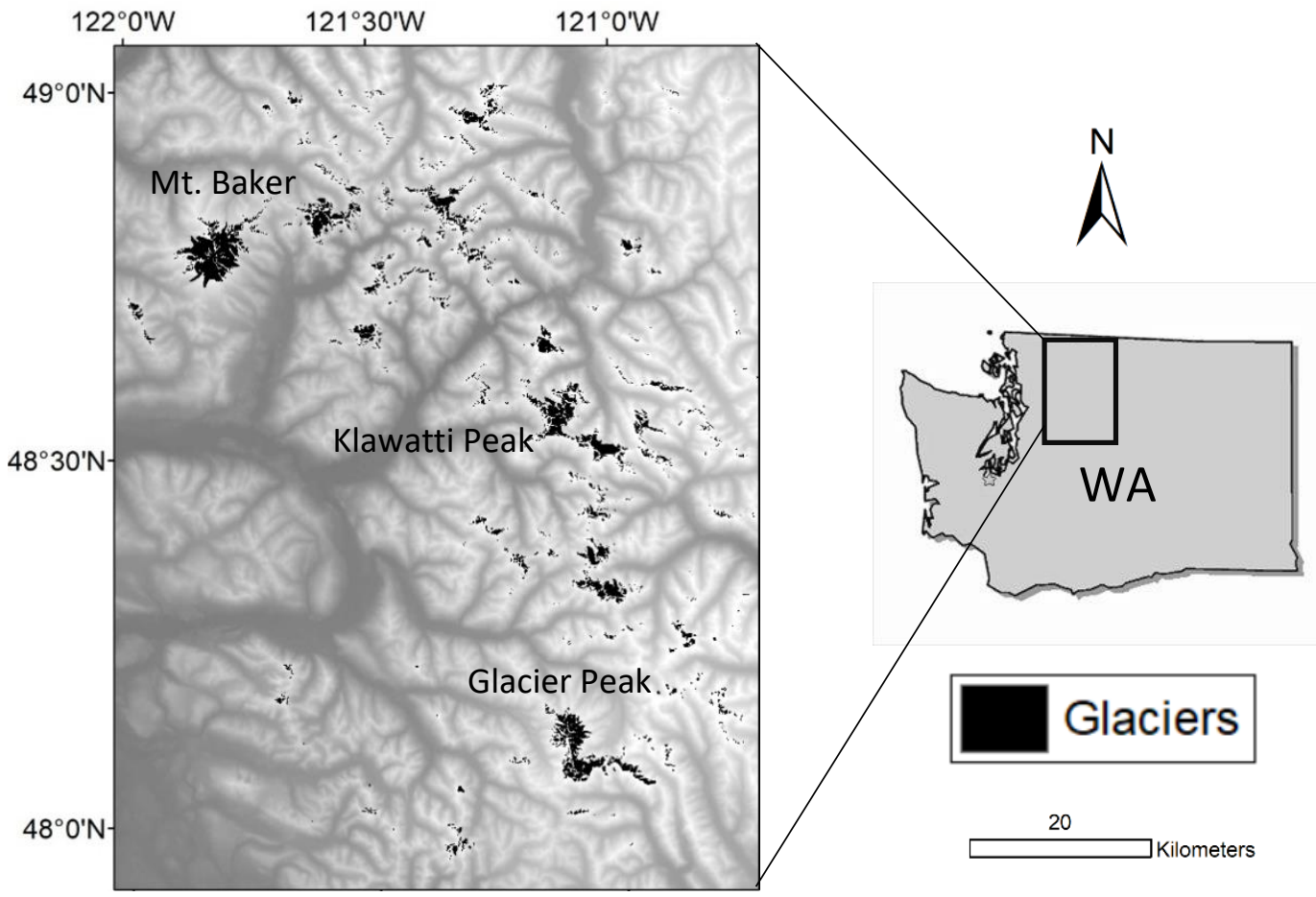

Figure 1.1: North Cascades region is picture here with the Randolph Glacier Inventory (in black) and with a background of the Shuttle Radar Topography Mission Digital Elevation Model and. The inset map shows Washington State and the approximate location of the North Cascades outlined in solid black. 
based on other observational studies (Dick, 2013). The goal of this thesis is to examine how glaciers in the North Cascades will respond to a future climate, determine the response spectrum of glacier retreat with respect to future climate, and conclude whether topography is an influence.

The study region covers $\sim 47^{\circ} 90^{\prime}$ to $49^{\circ} 0^{\prime} \mathrm{N}$ and $120^{\circ} 40^{\prime}$ to $122^{\circ} 0^{\prime} \mathrm{W}$ (Figure 1.1) and ranges in elevation from 500-3,300m asl. (Post et al., 1971; Fountain et al., 2017). In the alpine regions grand (Abies Grandis) and Douglas (Pseudotsuga Menziesii) firs dominate, and the tree line is at approximately $1800 \mathrm{~m}$ (USDA Forest Service, 1981). The climate of the North Cascades is maritime, characterized by mild weather of cool summers $\left(10.7^{\circ} \mathrm{C}\right)$ and relatively warm winters $\left(-3.5^{\circ} \mathrm{C}\right)(\mathrm{NOAA}, 2018)$. Two distinct climatic zones exist: precipitation on the western slopes is higher $(1,400-3,000 \mathrm{~mm}$ annually) than on the eastern slopes $(200-500 \mathrm{~mm})$, the latter being in a rain shadow (Ruffner, 1985; Hayes et al., 2002). Annual temperature on the western slopes are also $\sim 4{ }^{\circ} \mathrm{C}$ warmer on average than the eastern side due to pooling of cold, Arctic air masses (Colle and Mass, 1998; Mass 2015). Most precipitation in both zones falls between October and April ( 83\%) (NOAA, 2003). For the entire North Cascades, at high elevations (greater than $\sim 2000 \mathrm{~m}$ ) winter precipitation falls as snow, and snowpack is thickest between February and April, with spring melt beginning in March for most years (Natural Resource Conservation Service, 2017). Over the past 50 years peak seasonal snowpack has thinned because winter temperatures have warmed, changing the phase of precipitation (McCabe and Wolock, 2011; Mote et al., 2018). Alternatively, it has 
been proposed that declining streamflow from high elevations could be due to a weakened rainshadow effect caused by a lessening of lower tropospheric westerlies (Luce et al., 2013), decreasing snowpack through a lack of precipitation rather than warming temperatures.

The glaciers in the study region cover a combined area of about $288.4 \mathrm{~km}^{2}$ based on the US Geological Survey 1:24000 scale maps over the 28-year period of 1957-1985 (Granshaw and Fountain, 2006; Riedel and Larrabee, 2011; Dick, 2013; Fountain et al., 2017). Elevations range from 593 to $3,282 \mathrm{~m}$ above sea level (asl) with an average elevation of $1948 \mathrm{~m}$ asl. Most glaciers in this region ( 67\%) face north-easterly, as expected for glaciers in the Northern Hemisphere. In 2009 the North Cascades had a combined area of $236.2 \pm 12.6 \mathrm{~km}^{2}$, with the largest being Coleman Glacier $\left(6.83 \mathrm{~km}^{2}\right)$ (Dick, 2013). About 1,935 glaciers exist in the North Cascades, with a mean and median area of $0.15 \mathrm{~km}^{2}$ and of $0.03 \mathrm{~km}^{2}$ respectively (Dick, 2013).

Glaciers in the North Cascades show an overall retreat (Hodge et al., 1998; Pelto, 2008a; Riedel and Larrabee, 2011). For instance, between 1984 and 2006 the mean cumulative annual balance of 47 actively monitored glaciers in the North Cascades was 12.4 meter water equivalent (m.w.e.) (Pelto, 2008a). Assessment of historic changes in glacier area include the North Cascades (Bitz and Battisti, 1999; Granshaw and Fountain, 2006; Dick, 2013), Olympics (Riedel et al., 2015; Armstrong, 1989; Hubley, 1956), Mount Rainier (Sisson et al., 2011; Riedel et al., 2011), Mount Adams (Sitts et al., 2010), Mount Hood (Lillquist and Walker, 2006; Jackson and Fountain, 2007), Goat Rocks (Heard, 
2012), and the Three Sisters (O'Connor, 2013; Ohlschlager, 2015). These studies also note an overall glacier loss. For instance, Dick (2013) estimates that from 1900-2009 the glaciers of the North Cascades have lost over half their area (-56\%), even with a period of stability and growth from the 1950 s to 1980 s. The magnitude of loss is variable between glaciers, especially among small $\left(<0.5 \mathrm{~km}^{2}\right)$ glaciers. Also, smaller glaciers lose proportionately more area and volume than larger glaciers (Granshaw and Fountain, 2006; Dick, 2013). Such variability is common for glaciers elsewhere (Paul and Haeberli, 2008; DeBeer and Sharp, 2009). Although glacier growth and shrinkage are caused by regional climatic factors (Bennett and Glasser, 2009), changes in glacier area can be modified by local factors such as the altitude, slope, and aspect (DeBeer and Sharp, 2009; Basagic and Fountain, 2011; DeVisser and Fountain, 2015). Specific examples in the North Cascades are the North and South Klawatti glaciers, which area adjacent and therefore in approximately the same climate. They respond to climate differently because of the distribution of their areas with altitude. The South Klawatti Glacier has more area at higher elevations than the North Klawatti Glacier, leading to a greater accumulation and subsequent advance of the former and the recession of the latter (Tangborn et al. 1990). The North Klawatti glacier lost volume between 1947 and 1961 whereas the South Klawatti gained volume over the same time period, even though they are neighboring glaciers.

\subsection{Model Description}

To predict the future behavior of the glaciers in the North Cascades the Regional Glaciation Model (RGM) was employed (Clarke et al., 2015). The RGM is a distributed 2- 
dimensional plan-view model that assumes the shallow ice approximation, which only considers the effect of gravitational driving stress and basal drag (Le Meur et al., 2004; Cuffey and Patterson, 2010). Glacier mass is redistributed as ice deforms and moves downslope. Details of how the model handles ice dynamics are summarized in Appendix A. Adjustable model parameters include ice softness, density, and sliding. Ice softness and density control ice deformation and have a well-defined range for ice given the ice temperature (Marshall, 2005; Cuffey and Patterson, 2010). The sliding parameter controls the speed of basal movement over the substrate and is poorly constrained, and thus has often been a tuning parameter in glacier models (Le Meur et al., 2007; Farinotti et al., 2009; Goehring et al., 2012). Other parameters include climate forcing parameters, which are key in estimating ice melt, such as the bulk melt parameter, snow and ice radiation parameters, and solar illumination time, which is used to estimate insolation from the sun's position at a given time. The bulk melt and radiation parameters control the amount of snow/ice melt and are calculated empirically. Solar radiation has strong controls on glacier distribution with topography, particularly aspect.

Glacier mass gain and loss is estimated using a temperature index model/solar radiation at monthly time steps (Hock, 1999). A threshold air temperature differentiates whether precipitation falls as snow or rain, and the magnitude of snow or ice melt depends on air temperature and solar insolation. Mean monthly degree-days are calculated by a normal or Gaussian-distribution, and the bulk melt and snow/ice radiation parameters are necessary. Clear sky insolation is estimated using the 
Geographic Resources Analyses Support System (GRASS) (GRASS Development Team, 2014; Clarke et al., 2015) to make twelve monthly solar radiation grids for the model
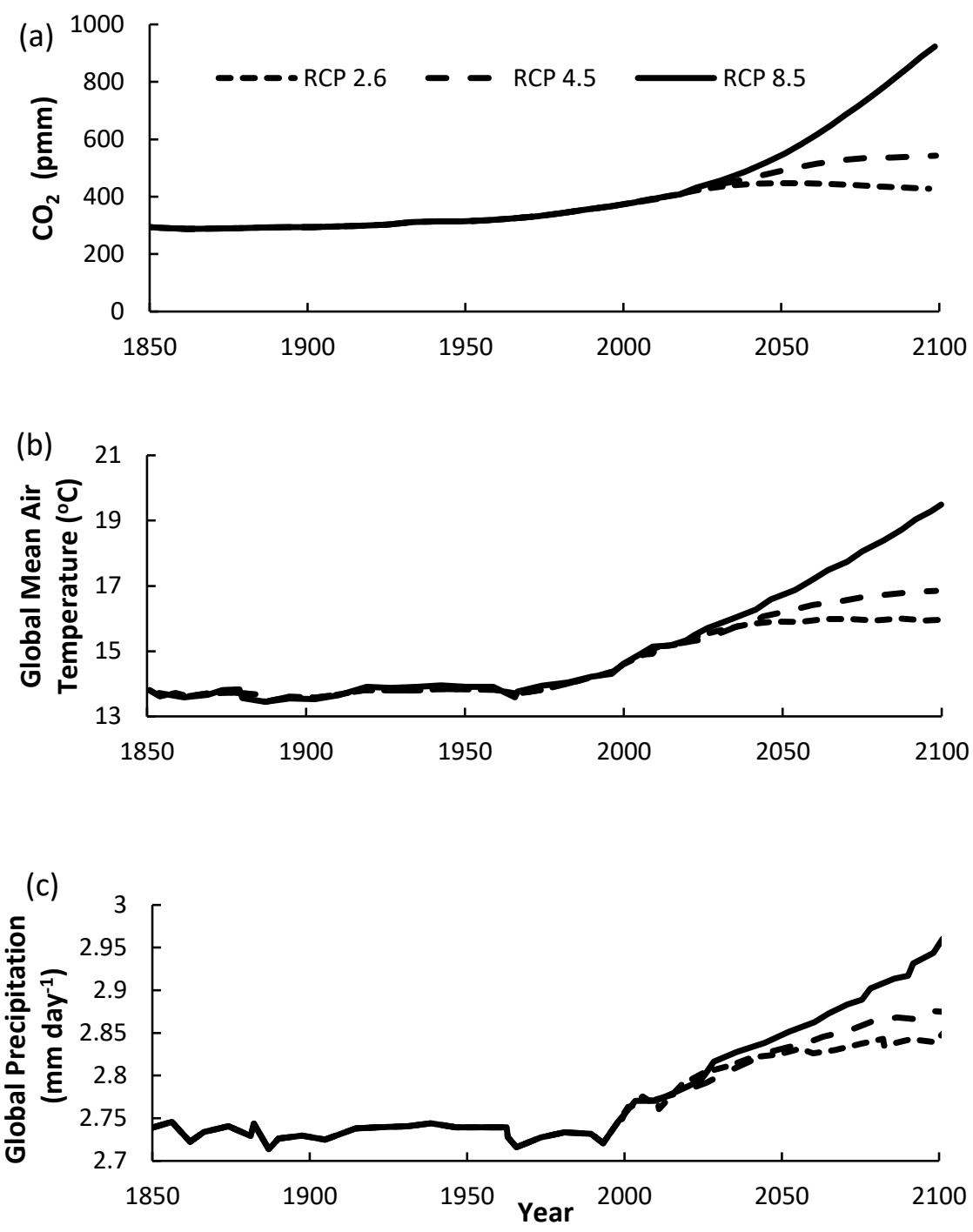

Figure 1.2: Comparison of different Representative Concentration Pathways (RCP) for future global climate change. RCP 2.6 is the most conservative, and RCP 8.5 the most extreme. The $\mathrm{CO}_{2}$ variation for each model (a), the global mean screen temperature (b), and the global mean precipitation ( $\mathrm{mm} /$ day) (c) over time. While the RCPs encompass many greenhouse gases $\left(\mathrm{CH}_{4}, \mathrm{~N}_{2} \mathrm{O}\right.$, etc.) only $\mathrm{CO}_{2}$ is reported here due to its long lifespan in the atmosphere causing relatively large and lasting effects on climate (Driver and Chapman, 1996). Figures modified from Arora et al. (2011). 
domain. The parameters that relate degree-days and solar insolation, including albedo, to melt of snow and ice (separately) are relatively unconstrained. Further detail can be found in Appendix A.

To estimate climate, past and future, a global climate model (GCM), the Community Climate System Model 4 (CCSM4) was used. Based on a comparison with other models, the CCSM4 family had less error relative to other models. CCSM4's highest error is with seasonal climate variations, but even this error is less than many other available models (Rupp et al., 2013). For air temperature, CCSM4 has trouble estimating short term variations (less than a year), but performance is better over longer time scales ( 8 years). For precipitation, its error is less or equal to other models (Moss et al., 2010; Rupp et al., 2013).

Future climate depends on the concentration of greenhouse gases in the atmosphere (Moss, 2010). To accommodate a variety of predictions, I employ three different Representative Concentration Pathways (RCPs): 2.6 , 4.5, or 8.5. These different scenarios are based on different assumptions about the future of climate policy, socioeconomics, technology, and environmental regulations (Moss et al., 2010). All RCPs predict increases in radiative forcing from the end of the preindustrial epoch (1850 C.E.) to 2100. RCP 8.5 is the "business-as-usual scenario", predicting greater than $8.5 \mathrm{~W} \mathrm{~m}^{-2}$ radiative forcing due to greenhouse gas emissions, a global air temperature increase of $4.5^{\circ} \mathrm{C}$ and $\sim 5 \%$ increase in global precipitation by 2100 (Figure 1.2). Alternatively, RCP 2.6 predicts a peak of $\sim 3 \mathrm{~W} \mathrm{~m}^{-2}$ in 2100 before a decline in carbon emissions, the largest 
driver in anthropogenic climate change, which would likely lead to a $1.5^{\circ} \mathrm{C}$ increase in air temperature and a $\sim 2 \%$ increase in precipitation (Moss et al., 2010). RCP 4.5 predicts an increase of $4.5 \mathrm{~W} \mathrm{~m}^{-2}$ by 2100 , which would lead to an increase in air temperature of $\sim 2-3{ }^{\circ} \mathrm{C}$ and $\sim 2.5 \%$ increase in precipitation. $\mathrm{RCP} 4.5$ provides a middle estimate, while RCP 2.6 and RCP 8.5 provide plausible bounds.

Spatial resolution of the $\operatorname{GCM}\left(1^{\circ}, \sim 100 \mathrm{~km}\right)$ is far too coarse to model the small alpine glaciers. Therefore, the GCM temperature and precipitation is downscaled using the North American Regional Reanalysis (NARR) (Mesinger et al., 2006). Reanalysis datasets such as NARR are traditionally poor at estimating surface variables such as temperature and precipitation compared to gridded datasets based on observations, but are better in regions with sparser weather station coverage, such as British Columbia, the original application of the model (Essou et al., 2016). "Deltas," which are the differences of the GCM output in a given month and year from a modern monthly GCM average (1981-2010), are added (temperature) or multiplied (precipitation) to the static NARR average over the same time period. NARR is re-gridded to $100 \mathrm{~m}$ resolution using a simple bilinear interpolation.

Before the model is run the surface must be bare-earth, vacant of glaciers, so subglacial topography can first be estimated before the addition of ice. This bare-earth model is the lower boundary condition of the model. Subglacial topography is estimated using the method of Huss and Farinotti (2012), which involves estimating the surface mass balance, calculating the volumetric balance flux, and then converting the 
volumetric flux into thickness. This method assumes the glaciers are in equilibrium. Initial glacier surface elevation is based on the Shuttle Radar Topography Mission DEM, 100 m resolution, acquired February 2000 (USGS, 2006), and the glaciers outlines are from the Randolph Ice Inventory (RGI), version 5 (Pfeffer et al., 2014) derived from glacier outlines delineated by USGS 1:24000 (24K) scale maps (USGS, 1998). Global ice volume calculated based on the surface inversion was found to have an uncertainty of $\pm 11 \%$, though for individual glaciers it could be as large as $30 \%$ (Huss and Farinotti, 2012).

The model was initially applied to British Columbia, a region of overall similar climate trends to the North Cascades, though further north the climate becomes much colder and trends in glacier retreat may by opposite those in Washington due the long term climate oscillations (Mantua et al., 1997; Hodge et al., 1998; Clarke et al., 2015). To predict future climate the study used an ensemble of GCMs from the Coupled Model Intercomparison Project Phase 5 with RCP 2.6, 4.5, 6.0, and 8.5, where applicable, to derive a median estimate for glacial response to climate change. Results show good correspondence between modeled and measured glacier-covered area with an overall uncertainty of $\pm 10 \%$ (Clarke et al., 2015). The model had the most difficulty modeling the coastal glacier extent (from St. Elias to Vancouver Island) (+17.8\%), whereas the Interior and Rocky Mountains had much smaller error (-3.6\% and $-2.9 \%$, respectively). This likely due to two reasons: error in the input precipitation data and very small glaciers in Vancouver Island. 
The original code was modified by Menounos in several ways (Menounos, personal communication, October, 2016), which included modifying the calculation of degree days to reduce processing timemand calculating solar radiation variations on the fly based on changes in the Sun-Earth distance over long time periods, which allows for passive consideration of cloudiness from the GCM input of radiate downwelling short wave radiation. Additionally, the code was also modified to employ a gridded observation dataset (PRISM), which interpolates values from snow telemetry (SNOTEL) weather stations, rather than a reanalysis dataset, which uses a model to estimate climate for spatial variations in temperature and precipitation. The melt subroutine was modified to calculate monthly degree-day values using an analytical derivation of an approximation, which reduces processing time (Calov and Greve, 2005). Originally the RGM employed a static solar radiation grid but to calculate radiation over millennia, an interest of Menounos, the RGM had to account for variations in the Earth's orbit, which varies significantly and greatly affects solar intensity over this time period. These variations are recalculated each month. This feature was not relevant to my application of the model, which focuses on a period of about two centuries. The model has the capability to begin in the far past, where the position of the sun relative to the earth is significantly different from present, but is less important in such a short period of time. The downscaling of the GCM was changed from the NARR to the Parameter-elevation Relationships on Independent Slopes Model (PRISM) (Daly et al., 2008) to better estimate spatial variations of surface temperature and precipitation. As mentioned 
previously, PRISM does better than NARR where surface observations are relatively common. Finally, the original code only calculated lapse rate at elevations over $1000 \mathrm{~m}$ to avoid temperature inversions in the valley bottom. Because glaciers in the Pacific Northwest exist below 1000 m, lapse rates were calculated from sea level. For further details, see Appendix A.

\subsection{Model Testing and Sensitivity Analyses}

I initially tested the modified code on the glaciers of the Olympic Peninsula, Washington, where the model domain is smaller than the North Cascades, significantly reducing run-time. The climates are comparable and the glaciers are similarly small. Initial tests revealed an error in the solar radiation code that offset the peak solar partition by $\sim 90^{\circ}$ counterclockwise, so instead of peak insolation occurring in the southwest it occurred in the northwest. Also, it was determined that the calculation of elevation gradient, which estimated local slope from the DEM and influences the calculation of aspect, was being affected by DEM error. By changing the calculation from a 3-cells in a line slope, applied to a center cell, to a simple average over six cells applied to a center cell, the gradient of the DEM is smoothed (Zhou and Liu, 2004). An arctangent function was then used on the $\mathrm{x}, \mathrm{y}$ gradients to estimate as slope direction. To convert the direction of azimuth degrees I added a new mapping (see Appendix c).

To test the sensitivity of the model, each of the five adjustable parameters were varied by $\pm 10 \%$. The sixth parameter, solar illumination time, was changed by $+2 \mathrm{hrs}$. and +4 hrs. from 5 PM UTC (10 AM PST) to 7 PM UTC (12 PM PST) and 9 PM UTC (2 PM 
local time), respectively. Because the sun is close to its zenith, the dependence of glaciers with aspect is minimized. Each parameter was individually changed while the others were held constant. The climate model was unchanged during this process. Glacier volume, while estimated in the model, is not used to calibrate the model here due to a lack of measured glacier volumes in this region.

Model performance is evaluated with a comparison to observed glacier inventories and measured glacier metrics. Comparison metrics include total glacier area, location, and root mean square error (RMSE) of glacier distribution with aspect, slope, and elevation. The location metric has three categories: correctly modeled, overlap between modeled and observed glaciers; extra, predicted but not observed; missing, observed but not predicted. Due to the size of the study area, calibration focused on optimizing correctly modeled glaciers and reducing missing and extra ice, but traditional accuracy measurements were also considered. Note that the model creates rasterized ice distributions rather than glacier outlines, and clusters of adjacent ice-filled cells are considered glaciers. The observed glacier extents were obtained from the Randolph Ice Inventory (Pfeffer et al., 2014), dating to 1986 for the Olympic Mountains.

\section{2: Sensitivity Analyses}

\subsection{Olympic Mountains}

Sensitivity analyses based on adjustments of the original model parameters (based on the initial application of the model in British Columbia) showed that in the model ice area is relatively insensitive to physical parameters such as ice softness and 
Table 2.1: Summary of sensitivity analyses for the Olympics using RCP 4.5 and their effects on the glacier area and the distribution of glaciers with topography. Original refers to the initial model runs based on parameters used from the previous British Columbia application of the RGM, Intermediate refers to initial adjustments to the various physical and climate forcing parameters to match modeled area to observed, and Final refers to the model where parameters were adjusted to minimize extra ice before employing a precipitation mask to double precipitation over areas of missing ice. Statistics include root mean square error (RMSE) values for aspect and elevation (raster cells, normalized to area), modeled glacier area and location misfit $\left(\mathrm{km}^{2}\right)$ the percent of the modeled area with respect to the 1986 observed glacier area (Percent Modeled), and the percent of glacier location correctly modeled with respect to 1986 observed glacier area (Correct Location).

\begin{tabular}{|c|c|c|c|}
\hline Parameters & Original & Intermediate & $\underline{\text { Final }}$ \\
\hline Bulk Melt (mm day $\left.{ }^{-1}{ }^{\circ} \mathrm{C}^{-1}\right)$ & $1.1 \times 10^{-3}$ & $1.15 \times 10^{-3}$ & $1.15 \mathrm{x}$ \\
\hline $\begin{array}{l}\text { Snow Radiation } \\
\left(\mathrm{m}^{2} \mathrm{~W}^{-1} \mathrm{~mm} \text { day }^{-1}{ }^{\circ} \mathrm{C}^{-1}\right)\end{array}$ & $1.022 \times 10^{-5}$ & $1.022 \times 10^{-5}$ & \\
\hline Ice Radiation $\left(\mathrm{m}^{2} \mathrm{~W}^{-1} \mathrm{~mm}\right.$ day $\left.^{-1}{ }^{\circ} \mathrm{C}^{-1}\right)$ & $2.5 \times 10^{-5}$ & $2.5 \times 10^{-5}$ & \\
\hline Solar Illumination Time (UTC) & 17:00:00 & 21:00:00 & $21: 00$ \\
\hline \multicolumn{4}{|l|}{ Results } \\
\hline Aspect RMSE & 0.42 & 0.05 & 0.13 \\
\hline Elevation RMSE & 0.15 & 0.03 & 0.04 \\
\hline Correctly Modeled & 38.34 & 27.00 & 35.14 \\
\hline Missing & 20.67 & 32.01 & 23.97 \\
\hline Extra & 145.89 & 27.19 & 8.5 \\
\hline Modeled Area & 184.23 & 54.19 & 43.54 \\
\hline Percent Modeled & $312 \%$ & $92 \%$ & $74 \%$ \\
\hline Correct Location & $65 \%$ & $46 \%$ & $59 \%$ \\
\hline
\end{tabular}

sliding in reasonable ranges, though changing these parameters outside of accepted ranges can cause significant effects. Ice volume was not tested due to a lack of measured volumes in this region. Changing physical parameters did little to improve errors in glacier area and glacier population (only a $\pm 2 \%$ change from the original error). Density, which was initially changed within the same $\pm 10 \%$ range to be consistent with the other parameters, changed the location error greatly $(-60 \%$ to $+100 \%$ of original error). However, this range is well outside the values expected for temperate ice, and changes in a more realistic range resulted in non-sensitive results (Cuffey and Patterson, 

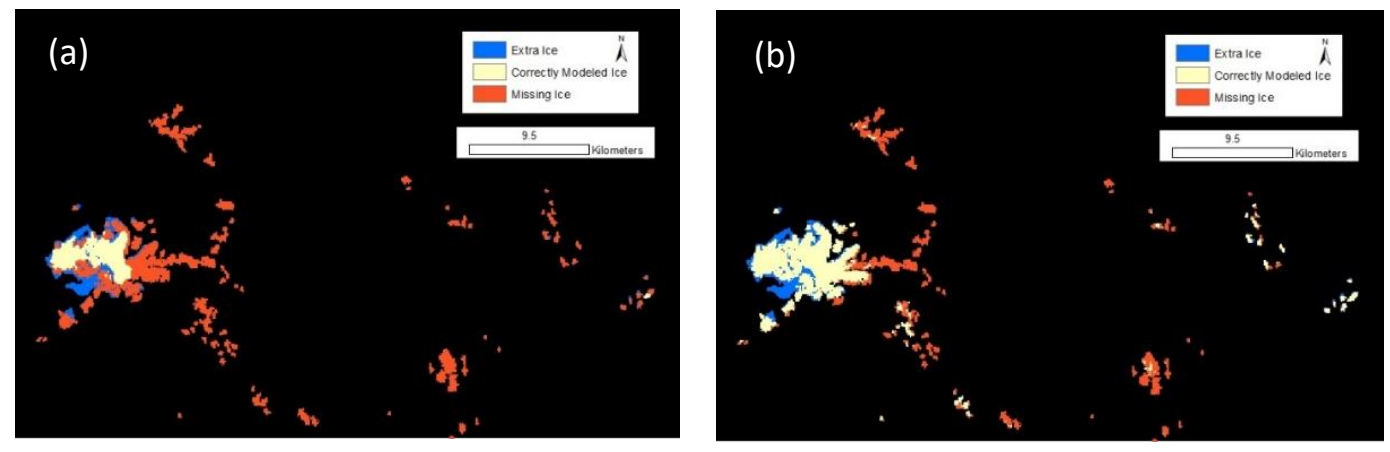

Figure 2.1: Figure of the location misfit of the application the intermediate model with parameters adjusted to match modeled and observed ice in the Olympic Mountains. (a) shows the final model with a $\times 2$ precipitation mask and (b) shows the model parameters using the RCP 4.5 scenario. The Bailey Range and other peaks in the central Olympics, which still have missing glaciers even after applying a multiplier, have been highlighted above in a dashed polygon.

1994). The model is most sensitive to forcing parameters (bulk melt and radiation for snow and ice) and the solar time, which control mass balance and affect the size of the glaciers, but not the quantity (Table 2.1; Appendix B). Changing ice radiation caused little change in the location error relative to the other forcing parameters $(< \pm 10 \%$ for location misfit) because it is not a factor until the snow is melted. Changing the bulk melt and snow radiation parameters greatly altered glacier area $(-38 \%$ to $+50 \%$ of the original location misfit), though it did little to improve location error.

The model was most sensitive to solar time, which was the only parameter that affected the distribution of glaciers with aspect. Solar times of 12 PM and 2 PM local time (PDT) closely matched the observed distribution compared to $10 \mathrm{AM}$, though total glacier area was smaller. Changing solar radiation to $2 \mathrm{PM}$, for example, reduced the aspect error by $30 \%$ of the original error, but increased total glacier area error by $+80 \%$. 
The solar time and forcing parameters were adjusted through trial and error to provide the best agreement between modeled and observed glacier area and distribution with aspect (intermediate model) (Table 2.1). Solar time was first used to fit the modeled aspect distribution to observed, and then bulk melt was used to broadly tune modeled area to observed. Snow and ice radiation were used to compensate for any remaining differences in error, with a final goal to get total modeled area error within a $\pm 10 \%$ range. Accuracy was improved from $91 \%$ to $97 \%$, though it is important to note that this statistic includes the entire study area, including low elevations valleys, which may overlook the misplacement of modeled ice compared to observed.

Overall, despite all adjustments, a total of $23.97 \mathrm{~km}^{2}$ were missing (41\%), most in the central Olympic Mountains around the Bailey Range (Figure 2.1). This could be due to error in PRISM, which used in the model to estimate spatial variation of temperature and precipitation. To test which climate variable may be the cause of the missing glaciers model runs were conducted using only the PRISM climate averages (1981-2010) to simulate steady state and varying temperature and precipitation values to improve model prediction (Appendix A). No realistic change in air temperature resulted in significant improvement, but precipitation is poorly known and can be quite heterogeneous in alpine terrain, and nominal changes were found to greatly improve results (Daly, 2006). Precipitation error was likely either due to orographic effects or local excesses and deficits. The former would be due to incorrectly estimating the rate that precipitation will increase with elevation (lapse rate), and the latter due to error in 
the interpolation scheme caused by the sparse network of weather stations. It was theorized that the region's high precipitation gradient was underestimated in PRISM due to its coastal location ( $0.5 \mathrm{~m} \mathrm{yr}^{-1}$ in the west to $0.2 \mathrm{~m} \mathrm{yr}^{-1}$ in the east, over $55 \mathrm{~km}$ ), so tests of precipitation weighting with elevation error (lapse rate) were conducted. To test if changing the lapse rate would improve ice misplacement, the Olympic Mountain region was divided into multiple subregions, and the model would then calculate multiple regional lapse rates and apply the values to those locals (for details of how the model handles lapse rate, see Appendix A). However, this led to little improvement, indicating that error may be due to the magnitude of local PRISM climate parameters. This is supported by Currier et al. (2017), who checked PRISM's accuracy in the Olympics at lower elevations and found that while average PRISM precipitation over their entire study region was correctly estimated, at smaller scales the error could be quite large. Because glacier size and location are tied so closely to climate, this has large implications for the accuracy of the model.

The model does not consider either avalanche accumulation or wind erosion and deposition, which can be essential to small, lower elevation glaciers (Kuhn, 1995). Additionally, extra ice was likely caused either due to error in PRISM or the lack of wind redistribution removing snow from high peaks. To account for possible error in precipitation a final version of the model, in which parameters were adjusted to reduce extra ice and a precipitation mask of a constant multiplier of $x 2$ over missing glaciers for all RCPs, was created. The multiplier $(x 1.25, x 1.5, x 1.75, x 2)$ was determined based on 
examining the previous testing of the model at steady state (no temporal changes in temperature or precipitation). The precipitation multiplier was initially applied over the entire model domain, but this led to excessive amounts of extra ice, and therefore was applied only over missing glaciers to avoid this issue. While the approach here is simple, precipitation masks have been used to account for precipitation deficits in other studies. For instance, Clarke et al. (2015) applied a similar mask to account for precipitation error in NARR but used a spatially varying factor rather than a static one. Results show greatly increased agreement between modeled and observed glaciers ( $74 \%$ of observed) after the application of the precipitation mask and re-optimization to decrease the total extra ice. Additionally, error in extra and missing glaciers were much smaller (Figure 2.1; Table 2.1), and total accuracy increased to $98 \%$. However, some glaciers are still missing, suggesting that precipitation variation is not adequately described.

\subsection{North Cascades}

The insight gained from applying the model to the Olympic Mountains was applied to the North Cascades. In all permutations of the Regional Glaciation Model (RGM), only the forcing parameters and solar time are changed. A precipitation mask was employed over the areas of missing glaciers following the procedure outlined for the Olympic Mountains. A constant precipitation enhancement was adjusted for all cells that contained observed but not modeled glaciers until the areas closely matched observed 1970 glacier extents. The best fit was a precipitation multiplier of 2 for all RCPs (Figure 2.2), based on the results of steady state analyses. Before the addition of the 


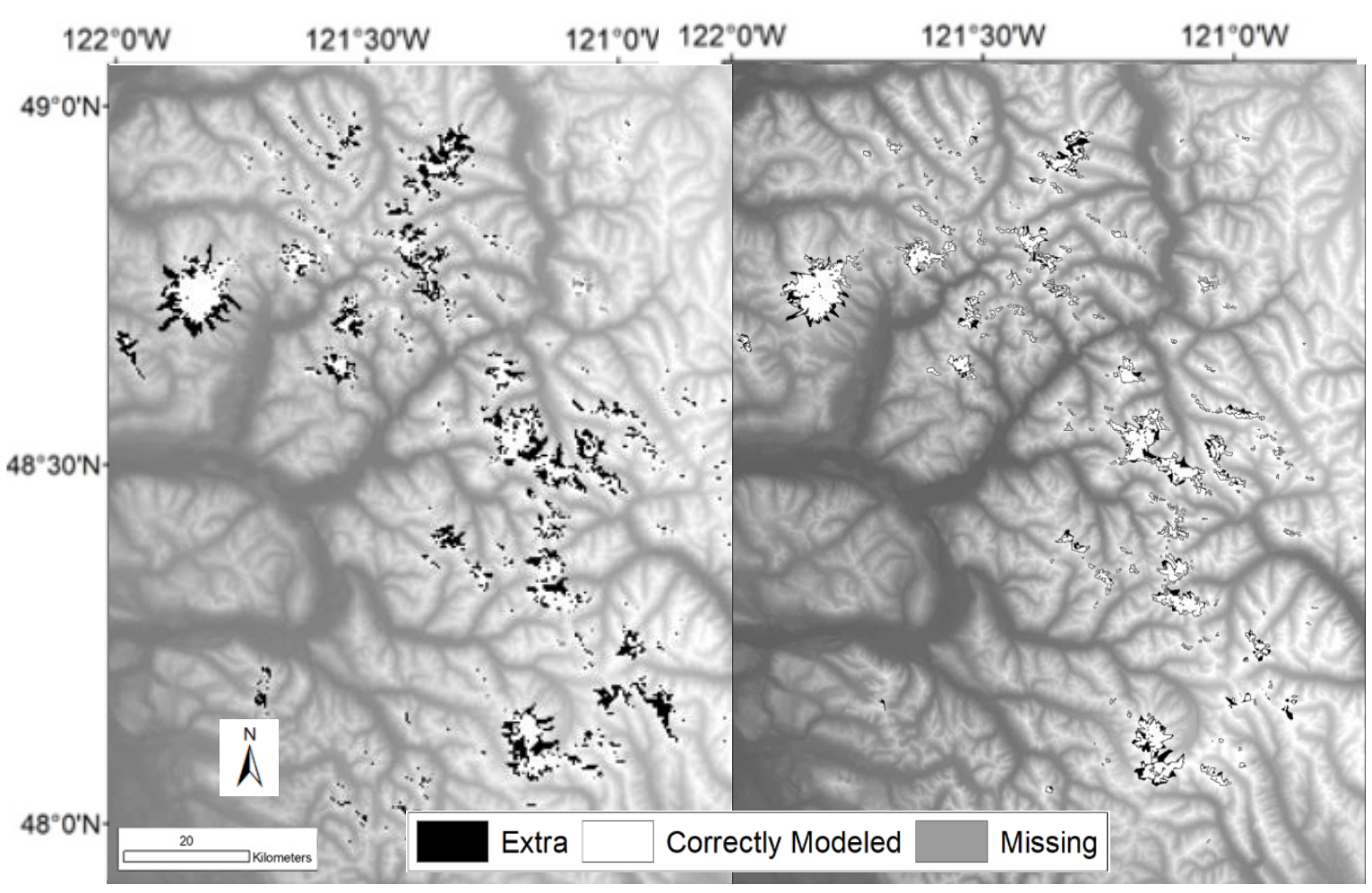

Figure 2.2: Distribution of modeled glaciers using RCP 4.5 as compared to 1970 observed glaciers extents in the North Cascades after the initial optimization (a) and (b) after reoptimizing model parameters to remove extra ice and applying a $\times 2$ precipitation multiplier to correct for low PRISM precipitation values.

tunable parameters were readjusted to minimize extra ice. The following text up to the discussion only refers to the model with the precipitation mask is used (final model), and RCP 4.5 will be the only scenario presented. After applying the mask, virtually all observed glaciers are captured, and total modeled area is comparable to what is observed in 1970 (103\% of observed).

Results for the final model show total modeled glacier area matches are of the observed glaciers. Most correctly modeled glaciers (glaciers in agreement 
Table 2.2: Comparison of the parameters used to model the North Cascades and their accuracy, including the original parameters based on the initial application to British Columbia (Original), the model where parameters used to optimize modeled area to observed (Intermediate), and the parameters used to minimize extra ice with the addition of the precipitation mask (Final). Statistics include the root mean square error (RMSE) values for aspect and elevation (raster cells, normalized for area), Correctly modeled area $\left(\mathrm{km}^{2}\right)$, missing and extra ice area $\left(\mathrm{km}^{2}\right)$, the fraction of the modeled area with respect to the 1970 observed glacier area (Percent Modeled), and the percent of glacier location correctly modeled with respect to 1970 observed glacier area (Correct Location). All statistics are for model runs that employ RCP 4.5.

\begin{tabular}{|c|c|c|c|c|}
\hline & \multirow{5}{*}{$\begin{array}{c}\text { Bulk Melt } \\
\text { Snow Radiation } \\
\text { Ice Radiation } \\
\text { Solar Illumination Time }\end{array}$} & Original & Intermediate & Final \\
\hline & & $\overline{1.1 \times 10^{-3}}$ & $9.0 \times 10^{-4}$ & $1.7 \overline{5 \times 10^{-3}}$ \\
\hline & & $1.022 \times 10^{-5}$ & $1.0 \times 10^{-5}$ & $1.1 \times 10^{-5}$ \\
\hline & & $2.5 \times 10^{-5}$ & $2.0 \times 10^{-5}$ & $2.6 \times 10^{-5}$ \\
\hline & & $17: 00: 00$ & 21:00:00 & 21:00:00 \\
\hline
\end{tabular}

\begin{tabular}{|c|c|c|c|c|}
\hline \multirow{7}{*}{ 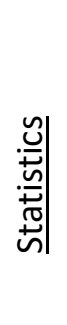 } & Aspect RMSE & 24.69 & 10.13 & 4.49 \\
\hline & Elevation RMSE & 0.21 & 0.09 & 0.01 \\
\hline & Correctly Modeled & 323.77 & 323.34 & 288.60 \\
\hline & Missing & 26.20 & 26.63 & 61.37 \\
\hline & Extra & 887.67 & 401.49 & 70.87 \\
\hline & Percent Modeled & $346 \%$ & $207 \%$ & $103 \%$ \\
\hline & Correct Location & $93 \%$ & $92 \%$ & $82 \%$ \\
\hline
\end{tabular}

between modeled and observed locations) were located on high peaks (such as Mt.

Baker and Glacier Peak) and western peaks, which receive more snowfall due to their higher elevations and coastal proximity. glaciers are more prevalent in the central area of the North Cascades, from approximately $48^{\circ} 20^{\prime} \mathrm{N}$ to $48^{\circ} 40^{\prime} \mathrm{N}$, north of Glacier Peak up to Klawatti Peak, where the peaks are lower by 500-1000m (Figure 2.2). Missing glaciers can also be found near large peaks, such as Mt. Baker. Before the correction of the solar radiation subroutine (Appendix c) missing glaciers faced mostly to the east, but in the final model version most missing ice was in a northeastern direction with a smaller subset facing to the southeast. The initial discrepancy was likely because precipitation comes from the west (Mass, 2008) and, like the situation in the Olympics 
Mountains, the redistribution of that of precipitation is not included in the model, causing precipitation "shadows" to the east. This discrepancy greatly decreased after the addition of the precipitation mask. 


\section{3: Climate and Topographic Analyses}

To examine the climate and topographic factors that control the presence and absence of glaciers on the landscape, the model results are reexamined in terms of air temperature, precipitation, and solar radiation. To examine this interaction, monthly precipitation and air temperature averages of PRISM data, (1960-1970) were used.

This period was chosen because glaciers in the North Cascades were generally stable (Meier and Post, 1962; Luckman et al., 1987; Dick, 2013). Using the seasonal and annual climate averages over the entire study region, correctly modeled and missing glacier distributions were compared. Winter was defined as months where the mean air temperature was negative (December, January, February), summer as months where the minimum temperature was positive (July, August, September), and months that met

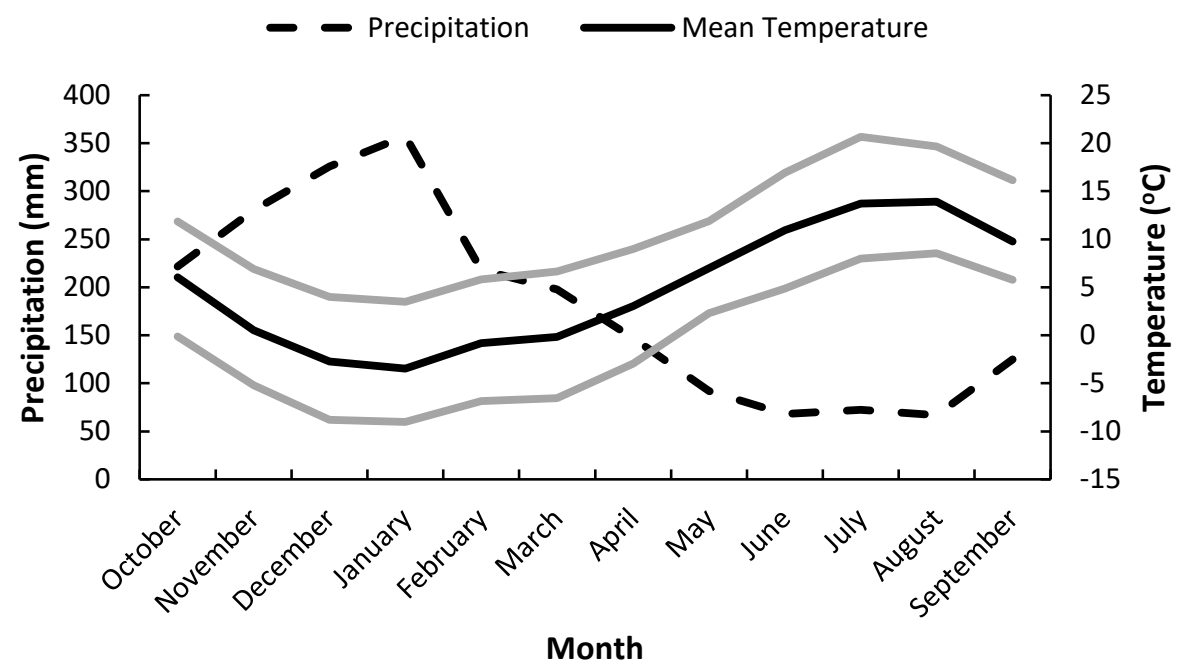

Figure 3.1: Monthly PRISM averages of mean precipitation and temperature from 1961-1970 over the North Cascades Study area. Gray solid lines show minimum and maximum temperature PRISM averages for the same time period. 
neither requirement as spring (March, April, May, June) or fall (October, November)

(Figure 3.1).

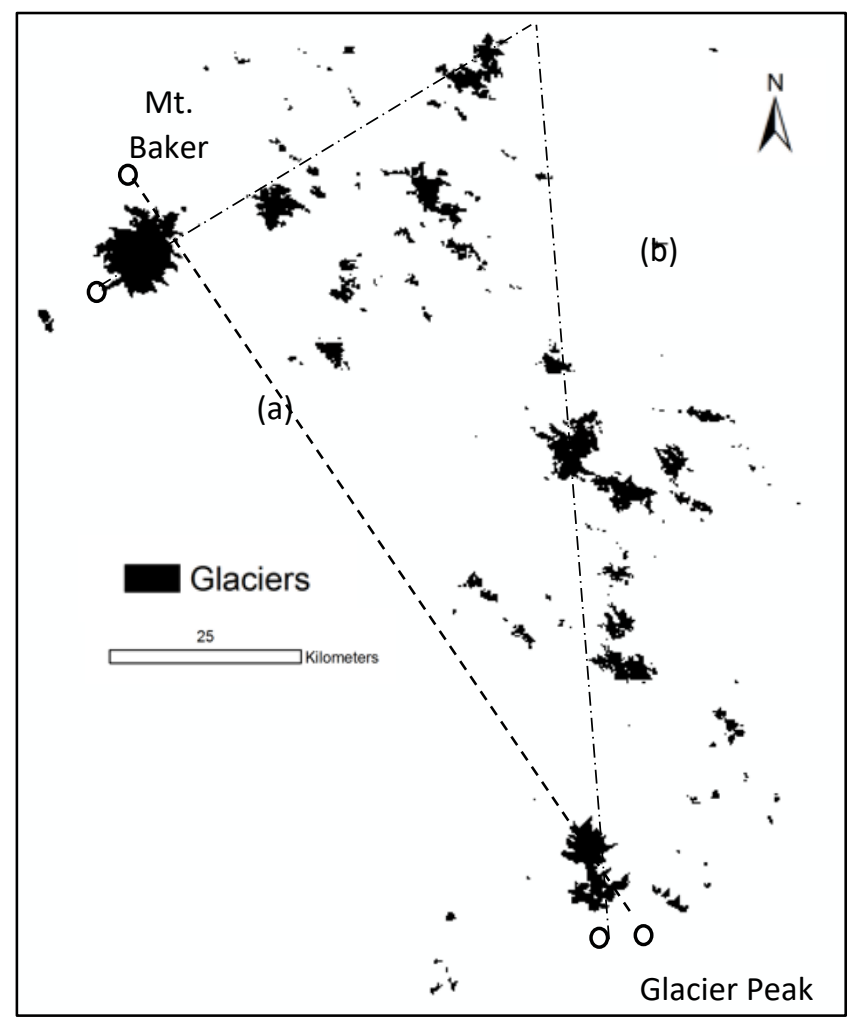

Figure 3.2: Map of two climate/glacier profiles though the North Cascades. Glacier extent data is based on the 1:24000 outlines from the USGS topographic maps (Fountain et al., 2017). Profiles (a) begin through Mt. Baker and Glacier Peak across a large span of no glaciers and (b) goes over Mt. Baker and Glacier Peak but traverses other large peaks such as Mt. Spikard and Klawatti Peak.

To determine if missing and correctly modeled glaciers are located in different mean climates or topography (seasonal precipitation and temperature, elevation, slope, and aspect) and to find if differences in their distributions over the same variables are significant, two tailed z-tests and F-tests were performed. For instance, it is of interest to see if correctly modeled glaciers are typically found in areas with a higher precipitation, or if missing glaciers are found in a range of summer air temperatures that 
are warmer than that of correctly modeled glaciers. For aspect, because it is circular, a Von Mises distribution is employed. Additionally, the concentration of the glacier directions is tested. Concentration is a measure of variability in directional data (Appendix A). When concentration is zero, glaciers are uniformly distributed with aspect. As concentration increases, there are more glaciers facing in the mean direction (Appendix D; Davis, 2002).

Qualitatively, the distribution of climate and the location of correctly modeled and missing glaciers with topography is observed along two profiles through the North Cascades (Figure 3.2; Figure 3.3). One profile was made to capture the largest concentrations of glaciers on Mt. Baker and Glacier Peak and give an overview of climate in areas of high glacier concentration. The second profile crossed peaks in the North Cascades and gave a more thorough view of climate with glaciers by including a variety of glaciated terrain, rather than just the largest.

Statistically, the means of missing and correctly modeled glaciers relative to summer air temperature were not significant (Z-test: -1.41) though their variances are (F-test: 17.1). This indicates that there is no true difference between the missing and correctly modeled glaciers relative to summer air temperature but, because correctly modeled glaciers are found on high peaks where temperatures are colder and only occasionally reach into lower elevation valleys (Mt. Baker, Glacier Peak) and missing glaciers only exist at lower elevations, differences can be found in their variances. One expects that a model will not predict ice in warmer temperatures, so this result is not 

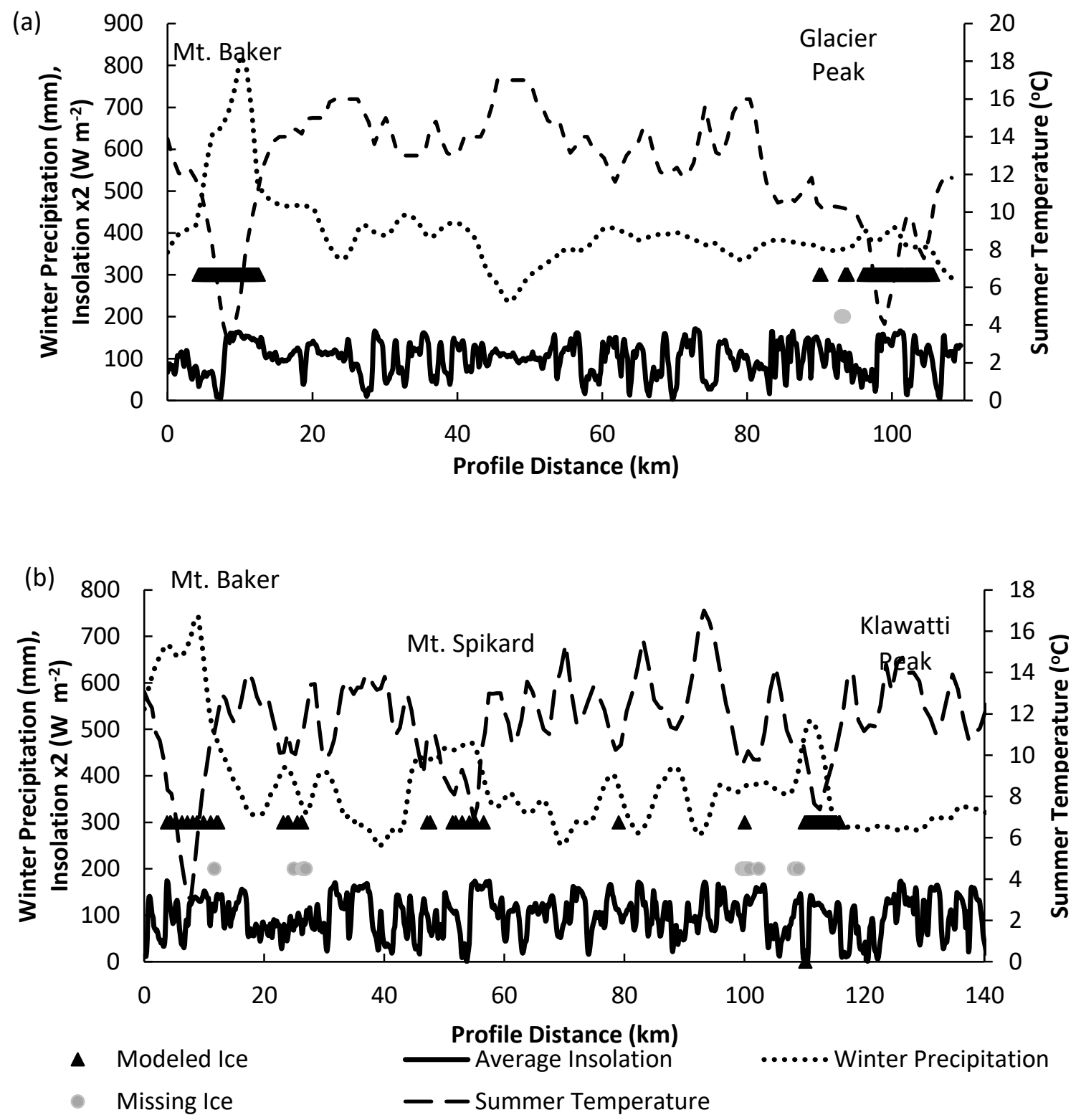

Figure 3.3: Distribution of summer air-temperature, winter precipitation, and average annual insolation over modeled glaciers and missing glaciers from the application of the final model where parameters are adjusted to minimize extra ice and the addition of the precipitation mask to the North Cascades. Climate data is based on averages from PRISM (1961-1970) (Daly et al., 2007). Insolation was exaggerated by two to better display the data. a) the profile between Mt. Baker and Glacier Peak and b) the profile that goes through many glaciated peaks. Extra ice is not plotted as in most cases it is an extension of correctly modeled ice due to the preferable location at high peaks with increased precipitation. 
Table 3.1: Statistical tests compare the location of correctly modeled glaciers and missing glaciers relative to climate (winter precipitation and summer air-temperature) and topography (slope, elevation and aspect) for the precipitation mask model with RCP 4.5 in the North Cascades. Slope and elevation statistics compare the means (z-test) and distribution (F-test) of missing glaciers and correctly modeled glaciers. Aspect statistics compare the mean direction of missing glaciers $\left(22.05^{\circ} \pm 3.1\right)$ to correctly modeled glaciers $\left(32.37^{\circ} \pm 1.3^{\circ}\right)$, the concentration (conc.) of the mean aspects, in addition to the circular version of an F-test. Ice concentration is a measure of the variability of glacier directions. The more glaciers facing in a similar direction, the stronger the concentration. Z- and F-tests were two tailed to allow for all differences in the means and variances to be observed. Z-tests were significant if the value was greater than \pm 1.9 and F-tests if the value is greater than \pm 1.47 . Aspect concentration was significant if larger than 0.244 , and the aspect pooled F-test was significant if greater than 250.1. Significant statistics are bolded.

\begin{tabular}{|c|c|c|c|c|}
\hline & $\begin{array}{c}\text { Winter } \\
\text { Precipitation }\end{array}$ & $\begin{array}{l}\text { Summer Air- } \\
\text { Temperature }\end{array}$ & Slope & Elevation \\
\hline Z-test & 3.16 & -1.41 & -3.07 & 11.3 \\
\hline F-test & 1.75 & 17.1 & 1.03 & 1.31 \\
\hline \multicolumn{5}{|c|}{ Aspect } \\
\hline Same Dir & \multicolumn{2}{|c|}{ Correctly Modeled Conc. } & Missing Conc. & Pooled F-test \\
\hline $\mathrm{N}$ & \multicolumn{2}{|c|}{0.69958} & 0.65242 & 74.8 \\
\hline
\end{tabular}

unexpected (Figure 3.3, Figure 3.4). Relative to winter precipitation, however, missing glaciers were found in areas of lower precipitation than correctly modeled glaciers (Table 3.1), suggesting snow accumulation (precipitation, avalanching, winddrift) is the major driver in glacier placement, and processes that redistribute accumulation are missing from the model.

Plotting summer air temperature against winter precipitation for missing and correctly modeled glaciers shows that much overlap exists within the climate space $\left(200-550 \mathrm{~mm}, 6-14^{\circ} \mathrm{C}\right)$, with a large number of the correctly modeled glaciers found in higher precipitation areas (Figure 3.4). This supports my previous conclusions that missing glaciers are likely caused by a precipitation deficit, either through PRISM error or a lack of snow redistribution. The transects also show similar distributions of glaciers 
with summer air temperature, winter precipitation, and average annual solar insolation.

Correctly modeled glaciers are located where summer air temperature is less than $14{ }^{\circ} \mathrm{C}$

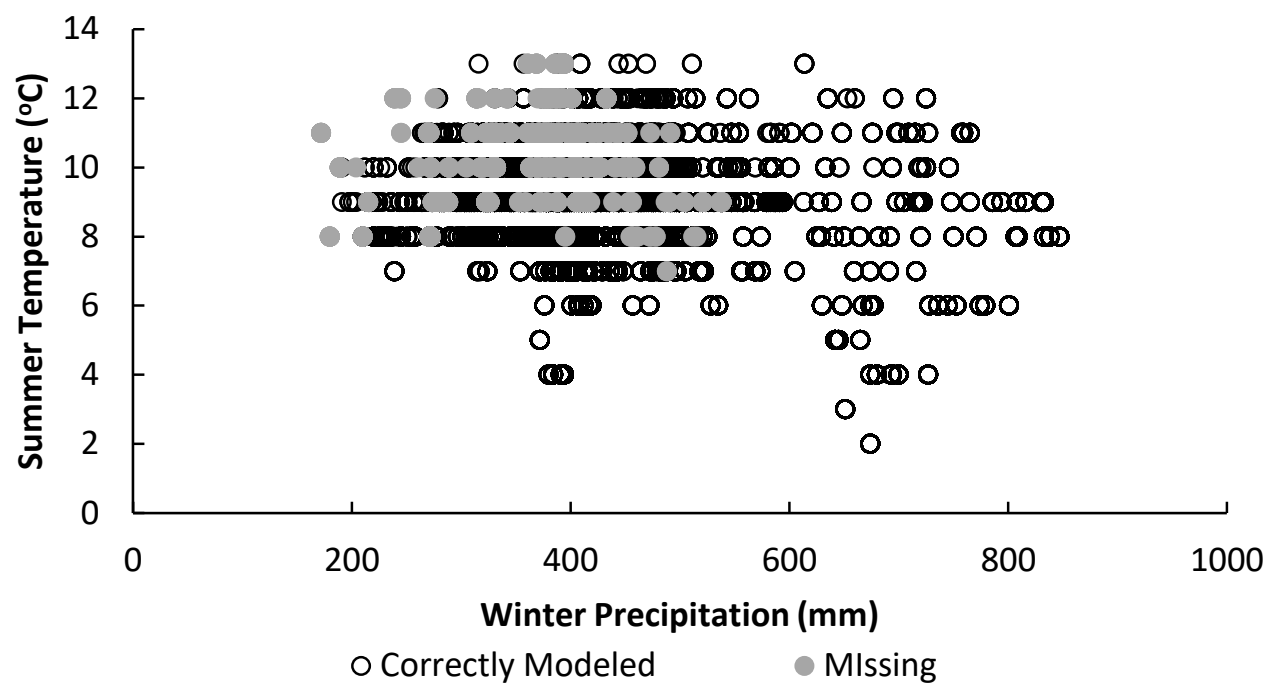

Figure 3.4: Comparison of the distribution of correctly modeled glaciers and missing glaciers with both summer air-temperature and winter precipitation for the application of the final model where parameters are adjusted to minimize extra ice and the addition of the precipitation mask to the North Cascades.

and winter precipitation is between $300-800 \mathrm{~mm}$. Missing glaciers are found where summer temperatures were greater than $6^{\circ} \mathrm{C}$ and winter precipitation less than $\sim 550 \mathrm{~mm}$ (Figure 3.3). Insolation differences do not appear to be important (Figure 3.3).

The distributions of correctly modeled and missing glaciers relative to aspect, elevation, and slope were examined and statistically significant differences were observed with all three topographic factors (Figure 3.5). Correctly modeled glaciers were north to northeast facing. The distribution of missing glaciers with aspect generally follows the distribution of correctly modeled glaciers (Figure 3.4). However, the mean direction for missing glaciers $\left(20.5^{\circ} \pm 3.1\right)$ was outside the $95 \%$ confidence 
interval for the correctly modeled glaciers $\left(31.7^{\circ} \pm 1.32^{\circ}\right)($ Table 3.1$)$, though the variances between populations for the distribution with aspect are similar, as Figure
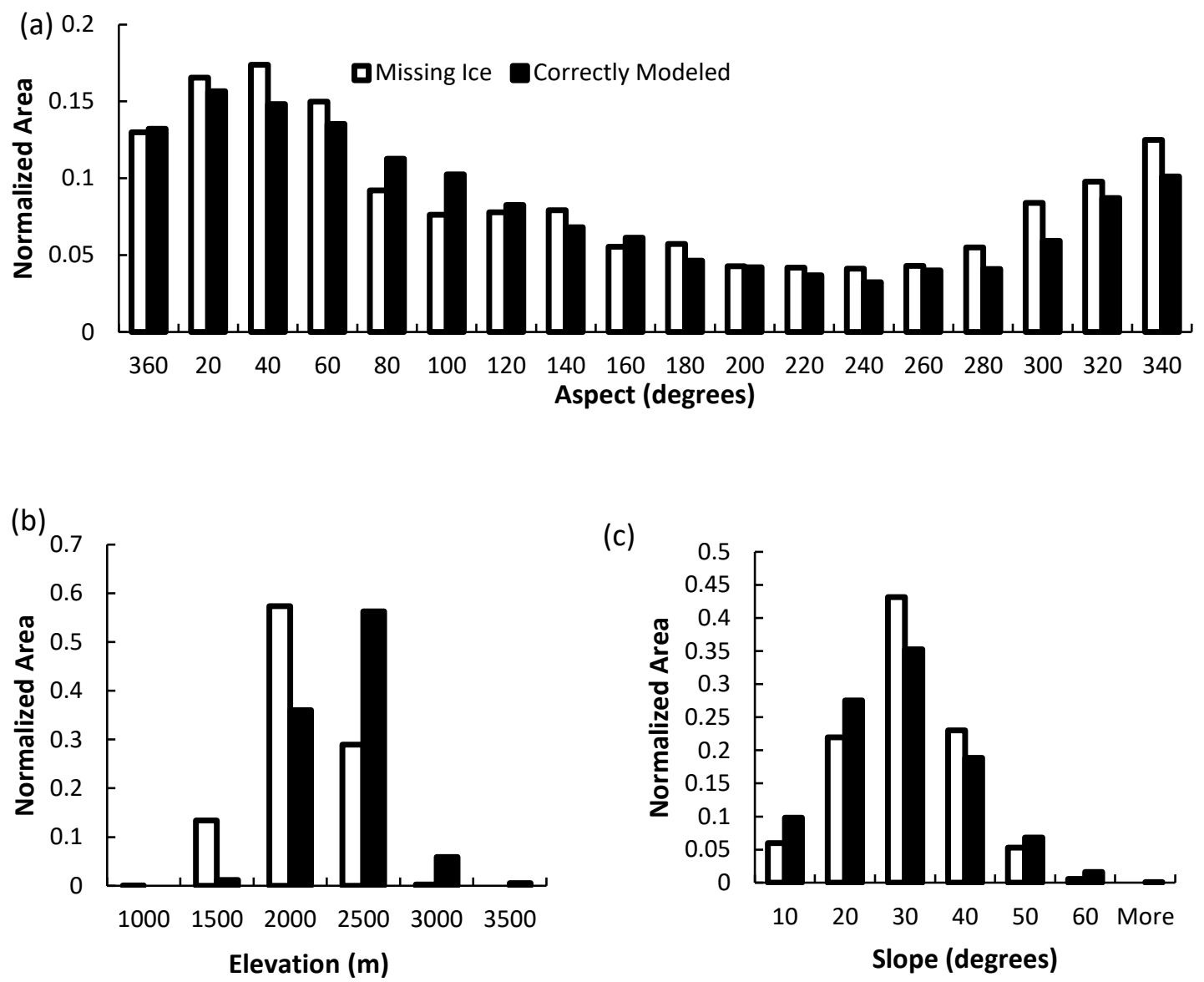

Figure 3.5: Histograms for glacier area with location misfit category. (a) Comparison with aspect, (b) elevation, and (c) slope. These comparisons use the final model where parameters are adjusted to minimize extra ice and the addition of the precipitation mask to the North Cascades. For aspect, intervals are $20^{\circ}$ and denoted by the highest value in the interval. Slope is in $10^{\circ}$ intervals which are denoted by the highest value in each. More indicates slopes greater than $60^{\circ}$ Elevation is divided into categories of $1000 \mathrm{~m}$ also denoted with the highest value in each category.

3.5(a) suggests. Elevation is the most significant factor. Correctly modeled (missing)

glaciers occur more frequently at higher (lower) elevation, which correspond to higher 
(lower) precipitation and colder (warmer) air temperatures. For slope, the mean of correctly modeled versus the missing glaciers was significantly different, but the range of the distributions were similar. Missing glaciers tend to be found on slightly less steep slopes than correctly modeled glaciers (Z-test:-3.07; Figure 3.5), though this may just be due to correctly modeled glaciers being found at higher elevations, where slopes are

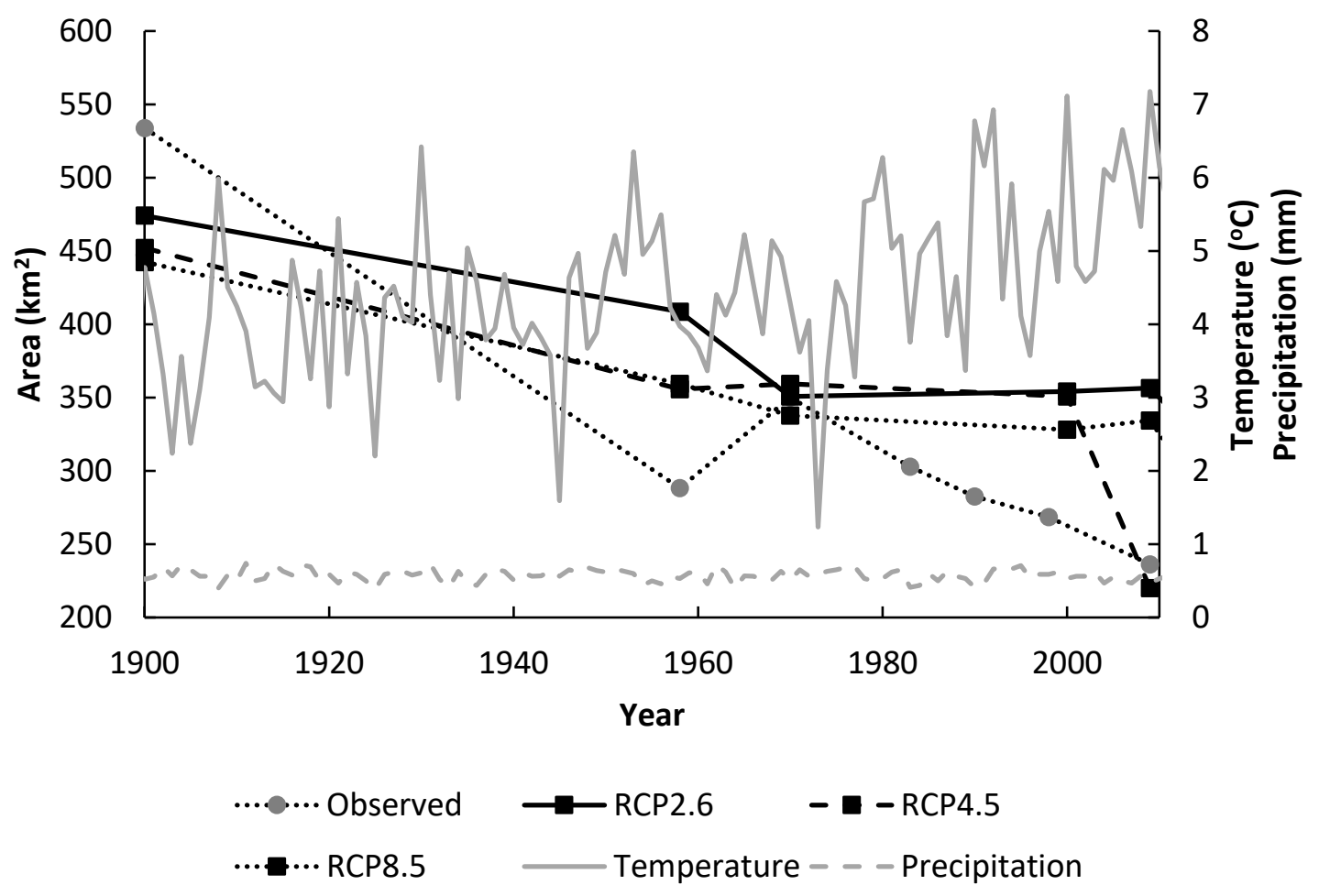

Figure 3.6: Comparison of historic output with estimated North Cascades glacier extents from LIA ( 1900), 1958, 1970, 1983, 1990, 1998, and 2009 (Post et al., 1971; Dick, 2013). Specific data points are included as round markers. Additionally, average temperature over the North Cascades and total precipitation from RCP 4.5, plotted on the same axis, are also included.

typically steeper and where there is more snow fall. To further assess the accuracy of the model, results were compared to observed glacier area over the period 1900-2009 (Dick, 2013). In that study the glacier perimeters were outlined using georeferenced 
aerial imagery. For all climate scenarios the model generally underestimates retreat before 2000 , predicting only $14-21 \%$ lost relative to 1900 , much less than Dick's estimate of $46 \%$ loss over the same time period (Figure 3.6), and misses the short stabilization between 1960-1980 due to the mid-century cooling. After the beginning of the $21^{\text {st }}$ century (not pictured here) the model predicted a rapid retreat similar to the trends observed by Dick (2013), even if there exists a discrepancy between the timing the glacier areas.

\section{4: Future Projections}

Future projections of glacier area in the North Cascades were estimated using the CCSM4 GCM coupled with RCP 2.6, 4.5, and 8.5 scenarios. RCP 8.5 is the most extreme RCP model (radiative forcing of $8.5 \mathrm{~W} \mathrm{~m}^{-2}$ by $2100,4.5^{\circ} \mathrm{C}$ global mean temperature), and represents my "business-as-usual" scenario, where it is assumed that there are no major economic restrictions on greenhouse gas emissions and that clean technology is frozen in the state is was in in 2005. RCP 4.5 is more moderate and is meant to represent the effect of imtermediate mitigation efforts in atmospheric emissions $\left(4.5 \mathrm{~W} \mathrm{~m}^{-2}\right.$ peak by $2100,2.5^{\circ} \mathrm{C}$ ) and then stabilization. $\mathrm{RCP} 2.6$ is the most conservate scenario (peak forcing of $\sim 3.0 \mathrm{~W} \mathrm{~m}^{-2}$ and then decreasing to $2.6 \mathrm{~W} \mathrm{~m}^{-2}$ by $2100\left(\sim 1.5^{\circ} \mathrm{C}\right)$, providing a lower bound on future glacier extents (Figure 1.2). RCP 4.5 and RCP 2.6 are mitagation scenatios, and both scenarios assume advances in "clean" 


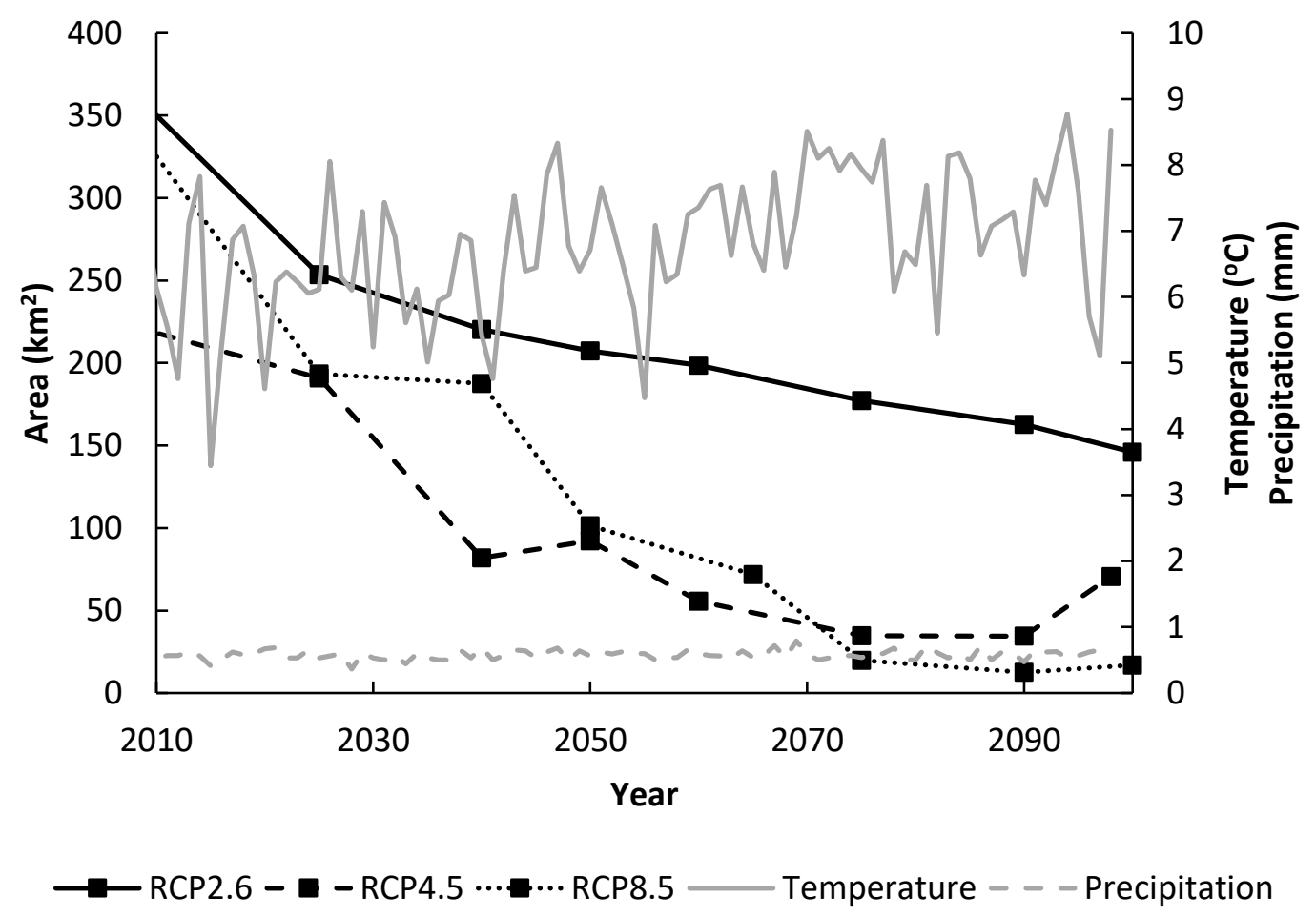

Figure 4.1: Area with respect to 1900 North Cascades modeled glacier area for all RCPs. Additionally, average temperature and total precipitation from RCP 4.5 over the North Cascades is also included.

technology, which would lessen emissions, and the implementation of policy that creates economic insentives for companies to convert to the new technology, though the value of incentives differs, creating the differences seen in global temperature at the end of the $21^{\text {st }}$ cenntury between the two scenarios (van Vuuren et al., 2011). Model runs with RCP 8.5 predicted much greater glacier loss than RCP 4.5, where glacier response was greater than RCP 2.6 (Figure 4.1). In all RCPs retreat slows between 2075 and 2100 as the last glaciers at the highest elevation locations disappear.

To observe the future distribution of glaciers with topography and climate only RCP 4.5 precipitation mask model results will be discussed, and results from other 
(a)

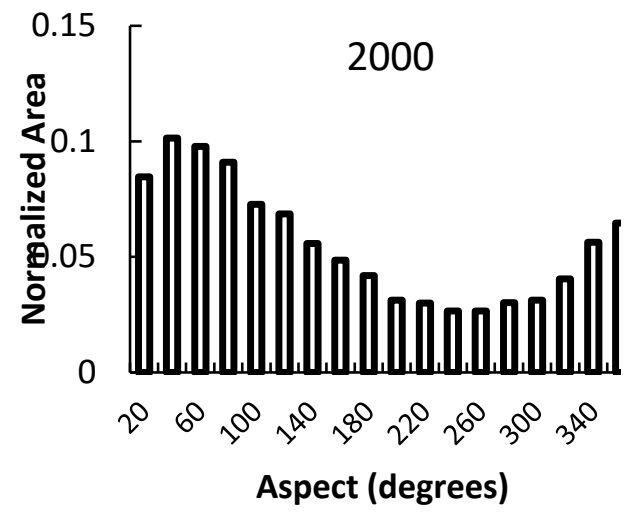

(c)

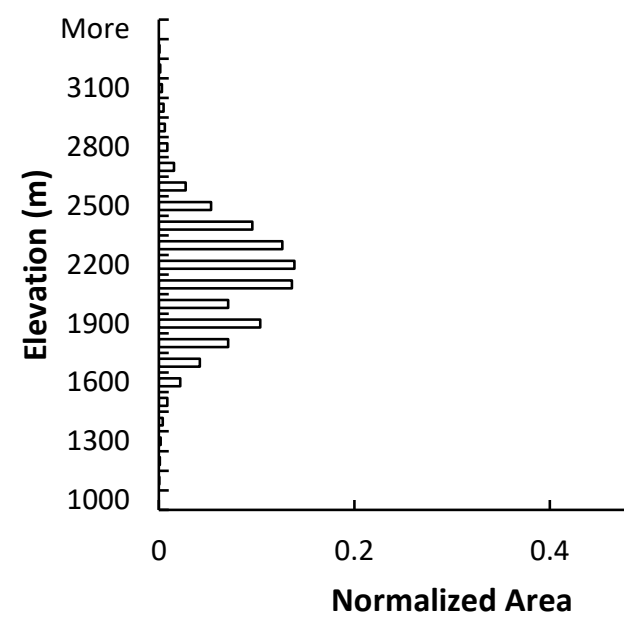

(b)

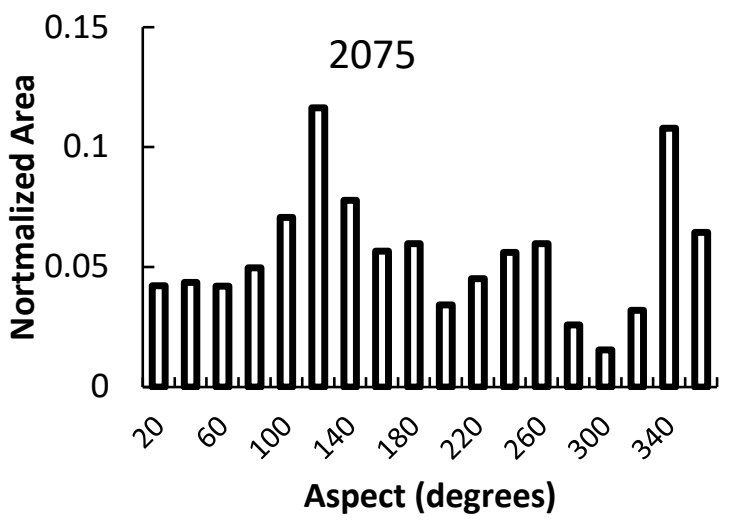

(d)

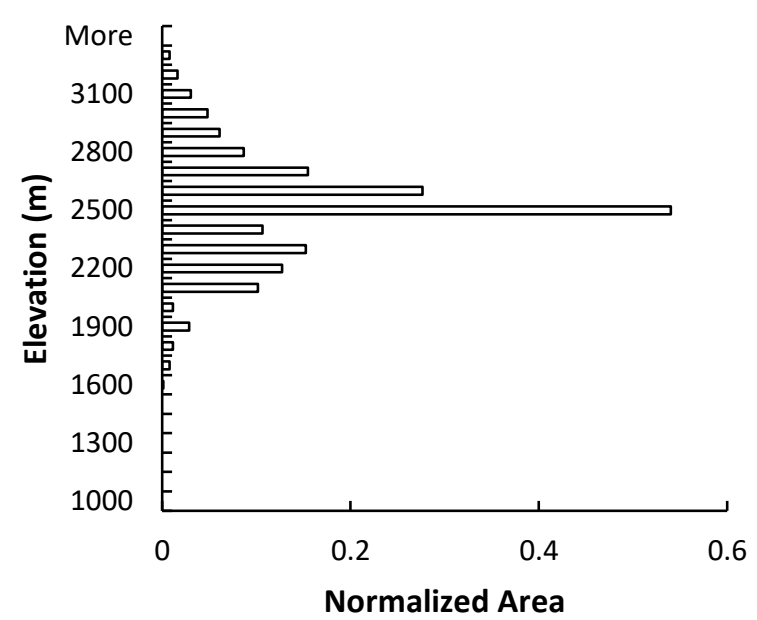

Figure 4.2: Change in glacier distribution with topography over time with the application of the final model where parameters are adjusted to minimize extra ice and the addition of the precipitation mask to the North Cascades, with RCP 4.5. Normalized glacier distributions with aspect are seen in $a$ and $b$, and normalized distributions with elevation are seen in $c$ and $d$. and $c$ show distributions for 2000, and b and d show distributions for 2075. Aspect is in intervals of $20^{\circ}$, with each interval denoted by the highest value.

Elevation is in intervals of 100 , which are denoted by the highest value in each interval. The smallest interval (1000) includes values from 0-1000 meters. More includes any values above the highest numbered interval.

scenarios can be found in Appendix E. No significant changes in glacier distribution with aspect were observed until glaciers had retreated to $10 \%$ of its 1970 area. Then the glacier distribution changes from facing north to northeast, which is typical of glaciers in 
this area, to shifting to more eastern and south-western facing (Figure 4.2). Glaciers also migrated to higher elevations. It is not surprising that glaciers are also expected to retreat to areas with colder air temperatures and higher precipitation in an attempt to reach a new equilibrium with the warming climate (Figure 4.3).

To estimate when glaciers will completely disappear in each scenario, a linear regression is fit to the area with time for two intervals, 1970-2100, and 2090-2100, producing two estimates, which bracket the timing of disappearance (Figure 4.1). Results from the RCP 8.5 and 2.6 scenarios show that the glaciers will disappear sometime between $2139-2187$ for the $2090-2100$ regression, and $2093-2192$ for the 1970-2100 regression, where RCP 8.5 predicts the earlier disappearance year and RCP 2.6 the later.

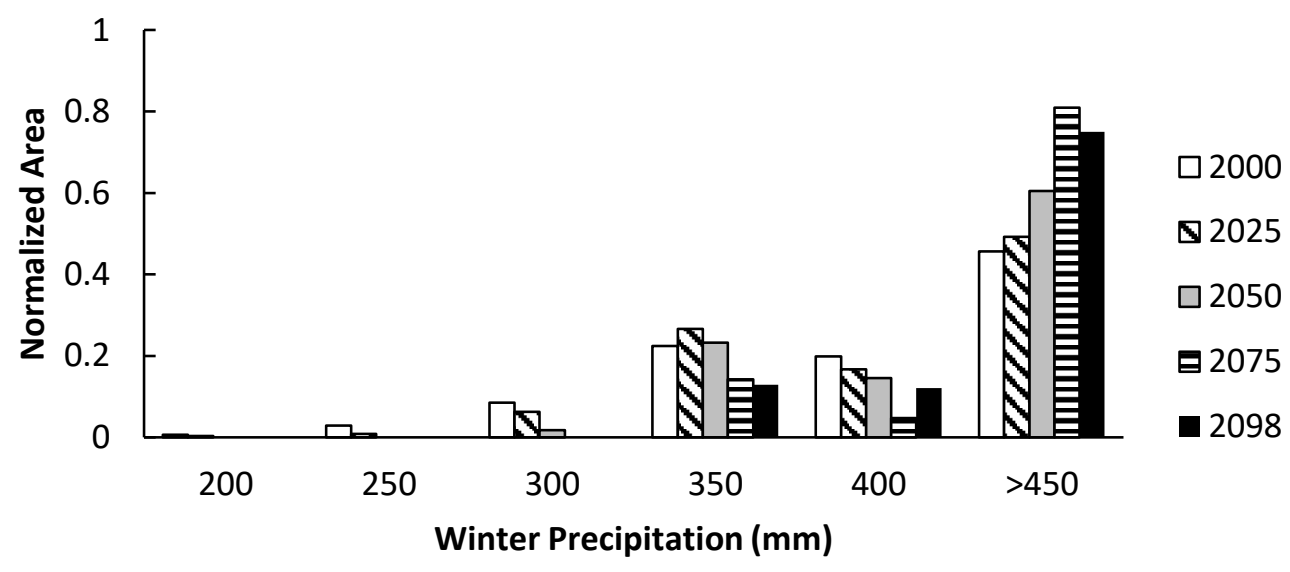

Figure 4.3: Change in glacier area with winter precipitation over time for the application of the final model where parameters are adjusted to minimize extra ice and the addition of the precipitation mask to the North Cascades, with RCP 4.5. Precipitation is estimated on the winter PRISM climate averages from 1960-1970. Precipitation is in $50 \mathrm{~mm}$ intervals, denoted by the highest value in each value, with the lowest category (denoted by 100) any value between 0 and up to $100 \mathrm{~mm}$. Area is normalized to more easily see the shift away from lower precipitations. 
With the RCP 4.5 scenario, glaciers are expected to decrease by roughly $92 \%$ from 1970 extents by 2100 , similar to RCP $8.5(96 \%)$, and completely disappear by 2200 for any RCP scenario. Glaciers will continue to retreat to higher elevation peaks with more snow accumulation such as Mt. Baker, Glacier Peak, Mt. Shuksan, and Mt. Spikard, where conditions are more favorable for glacier survival. More conservative climate scenarios, such as RCP 2.6 predict that 2100 glaciers will decrease by $60 \%$ of 1970 glacier extents, rather than by $94 \%$. 


\section{5: Discussion and Conclusions}

Attempts to simulate glacier distribution and area by changing physical and climate forcing parameters alone were not successful. Sensitivity tests, which involved changing the parameters by $\pm 10 \%$ of the values in the initial application to British Columbia, found the RGM to be insensitive to physical ice parameters. However, the model was quite sensitive to forcing parameters. For example, bulk melt varied the error $₫ 43 \%$ for topographic RMSE and location error statistics, on average. However, this range is much larger than established density ranges for ice (Cuffey and Patterson, 2010; Appendix C). Sliding also had very little influence on glacier area, similar to the results of Clarke et al., (2015). Perhaps seasonal changes in sliding, which lessen (winter) or increase (summer) depending on the amount of melt water present compensate, leading to a net lack of importance (Benn and Evens, 2006). Parameters that control available energy for melt, such as the bulk melt factor, radiation parameters for ice and snow, and the solar position had significant effects on the ice location and extent. The bulk melt factor and the radiation factors most strongly controlled glacier extent ( $9 \%)$, and solar time had greatly affected the distribution of glaciers with topography (-71\% aspect RMSE reduction from the original model error). Many studies show that even in the simplest mass balance model solar radiation and air temperature must be key factors, and direct comparison of various model parameters indicate solar radiation and parameters that modulate solar radiation (bulk melt, snow/ice radiation) are the most associated with the best observed ice agreement, which is in concurrence with what is seen here 
(Oerlemans, 2001; Pellicciotti et al., 2005; Ragettli and Pellicciotti, 2012; Gabbi et al, 2014).

A comparison of the final parameters from all three applications of the model shows that all three regions have different melt parameters (Table 5.1). Note that these parameter values were achieved through trial and error, rather than an objective optimizing algorithm, so at best the differences in these parameters may be suggestive of differences in regional environment, such as humidity, local albedo, debris cover, cloudiness and more. Additionally, while solar radiation was determined to be

Table 5.1: Comparison of the final parameters of all final model applications. Parentheses show the percent difference of each Washington application to the initial application in British Columbia. Solar Angle Time is in UTC, snow and ice radiation is in $\mathrm{m}^{2} \mathrm{~W}^{-1} \mathrm{~mm}$ day $\mathrm{y}^{-1} \mathrm{C}^{-1}$, and bulk melt is in $\mathrm{mm} \mathrm{day}^{-1}{ }^{\circ} \mathrm{C}^{-1}$

\begin{tabular}{llllr} 
& Snow Radiation & & \multicolumn{1}{c}{ Bulk Melt } & Ice Radiation \\
\cline { 2 - 5 } British Columbia & $1.022 \times 10^{-5}$ & & $8.0 \times 10^{-4}$ & $1.23 \times 10^{-5}$ \\
Olympics & $2.0 \times 10^{-5}(+96 \%)$ & $1.8 \times 10^{-3}(+125 \%)$ & $3.0 \times 10^{-5}(+143 \%)$ \\
North Cascades & $1.0 \times 10^{-5}(-2 \%)$ & $9.0 \times 10^{-4}(+13 \%)$ & $2.0 \times 10^{-5}(+63 \%)$
\end{tabular}

important to glacier distribution with aspect, it will not be discussed here because the original model application in $\mathrm{BC}$ used a different method to calculate solar radiation than the two Washington applications, making it difficult to compare directly in terms of solar radiation. Also, the two Washington applications use the same solar radiation time because they are essentially the same latitude. However the melt model, which includes bulk melt and snow/ice radiation parameters, is relatively similar between all applications, so forcing parameters can be compared. Before discussing how differences 
in forcing parameters may indicate differences in local climate, it is important to note that the $\mathrm{BC}$ application includes a wide variety of climates, from the wet coast to the dry Rockies, making only broad generalizations for the entire region possible. Therefore, while it is possible to compare $\mathrm{BC}$ to the Olympic Mountain and North Cascades applications, latter applications are over much smaller domains and their parameters are more tuned for their individual environments than those of the BC application.

With the exception of the North Cascades snow radiation parameter, all forcing parameters for the two Washington applications are larger than those for BC. The Olympics showed the largest changes from the original BC application, with parameters being roughly doubled, while the North Cascades parameters varied much less (Table 5.1). The differences between the North Cascades and Olympics seem to be related to distance from the coast and topographic differences. Conditions are drier in the interior of Washington than on the coast and glaciers exist in areas with lower humidity and therefore lower turbulent heat flux, and typically have lower melt than glaciers in more humid environments (Benn and Evens, 2006). Additionally, cold Arctic air pooling against the eastern flanks of the North Cascades may further contribute to lowering the expected melt over the entire region (Mass, 2010). The North Cascades have also have higher elevation peaks than the those in the Olympics, and its glaciers exist in colder conditions and are more buffered against the effects of climate change (DeBeer and Sharp, 2007/2009; Devisser and Fountain, 2015). British Columbia is higher in latitude than the Washington applications and contains a portion of the dry Rocky Mountains, 
which may be large factors to why the $B C$ forcing parameters are the smallest of the three applications. Cloudiness is likely to be similar between the three regions, and therefore is unlikely to cause differences in the forcing parameters. Differences in debris cover, rock glacier prevalence, and local albedo may also contribute to local differences, but studies that compare the prevalence of these factors on scales large enough to have meaning for this study are rare. The effects of albedo would be seen in the ice and snow radiation parameters, which are directly related to local albedo and factors such as debris cover that modify it. However, these parameters were modified in the model after the bulk melt was broadly tuned to minimize glacier area error. It is therefore difficult to tell if differences in the snow and ice radiation parameters reveal any significant differences between the regions or are simply a result of model tuning.

The model did not predict the presence of glaciers in large areas of both the Olympics and North Cascades, requiring the application of the precipitation mask with a spatially constant value to enhance precipitation. After re-optimization, where forcing parameters were chosen to reduce extra ice before the addition of the precipitation mask, which is assumed to account for all missing glaciers, the total area in the Olympics decreased from $312 \%$ to $100 \%$ of the observed glacier area, and in the North Cascades from $346 \%$ to $103 \%$, as well as increased agreement between the placement of glaciers relative to observed glacier area in each region. The Olympics also had a larger fraction of missing glaciers ( $41 \%$ of modeled area) compared to the North Cascades (17\%), though the amount of extra ice is similar (14-20\%). I argue that this error is due to 
relatively poor climate modeling across the mountain ranges. Given that spatial variations of air-temperature can be somewhat reliably predicted (Daly et al., 2008) most of the error likely resides in precipitation. Precipitation is a problem common to complex terrain in mountainous regions, which is notoriously difficult to model over the small spatial scales $\left(<0.2 \mathrm{~km}^{2}\right)$ common to glaciers in the Northwest (Giorgi and Shields, 1999; Minder et al., 2010; Wang et al., 2004; Daly et al., 2008; Currier et al., 2017).

The effect of topography on glaciers of the Olympic Mountains and North Cascades show similar error when normalized to modeled area. For both regions, glacier distribution with aspect has the highest error (0.33-0.24 degrees RMSE, normalized to modeled area) and elevation the lowest (0.061-0.12 m, RMSE normalized to modeled area). Higher aspect RMSE may be due to the use of single solar time (the time each month that the position of the sun is estimated and used to downscale the since radiation value from the GCM). Solar time was chosen to be 2 PM PDT to estimate solar noon (where the sun is at its highest position in the sky). This disregards the daily variation in solar radiation, which would include the weaker morning insolation to the east as well as the stronger late afternoon radiation to the west, rather than some value in between. The lower elevation RMSE is likely because the relationship between glacier formation and elevation is relatively well constrained: higher elevations have cooler air temperatures and greater precipitation accumulation than lower elevations. Excess ice appears on high peaks such as Mt. Olympus and Mt. Baker, but a deficit of ice appears on lower peaks. For instance, in the North Cascades by 2100 most glaciers are expected 
to remain at elevations greater than approximately $2400 \mathrm{~m}$ on various high peaks such as Mt. Baker or Glacier Peak (Figure 3.2).

Overall, the Olympics have greater location misfit than the North Cascades, possibly because the PRISM climate averages have greater error in that region. Both regions are mountainous and weather stations are relatively sparse, making modeling important processes such as local air temperature (e.g. cold air pooling; Lundquist 2008) and snow redistribution (Ferguson et al., 1990; Kuhn, 1995; Mass 2010) difficult, introducing uncertainty to PRISM

Local climate is difficult to model due to microclimates and the difficulty of constraining precipitation to topographic variation, and interpolation between weather stations in mountainous regions is not always accurate (Giorgi and Shields, 1999; Daly et al., 2008; Currier et al., 2017). The model does not include a full energy balance to calculate ablation so variables such as wind speed, humidity, and surface roughness are not included, and the local effect of snow accumulation via wind redistribution and avalanching cannot be evaluated directly. Avalanching, which is an important process to feeding small glaciers, is caused by stability issues in part due to cold Arctic air, which pools against the eastern slopes of the North Cascades and drains through the passes creating layered snow packs due to air-temperature inversions, as well as steep slopes at the peaks of mountains (Ferguson et al., 1990; Kuhn, 1995). West slope inversions also can occur, though these are shallower and infrequent (Ferguson et al., 1990). Additionally, the west slopes are more susceptible to warm westerlies, which can cause 
snow to change to rain, and weaken existing snow on the slopes, causing western slope avalanches (Ferguson et al. 1990). Similarly, the model cannot predict wind redistribution of snow, which is also a highly localized process and has been cited as one of the strongest influences on differences in snow accumulation in the same basins, though this process is more important in arid conditions than temperate (Elder et al., 1991; Luce et al., 1998; Winstral and Marks, 2002). While most wind that reaches the North Cascades comes in a southwesterly to westerly direction, this air can be channelized through valleys. These two processes, avalanching and wind redistribution of snow, which are missing in the model, may partially explain the missing glaciers. The large number of missing glaciers observed in the central area of the North Cascades are believed to be due to the PRISM climate data used to estimate spatial variation in climate. Precipitation is the variable with the highest error in PRISM (Wang et al., 2012; Daly et al., 2007), likely due to the few weather stations in the Cascades and an absence of detailed precipitation physics. Snowfall measurements are also prone to error, as snow can drift, gauges can under catch snow, and sensors can freeze (Julander et al., 2007; Oyler et al., 2015). Therefore, only large-scale patterns can be observed, and smaller local processes, which many glaciers depend upon, are improperly parameterized, increasing model error (Daly et al., 2007). However, PRISM precipitation is well-correlated to observation stations $\left(R^{2}\right.$ of 0.920) and mean absolute error precipitation as snow of $\pm 75 \mathrm{~mm}$ (Wang et al., 2012). Also, topographic weighting in PRISM estimates, which controls how much precipitation falls with elevation, may also 
need to be adjusted. If topographic weighting is not considered, precipitation becomes a function of coastal proximity (Daly et al. 2002). It is possible that too strong of topographic weighting may cause the precipitation to fall too strongly at high elevations, starving the low elevation central region.

In the North Cascades application, the similariton of projected glaciers showed a shift from the 2000 preferred aspect of $\sim 30^{\circ}$ to a preferred of $\sim 110^{\circ}$ in 2075 and higher elevations (Figure 4.2). The glaciers of the Olympic Mountains stay northeast facing until 2100, which is what is expected for glaciers in the northern hemisphere (Evens, 2006; DeBeer and Sharp, 2007/2009). While it is expected that north or northeast facing glaciers in this region will be less sensitive to climate change (Arnold et al., 2006; Fountain et al., 2009; Dick, 2013, it is interesting that once the precipitation mask is applied my results diverge from this norm, especially in the case of the North Cascades (Kuhn, 1995; DeBeer and Sharp, 2009; Dick, 2013). This could be due to my choice in solar time (2 PM local time, approximately solar noon), which would place the sun in a more central position and decrease melt in the west while simultaneously increasing it in the east, leading to less glacier dependence on aspect. The shift to higher elevations follows expected trends (Nuth et al., 2007; Rivera et al., 2007; Paul and Haeberli, 2008).

The model is able to recreate historic glaciers extents with some accuracy. The British Columbia application was able to accurately model area with a net \pm 14 . $1 \%$ error relative to their calibration year, 2005 , though volumetric error could be up to $\pm 60 \%$ (Clarke et al., 2015). Additionally, the BC application covered a huge region, and error 
varied greatly between regions. For instance, the highest error was found on the coast $(+17.8 \%$ area error), and the smallest for the Rockies (-2.9\%). However, no comparison of historic times series of observed glacier area with modeled area was presented. The Olympics application matches total area well compared to different inventories (-5.2\% in 1986 compared to the RGI, 3.2\% for a 2009 from Fountain (unpublished)). While direct inventories before the 1980s for the entirety of glaciers in the Olympic Mountains are not available, Blue Glacier on Mt. Olympus has a record to as early as 1815. A trend has been fit to changes between Blue glacier and the rest of the Olympics, so historic glacier extents for the past can be estimated (Dick, 2013), and on average the model error is $\sim 18 \%$. For North Cascades, however, the error between modeled and observed glacier area was $+2.7 \%$ in the calibration year, 1970 . Some model error before and after the calibration year may be due to simplified physics in the melt subroutine. This model uses a variation of the temperature index model in Hock (1999), which is discussed in detail in Appendix A. However, the Hock (1999) model performs poorly outside of the calibration year (Gabbi et al., 2014), likely due to the simplistic treatment of albedo as snow/ice radiation parameters. For instance, rock falls over the glacier face can cause local variation in snow/ice albedos, as can impurities in the ice, which additionally affect ice deformation (Benn and Evens, 2006). Modifications to allow snow albedo to vary temporally and spatially, indexed by maximum temperature, and the addition of a cloud cover factor, may increase model accuracy (Gabbi et al., 2014). 
Many observational studies have predicted that glaciers in favorable topographic locations (higher elevations with north to northeast facing aspects), regardless of size, lose a lower percentage of their volume than glaciers in less favorable conditions, possibly due to lowered melt from shading and the collection of snow from wind redistribution and avalanching (Kuhn, 1995; DeBeer and Sharpe, 2007, 2009; Evans 2006; Basagic and Fountain, 2011; DeVisser and Fountain, 2015), and in general the RGM is able to replicate observed patterns. DeBeer and Sharp $(2007,2009)$ found that small glaciers retreat less in the Canadian Cordillera than larger glaciers, likely due to favorable topographic conditions which can shade glaciers from incoming solar radiation and at higher elevations reduce melt and lead to extra precipitation from avalanching and wind redistribution. Some studies note that small glaciers often disappear before larger ones (Granshaw and Fountain, 2006; DeVisser and Fountain, 2015; Huss and Fischer, 2016). However, others indicate that small glaciers can often be located in favorable conditions (high elevation, preferred aspect for its hemisphere, and extra accumulation from avalanching and wind redistribution), which can cause them to be less sensitive to warming climate than larger, more exposed glaciers (Kuhn, 1995; DeBeer and Sharp, 2007/2009).

Qualitatively, it appears that the RGM predicts that small glaciers in the North Cascades disappear before larger glaciers, which is supported by the quantitative results of Dick (2013)'s 1900-2009 inventories of the North Cascades. The RGM also predicts lower elevation ice will disappear first, in agreement with observational studies for the 
North Cascades and elsewhere (Kuhn, 1995; Granshaw and Fountain, 2006; DeBeer and Sharp, 2007/2009; Dick, 2013). However, the dependence of the model with aspect is weak, and starts to veer away from the expected preference for north to northeast facing ice. Over time, the RGM predicts that North Cascade glaciers will have increased variability in aspect, and retreat does not appear to be closely related to aspect. This is in agreement with some observational studies of the North Cascades which found that glacier loss in that region was not correlated with aspect (Granshaw and Fountain, 2006), but in disagreement with others that did (Dick, 2013), so it is difficult to tell if this weakness is a model error or related to the region. It is possible that the solar radiation subroutine may be leading to an underestimate of the importance of aspect. In this application solar position, and therefore incoming radiation, is estimated only once each month. It is possible that diurnal variation of solar radiation may be playing a larger role in glacier placement with aspect than anticipated, and updating the model to better estimate the magnitude of daily solar radiation change may be beneficial.

However, there are several modeling reasons why RGM results from the North Cascades differ from other regions. For instance, my choice of solar time, 2 PM was chosen because it best reduced the aspect RMSE in the calibration year, but perhaps it also reduced the regional dependence of glaciers on aspect. Snow redistribution through snow and avalanching can also cause a stronger topographic dependence, siphoning snow from surrounding topography and placing it on the surface of others (Kuhn, 1995), and the RGM application to the North Cascades does not include snow redistribution. To 
Table 5.2: Table of the total area and Fractional Area Change (FAC) with respect to the modeled glacier area for the application of the final model where parameters are adjusted to minimize extra ice and the addition of the precipitation mask to the North Cascades, with RCP $8.5\left(337.75 \mathrm{~km}^{2}\right), \operatorname{RCP} 4.5\left(359.46 \mathrm{~km}^{2}\right)$, and RCP $2.6\left(350.69 \mathrm{~km}^{2}\right)$. The observed 1970 area is based on the RGI, and the rest of the observed data is estimated based on Dick (2013), who did an inventory of 2009 North Cascade glaciers. RCP 4.5 only goes up to 2098, whereas the other two scenarios go up to 2100 due to the availability of data.

\begin{tabular}{|c|c|c|c|c|}
\hline & \multicolumn{2}{|c|}{ Observed } & \multicolumn{2}{|c|}{$\underline{\mathrm{RCP}} 8.5$} \\
\hline & Area & $\triangle \mathrm{FAC}$ & Area & FAC \\
\hline 1900 & 533.89 & -- & 442.52 & -- \\
\hline 1958 & 288.30 & $46 \%$ & 359.34 & $19 \%$ \\
\hline 1970 & 344.97 & $35 \%$ & 337.75 & $24 \%$ \\
\hline 2009 & 268.41 & $56 \%$ & 328.16 & $24 \%$ \\
\hline 2025 & -- & -- & 193.32 & $56 \%$ \\
\hline 2050 & -- & -- & 101.42 & $77 \%$ \\
\hline 2075 & -- & -- & 19.89 & $96 \%$ \\
\hline \multirow[t]{3}{*}{2100} & -- & -- & 16.82 & $96 \%$ \\
\hline & \multicolumn{2}{|c|}{ RCP 4.5} & \multicolumn{2}{|c|}{ RCP 2.6} \\
\hline & Area & $\triangle \mathrm{FAC}$ & Area & $\triangle \mathrm{FAC}$ \\
\hline 1900 & 452.09 & -- & 474.09 & -- \\
\hline 1958 & 355.73 & $21 \%$ & 406.61 & $14 \%$ \\
\hline 1970 & 359.46 & $20 \%$ & 350.69 & $26 \%$ \\
\hline 2009 & 219.98 & $51 \%$ & 356.58 & $25 \%$ \\
\hline 2025 & 190.95 & $58 \%$ & 253.47 & $47 \%$ \\
\hline 2050 & 92.28 & $80 \%$ & 207.22 & $56 \%$ \\
\hline 2075 & 34.78 & $92 \%$ & 177.25 & $63 \%$ \\
\hline 2100 & 70.49 & $84 \%$ & 145.98 & $69 \%$ \\
\hline
\end{tabular}

account for any PRISM error and the lack of snow redistribution in the RGM a precipitation mask over missing glaciers was applied. Overall, it greatly improved glacier misplacement, but the grid is static temporally and spatially, which may introduce increased extra ice in some areas while failing to reproduce missing glaciers in others. The application of the RGM to British Columbia, Clarke et al., (2015) employed a temporally static precipitation mask but varied the multiplier over the study region, potentially leading to a more accurate solution. 
Overall, the model had the best performance in the North Cascades with error as low as $+2.7 \%$ more glacier area in the calibration year than expected by the $R G$ in our inventory year, followed by Clarke et al. (2015)'s application in British Columbia $( \pm 14.1 \%$ of the total area), and the worst in the Olympics (26\%). Note, this does not consider location error. Regional glaciation models perform better over larger study regions where errors may better compensate for each other (Clarke et al., 2015). Similarly, in terms of glacier distribution, a highly glaciated region will have better agreement with observed glaciers than a region of few, widely spread glaciers. For the three RGM model applications (two introduced here and the initial application by Clarke et al., (2015) in $\mathrm{BC})$, the Olympic Mountains region is much smaller (59.11 $\mathrm{km}^{2}$ observed ice area, 1986) than the North Cascades $\left(349.97 \mathrm{~km}^{2}, 1970\right)$ and British Columbia $\left(733 \mathrm{~km}^{2}, 2005\right)$. For British Columbia the model predicts a $-70 \%$ area loss (RCP 2.6 ) and $-95 \%$ (RCP 8.5 ) relative to 2005 , for the Olympics -91 to $-100 \%$ relative to 1900 , and for the North Cascades 60-65\% area loss with RCP 2.6 and 94-96\% with RCP 8.5 relative to 1900 (Table $5.2)$.

Additionally, the RGM appears to correlate well to other global studies, observational and modeling) of glacier retreat (Figure 5.1). Moller and Schneider (2010) predict a $35 \%$ area loss from $1984-2100$ for Glaciar Noroeste, Chile, which is significantly less than the loss estimated between $1970-2100$ for the North Cascades here. Similarly, by 2050 Himalayan glaciers are expected to retreat by $20 \%$ of their 2000 extents, which 


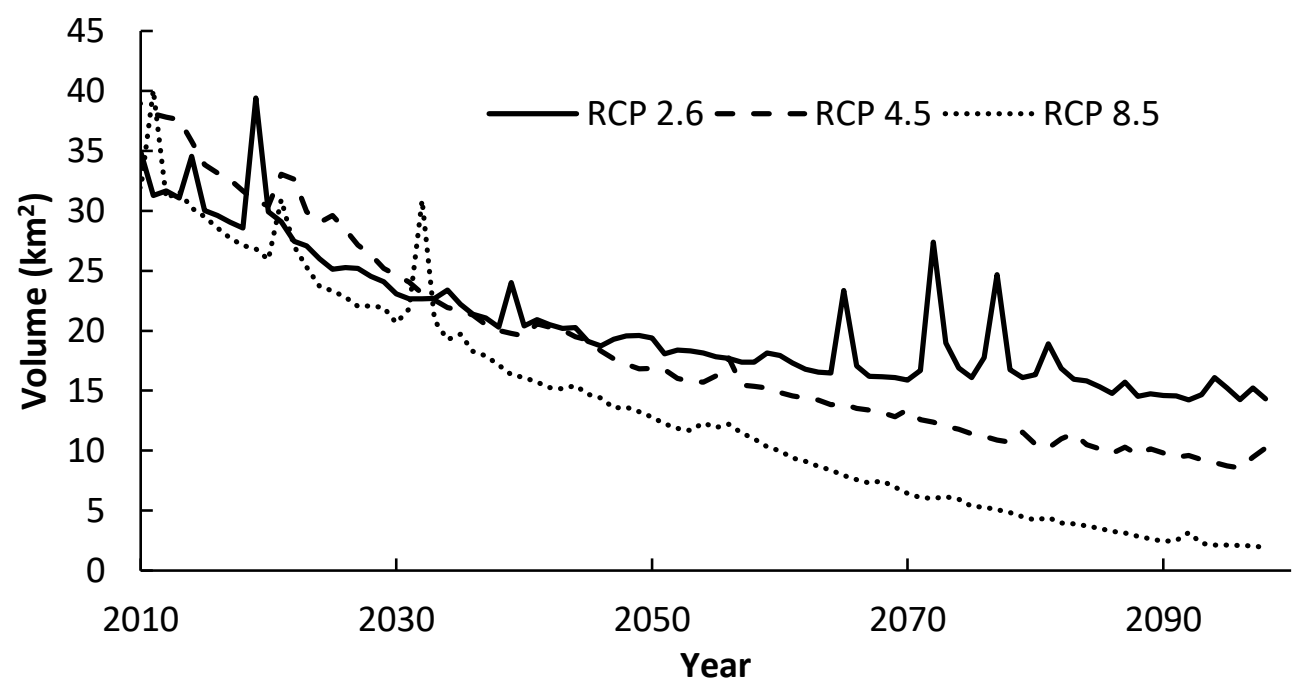

Figure 5.1: Change in volume over time in the North Cascades for each RCP. Only ice greater than $10 \mathrm{~m}$ thick is included to prevent large spikes in the trend due to high or low snow years.

is half what is predicted for the North Cascades over the same period (Zhao et al., 2014). However, greater agreement is seen with Swiss glaciers, which exist in a temperate, maritime environment similar to those in the North Cascades. Over the $21^{\text {st }}$ century $60-80 \%$ of the glacier area in the Swiss Alps are expected to disappear, and $88 \%$ of those glaciers may to disappear completely by 2060 with the remaining having lost over half their current area (Linsbauer et al., 2013; Huss and Fischer, 2016).

My results for glacier volume loss are typically lower than expected when compared to other studies. For instance, the RGM predicts $56-65 \%$ volume loss. Radic et al. (2014) applied a similar model to predict global glacier loss using ensemble GCM approach. The mean of many GCMs with RCP 8.5 estimated global mean airtemperature increase of $\sim 6.5^{\circ} \mathrm{C}$.

Between 2006 and 2100 they estimated that $~ 85 \%$ of ice volume would be lost in 
Western Canada and the U.S., which is greater than the volume loss estimated in my study by $20-30 \%$. Similarly, Oerlemans et al., (1998) used several simple models that assume ice dynamics, with different mass balance formulations (day-degree or energy balance) on select glaciers globally to predict that at elevated warming $\left(+0.04{ }^{\circ} \mathrm{C} /\right.$ year, $3.81{ }^{\circ} \mathrm{C}$ increase in global mean air-temperature by 2100 from current temperatures, similar to RCP 8.5) with no increase in precipitation that little or no ice would be left by 2100. However, if temperature increases are small $\left(+0.01^{\circ} \mathrm{C} /\right.$ year, $0.51^{\circ} \mathrm{C}$ warmer from current by 2100 , similar to RCP 2.6 ) and precipitation is increased by $10 \%$ of late 90 's

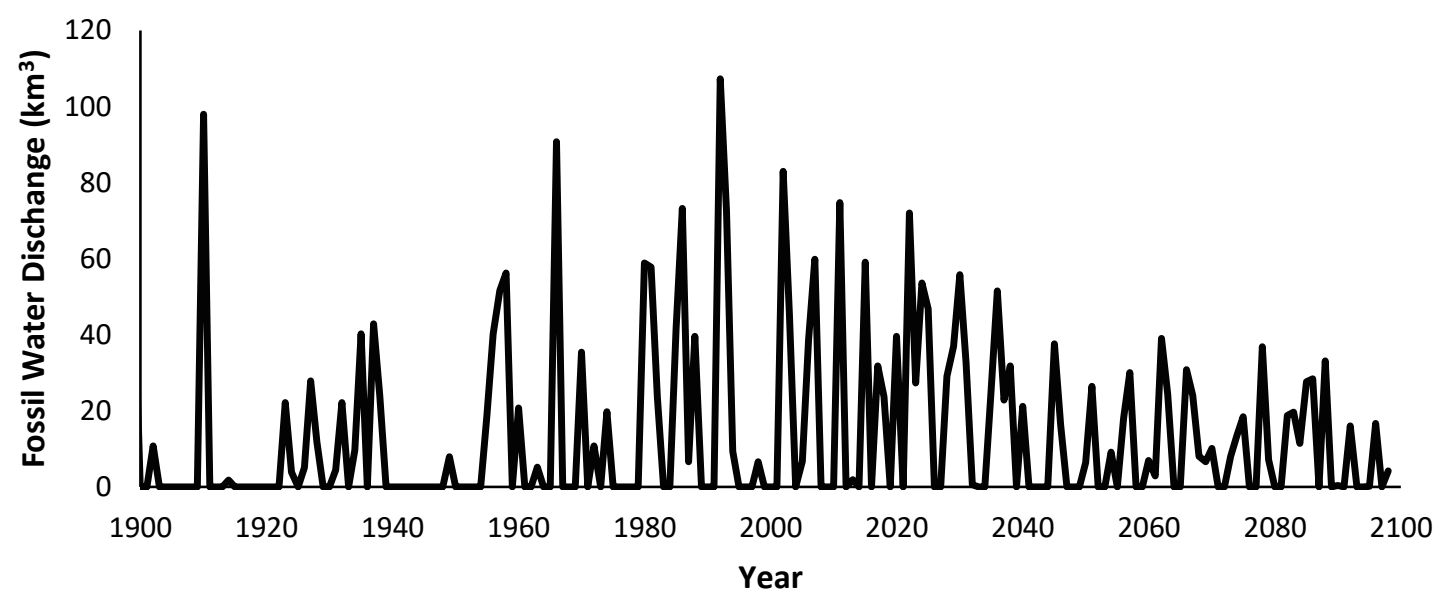

Figure 5.2: The amount of glacier discharge from fossil water, which is water stored as ice in the glacier, for RCP 2.6 .

values, the volume loss could be restricted to $80-90 \%$. Overall, these studies suggest that by the end of the century glaciers worldwide will lose over $85 \%$ of 1990 volume, and potentially even complete loss in some regions. Additionally, peak fossil water (the part of glacier discharge from water stored as ice), appears to be currently reaching its maximum for this study region, and likely will only decrease with time (Figure 5.2). 


\subsection{Conclusions}

Here, I successfully used the RGM to estimate the future of glaciers in the North Cascades. Model error was low with only $\sim 2.7 \%$ area error in the calibration year compared to observed, and total glacier placement accuracy was $98 \%$, indicating that future estimates are likely to be reliable. Model results predict $66 \%-96 \%$ loss relative to 1900. Overall, the Clarke et al., (2015) model modified by Menounos (Menounos, personal communication, October, 2016) is only able to capture broad regional trends since, unlike models that are fit to individual glaciers, physical and state parameters can only be fit over the entire domain. Additional modifications from this study to correct the calculation of the incidence angle to the true solar position and the gradient calculation improved the predicted location of glaciers (Zhou and Liu, 2004; Appendix D). Further, snow accumulation was underpredicted in some regions, and the model was significantly improved with additional precipitation mask over places where the model was not predicting observed glaciers in 1970. Whether the underpredicted snow accumulation is a result of poor precipitation prediction and/or ignoring contribution from avalanching and wind drift is unclear.

However, the RGM can quickly calculate changes in thickness and extent for many glaciers because it does not need to be recalibrated for each glacier. Additionally, most regional glaciation models lack a physics-based treatment of glacier dynamics, but the RGM includes subroutines to redistribute mass through deformation and sliding (Clarke et al., 2015). Despite uncertainties with snow redistribution, climate data accuracy, and surface inversion data, temporal variability should be reasonable as over a region errors 
will be compensated for to produce a good reproduction of glacier distribution (Clarke et al., 2015).

The model for the North Cascades was "optimized" for observed 1970 glacier area from Randolph Glacier Inventory (Pfeffer et al., 2014). Optimization included adjusting the solar time to most decrease error in the modeled distribution of glaciers with aspect compared to observed, and then using forcing parameters (bulk melt, snow/ice radiation parameters) to match modeled and observed areas. Overall the total area matched, though there were compensating errors of placement. Modeled glacier area from 1970 to the late 90 s decreased by $\sim 2 \%$, about half of the observed retreat (Dick, 2013). However, from 1990 to 2009 modeled glacier area decreased by 29\%, about triple of that observed (Dick, 2013), due to an increased retreat rate. By 2100, model results indicate the glaciers are projected to mostly disappear. RCP 2.6, our conservative estimates of future climate, predicts that the remaining glaciers will be $65 \%$ of modeled 1970 extents by 2100 , RCP 4.5 predicts $84 \%$ loss, and RCP 8.5 , the extreme scenario predicts $94 \%$ loss by the same time. Overall, glaciers will likely be gone between 2100 to 2200 and will be a loss to water resources and the local ecosystems that benefit from glacial discharge. The model supports this, showing decreasing variation in volume change over time (Figure 5.1).

Less glacier melt water will lead to raised water temperature in the rivers and streams that are fed by glaciated basins (Grah and Beaulieu, 2013). For instance, ice is largely responsible for late summer discharge in alpine watersheds. By delaying 
maximum flow temporarily through englacial water storage water then releasing the water midsummer thought melt the decline in runoff due to decreasing snowpack is buffered. But, as glaciers recede and disappear, this buffer will also decline (Fountain and Tangborn, 1985; Frans et al., 2018). Observing the difference between the volume for a given year and the year before, it is clear that we are currently in or just past the period of peak discharge, and the contribution of glacier melt to runoff will only decrease going forward (Figure 5.2). Additionally, for local aquatic life, such as salmonids like the bull trout, this shift to warmer water temperatures will exceed their tolerance levels and kill them (Grah and Beaulieu, 2013). As glaciers retreat glacial melt, which is sediment rich due to abrasion at the base of the glacier (Benn and Evens, 2006) will increase causing more suspended sediment, subjected to different weathering processes in the subglacial environment, to be released into alpine streams, changing water chemistry (Moore et al., 2009). Glacial retreat increases geologic hazards risk, landslides from over-steepened valley walls that are no longer supported by ice, and debris flows from failed moraines (Chiarle et al., 2007; Moore et al., 2009). With the knowledge that glaciers are retreating and could potentially be gone within the next 100-150 years, it will be important to protect this region's ecosystems as climate change continues. Overall, this study shows agreement with global future predictions of glacier area, and that glaciers will continue to disappear. 


\section{References}

Arora, V., Scinocca J., Boer, G., Christian, J., Denman, K., Flato, G., Kharin, V., Lee, W., and Merryfield W., (2011), Carbon emission limits required to satisfy future representative concentration pathways of greenhouse gases. Geophysical Research Letters, 38(5).

Armstrong, R., (1986), Mass balance history of Blue Glacier, Washington, USA, Oerlemans J. (eds) Glacier Fluctuations and Climatic Change, 6, 183-192.

Arnold, N., Rees, G., Hodson, A., and Kohler, J., (2006), Topographic controls on the surface energy balance of a high Arctic valley glacier, Journal of Geophysical Research, 111.

Basagic, H., and Fountain, A. (2011), Quantifying $20^{\text {th }}$ century glacier change in the Sierra Nevada, Artic, Antarctic, and Alpine Research, 43(3), 317-33.

Beedle, M., Menounos, B., and Wheate R., (2015), Glacier change in the Cariboo Mountains, British Columbia, Canada (1952-2005), The Cryosphere, 9, 65-80.

Benn, D. and Evans, D. (2006), Glaciers ad Glaciations, $2^{\text {nd }}$ ed., Routledge, London and New York.

Bennett, M., and Glasser, N. (2009), Glacial geology: ice sheets and landforms, WileyBlackwell, Chichester, UK.

Bitz, C., and Battisti, D. (1999), Interannual to decadal variability in climate and the glacier mass balance In Washington, Western Canada, and Alaska. Journal of Climate, 12(11), 3181-3196.

Brown, L., Hannah, D., and Milner, A. (2007), Vulnerability of alpine stream biodiversity to shirking glaciers and snowpacks, Global Change Biology, 13(5), 958-966.

Chiarle, M., Iannotti, A., Mortara, G., and Deline, P. (2007), Recent debris flow occurrences associated with glaciers in the Alps, Global and Planetary Change, 56(12), 123-136.

Clark, A., Fagre, D., Peitzsch, E., Reardon, B., and Harper, J. (2017), Glaciological measurements and mass balances from Sperry Glacier, Montana, USA, years 20052015, Earth System Science Data, 9(1), 47-61.

Clarke, G., Jarosch, A., Anslow, F., Radić, V., and Menounos, B. (2015), Projected deglaciation of western Canada in the twenty-first century, Nature Geoscience, 8(5), 372-37. 
Calov, R. and Greve, R. (2005), A semi-analytical solution for the positive degree-day model with stochastic temperature variations, Journal of Glaciology, 51(172), 173175.

Colle, B., and Mass, C. (1998), Windstorms along the western side of the Washington Cascades Mountains. Part I: A High-Resolution observational and modeling study of the 12 February 1995 event, Monthly Weather Review, 126(1), 28-52.

Cuffey, K., and Paterson, W. (2010), The Physics of Glaciers, Academic Press.

Currier, W., Thorson, T., and Lundquist, J. (2017), Independent Evaluation of Frozen Precipitation from WRF and PRISM in the Olympic Mountains, Journal of Hydrometeorology, 18(10), 2681-2703.

Daly, C., Taylor, G., and Gibson, W. (1997), The PRISIM approach to mapping precipitation and temperature, Proceedings, $10^{\text {th }}$ AMS Conference on Applied Climatology, 20-23.

Daly, C. (2006), Guildlines for accessing the suitability of spatial climate data sets, International Journal of Climatology, 26, 707-721

Daly, C., Smith, J., Smith, J., and Mckane, R. (2007), High-Resolution Spatial Modeling of Daily Weather Elements for a Catchment in the Oregon Cascade Mountains, United States, Journal of Applied Meteorology and Climatology, 46(10), 1565-1586.

Daly, C., Halbleib, M., Smith, J., Gibson, W., Doggett, M., Taylor, G., Curti,s J., and Pasteris, P. (2008), Physiopgraphically sensitive mapping of climatological temperature and precipitation across the conterminous United States, International Journal of Climatology, 28(15), 2031-2064.

Davis, J. (2002) Statistics and Data Analysis in Geology, $2^{\text {nd }}$ ed., John Wiley \& Sons Inc., New York, NY.

DeBeer, C., and Sharp, M. (2007), Recent changes in glacier area and volume within the southern Canadian Cordillera, Annals of Glaciology, 46, 215-221.

DeBeer, C, and Sharp, M. (2009), Topographic influences on recent changes of very small glaciers in the Monashee Mountains, British Columbia, Canada, Journal of Glaciology, 55(192), 691-700.

Dick, K. (2013), Glacier Change in the North Cascades, Washington: 1990-2009, M.S. thesis, Portland State University, Portland, Oregon.

DeVisser, M., and Fountain, A. (2014), A Century of Glacier Change in the Wind River Range, WY, Geomorphology, 232, 103-116. 
Evans, I., (2006), Local aspect asymmetry of mountain glaciation: A global survey of constancy of favored directions for glacier numbers and altitudes, Geomorphology, 73(1-2), 166-184.

Essou, G., Brissette, F., and Lucas-Picher, P. (2017), The use of reanalyses and gridded observations as weather input data for a hydrological model: Comparison of performances of simulated river flows based on the density of weather stations, Journal of Hydrometeorology, 18(2), 497-513.

Farinotti, D., Huss M., Bauder, A., Funk, M., and Truffer, M. (2009), A method to estimate the ice volume and ice-thickness distribution of alpine glaciers, Journal of Glaciology, 55(191), 422- 430.

Farr T., Rosen P., Caro E., Crippen R., Duren R., Hensley S., Kobrick M., Paller M., Rodriguez E., Roth L., Seal D., Shaffer S., Shimada J., Umland J., Werner M., Oskin M., Burbank D., and Alsork D, (2007), The shuttle radar topography mission, Review of Geophysics, (45),

Feddema, J., Oleson, K., Bonan, G., Mearns, L., Buja, L., Meehl, G., and Washington, W. (2005), the importance of land-cover change in simulating future climates, Science, 310(5754), 1674-1678.

Ferguson, S., Moore, M., Marriott, M., and Speers-Hayes, P, (1990), Avalanche weather forecasting at the Northwest Avalanche Center, Seattle Washington, USA, Journal of Glaciology, 36(122), 57-66.

Fountain, A., Glenn, B., and Basagic, I. (2017), The geography and perennial snowfields in the American West, Arctic, Alpine, and Antarctic Research, 43(3), 391-410.

Fountain, A., Hoffman, M., Granshaw, F., and Riedel, J., (2009), The 'benchmark glacier' concept- does it work? Lessons from the North Cascade Range, USA, Annals of Glaciology, 50, 163-168.

Fountain, A., and Tangborn, W. (1985), The effect of glaciers on streamflow variations, Water Resources Research, 21(4), 579-586.

Frans, C., Istanbulluoglu, E., Lettenmeier, D., Fountain, A., and Riedel, J. (2018), Glacier recession and the response of summer streamflow in the Pacific Northwest United States, 1960-2099, Water Resources Research, 54(6), 6202-6225.

Gabbi, J., Carenzo, M., Pellicciotti, F., Bauder, A., and Funk, M. (2014), A comparison of empirical and physically based glacier surface melt models for long-term simulations of glacier response, Journal of Glaciology, 60(224), 1140-1154.

Garnier, B. and Ohmura, A. (1968), A method of calculating the direct shortwave radiation income of slopes, Journal of Applied Meteorology, 7(5), 796-800. 
Gent, P., Danabasoglu, G., Donner, L., Holland, M., Hunke, E., Jayne, S., Lawrence, D., Neale, R., Rasch, P., Vertenstein, M., Worley, P., Yang, Z., and Zhang, M. (2011), The Community Climate System Model Version 4, Journal of Climate, 24(19), 4973-4991.

Gesch, D., Oimen, M., Greenlee, S., Nelson, C., Steuck, M., and Tyler, D. (2002), The national elevation dataset, Photogrammetric engineering and remote sensing, 68(1), 5-32.

Giorgi, F. and Shields, C. (1999), Test of precipitation parameterizations available in the latest version of NCAR regional climate model (RegCM) over continental United States, Journal of Geophysical Research, 104(6), 6353-6375.

GLIMS, and National Snow and Ice Data Center, (2017), GLIMS Glacier Database, Boulder, CO, doi:10.7765/N5V98602.

Goehring, B., Vacco, D., Alley, R., and Schafer, J., (2012), Holocene dynamics of the Rhone Glacier, Switzerland, deduced from ice flow models and cosmogenic nuclides, Earth and Planetary Science Letters, 351, 27-35.

Grah, O., and Beaulieu, J. (2013), The effect of climate change on glacier ablation and baseflow support in the Nooksack River basin and implications on Pacific salmonid species protection and recovery, Climatic Change, 120, 657-670.

Granshaw, F. (2002), Glacier change in the North Cascade National Park Complex, Washington USA, 1958-1998, M.S. thesis, Portland State University, Portland, Oregon.

Granshaw, F., and Fountain, A. (2006), Glacier change (1958-1998) in the North Cascades National Park Complex, Washington, USA, Journal of Glaciology, 52(177), 251-256.

GRASS Development Team (2014), Geographic Resources Analyses Support System (GRASS) Software, Version 6.4.4. Open Source Geospatial Foundation, http://grass.oegeo.org.

Hayes P., Rasmussen L., and Conway, H. (2002), Estimating precipitation in the Central Cascades of Washington, Journal of Hydrometeorology, 3(3), 335-346.

Haeberli, W., and Hoelzle, M. (1995), Application of inventory data for estimating characteristics of and regional climate-change effects on mountain glaciers: a pilot study with the European Alps, Annals of Glaciology, 21, 206-212.

Heard, J. (2012), Glacial Geology of Goat Rocks, Washington, M.S. Thesis, Portland State University, Portland, Oregon.

Hock, R., (1999), A distributed temperature-index ice-and snowmelt model including potential direct solar radiation, Journal of Glaciology, 45(149), 101-111. 
Hodge, S., Trabant, D., Krimmel, R., Heinrichs, T., March, R., and Joesberger, E. (1998), Climate variations and changes in mass of three glaciers in Western North America, Journal of Climate, 11(9), 2161-2179.

Hoffman, R., Woodward, A., Haggarty, P., Jenkins, K., Griffin, P., Adams, M., Hagar, J., Cummings, T., Duriscoe, D., Kooper, K., Riedel, J., Marin, L., Mauger, G., Bumbaco, K., and Littell, J., (2015) North Cascades National Park Service Complex, Natural Resource Condition Assessment: Natural Resource Report NPS/NOCA/NRR2015/901 .

Holmlund, P. and Schneider, T. (1997), The effect of continentality on glacier response and mass balance, Annals of Glaciology, 24, 272-276.

Houze, R., McMurdie, L., Petersen, W., Schwaller, M., Baccus, W., Lundquist, J., Mass., C., Nijssen B., Rutledge, S., Hudak, D., Tanelli, S., Mace, G., Poellot, M., Lettenmaier, D., Zagrodnik, J., Rowe, A., DeHart, J., Madaus, L., Barnes, H., and Chandrasekar, V. (2017), The Olympic Mountains Experiment (OLYMPEX), American Meteorological Society, 98(10), 2167-2188.

Hubley, R., (1956), Glaciers of the Washington Cascade and Olympic Mountains; their present activity and its relation to local climatic trends, Journal of Glaciology, 2(19), 669-674.

Huss, M. and Farinotti, D. (2012), Distributed ice thickness and volume of all glaciers around the globe, Journal of Geophysical Research, 117(F4).

Huss, M., and Farinotti, D. (2014), A high-resolution bedrock map for the Antarctic Peninsula, The Cryosphere, 8(4), 1261-1273.

Huss M., and Fischer, M. (2016), Sensitivity of very small glaciers in the Swiss Alps to future climate change, Frontiers in Earth Science, 4(34), 1-17.

Hussein, M., and Albarqouni, S. (2010), Enhanced model of one axis-two positions manual tracking photovoltaic panels for lighting projects in Palestine, Proceedings of the Second LASTED International Conference, 937, 15-17.

Jackson, K., and Fountain, A, (2007), Spatial and morphological change on Eliot Glacier, Mount Hood, Oregon, USA, Annals of Glaciology, 46(1), 222-226.

Julandar, R., Curtis, J., and Beard, A. (2007), The SNOTEL temperature dataset, Mountain Views Newsletter, 1(2), 4-7.

Kanji, G. (2006), 100 Statistical Tests, $3^{\text {rd }}$ ed., Sage Publications Ltd., Thousand Oaks, California. 
Kessler, M., Anderson, R., and Stock, G. (2006), Modeling topographic and climatic control of east-west asymmetry in Sierra Nevada glacier length during the Last Glacial Maximum, Journal of Geophysical Research, 111

Krimmel, R. (1994), Runoff, precipitation, mass balance, and ice velocity measurements at South Cascade glacier, Washington, 1993 balance year, Open-File Report 94-4139; US Geological Survey.

Kuhn, M. (1995), The mass balance of very small glaciers, Zeitschrift fur Gletscherkunde und Glazialgeologie, 31(1-2), 171-179.

Le Meur E., Gerbaux, M., Schafer, M., and Vincent, C. (2007), Disappearance of an Alpine glacier over the $21^{\text {st }}$ Century simulated from modeling its future surface mass balance, Earth and Planetary Science Letters, 261(3-4), 367-374.

Lillquist, K., and Walker, K. (2006), Historical Glacier and Climate Fluctuations at Mount Hood, Oregon, Arctic, Antarctic, and Alpine Research, 38(3), 399-412.

Linsbauer, A., Paul, F., Machguth G., and Haeberli W. (2013), Comparing three different methods to model scenarios of future glacier change in the Swiss Alps, Annals of Glaciology, 54(63), 241-253

Locke, W. (1990), Late Pleistocene glaciers and the climate of Western Montana (Arctic and Alpine Research, 22(1), 1-13.

Luce, C., Abatzoglou, J., and Holden, Z., (2013), The missing mountain water: Slow westerlies decrease orographic enhancement in the Pacific Northwest USA, Science, 342, 1360-1364.

Luckman, B., Harding, K., and Hamilton, J. (1987), Recent glacier advances in the Premier Range, British Columbia, Canadian Journal of Earth Sciences, 24(6),1149-1161.

Lundquist, J., Pepin, D., and Rochford, C. (2008), Automated algorithm for mapping regions of cold-air pooling in complex terrain, Journal of Geophysical Research, 113(D22).

Manuta, N., Hare, S., Zhang, Y., Wallace J., and Francis, R., 1997), A Pacific interdecadal climate oscillation with impacts on salmon production, bulletin of the American Meteorological Society, 78 (6), 1069-1079.

Marshall, S., (2005) Recent advances in understanding ice sheer dynamics, Earth and Planetary Science Letters, 240(2), 191-204.

Mauger, G. (2016), Global Climate Model Projections for the PNW, Climate Impacts Group, Seattle, WA.

Mass, C. (2008), The Weather of the Pacific North West, University of Washington Press, Seattle. 
Mass, C. (2010), Topographically Forced Convergence in Western Washington State, Monthly Weather Review, 109(6), 1335-1347.

McCabe, G., and Wolock, D. (2011), Independent effects of temperature and precipitation on modeled runoff in the conterminous United States, Water Resources Research, 47(11).

Meier, M. and Post, A. (1962), Recent variations in mass net budgets of glaciers in western North America, International Association of Hydrological Science Publication, 58, 6377.

Meier, M. (1984), Contribution of Small Glaciers to Global Sea Level, Science, 226(4681), 1418-1421.

Menounos, B., Hugonnet, R., Shean, D., Gardner, A., Howat, I., Berthier E., Pelto, B., Tennant, C., Shea, J., Noh, M., Brun, F., and Dehecq, A., (2019), Heterogeneous changes in Western North American glaciers linked to decadal variability in zonal wind strength, Geophysical Research Letters, 46, (1),

Mesinger, F., DiMego, G., Kalnay, E., Mitchell, K., Shafram, P., Ebisuzaki, W., Jovic, D., Wollen, J., Rogers, E., Berbery, E., Ek, M., Fan, Y. Grumbine, R., Higgins, W., Li, H., Lin, Y., Mankin, G., Parrish, D., and Shi, W. (2006), North American Regional Reanalysis, American Metrological Society, 87(3), 343-360.

Mitchell, S., and Montgomery, D. (2006), Influence of a glacial buzzsaw on the height and morphology of the Cascade Range in central Washington State, USA, Quaternary Research, 65(1), 96-107.

Moller, M. and Schneider, C. (2010), Calibration of glacier volume-area relations from surface extent and application to future glacier change, Journal of Glaciology, 56(195), 33-40.

Moore, R., Fleming, S., Menounos, B., Wheate, R., Fountain, A., Stahl, K., Holm, K., and Jakob, M. (2009), Glacier change in western North America: influences on hydrology, geomorphic hazards and water quality, Hydrological Processes, 23(1), 42-61.

Moss, R., Edmonds, J., Hibbard, K., Manning, M., Rose, S., van Vuuren, D., Carter, T., Emori, S., Kainuma, M., Kram, T., Meehl, G., Mitchell, J., Nakicenovic, N., Riahi, K., Smith, S., Stouffer, R., Thomson, A., Weyant, J., and Wilbanks, T. (2010), The next generation of scenarios of climate change research and assessment, Nature, 463(7282), 747-756.

Mote, P., Parson, E., Hamlet, A., Keeton, W., Lettenmaier, A., Mantua, N., Miles, E., Peterson, D., Peterson, D., Slaughter, R., and Snover, A. (2003). Trends in temperature and precipitation in the Pacific Northwest during the twentieth century, Northwest science, 77(4), 271-282. 
Mote, P., Li, S., Lettenmaier, D., Xiao, M., and Engel, R. (2018), Dramatic declines in snowpack in the western US, Climate and Atmospheric Science, 1(2), 1-6.

Mote, P., and Salathé, E., (2010), Future climate in the Pacific Northwest, Climatic Change, 102(1-2), 29-50.

Natural Resource Conservation Service (2017), SNOTEL water equivalent (SWE) and snow depth data, United States Department of Agriculture, retrieve April 27 $7^{\text {th }}, 2017$

NOAA National Centers for Environmental information, Climate at a Glance: Regional Time Series, published April 2018, retrieved on May 15, 2018 from http://www.ncdc.noaa.gov/cag/.

Nuth, C., Kohler, J., Aas, H., Brandt, O., and Hagen, J. (2007), Glacier geometry and elevation changes on Svalbard (1936-90): a baseline dataset, Annals of Glaciology, 46, 106-116.

O'Connor, J. (2013), "Our vanishing glaciers": One hundred years of glacier retreat in the Three Sisters Area, Oregon Historical Quarterly, 11 (4), 402-427.

Oerlemans, J., and Dool, H. (1978), Energy balance climate models: Stability Experiments with a refined albedo and updated coefficients for infrared emission, Journal of Atmospheric Sciences 35(3), 371-381.

Oerlemans, J., Anderson, B., Hubbard, A., Huybrechts, P., Johannesson, T., Knap, W., Schmeits, M., Stroeven, A., van de Wal, R., Wallinga, J., and Zuo, Z. (1998), Modelling the response of glaciers to climate warming, Climate Dynamics, 14(4), 267-274.

Oerlemans, J., (2001), Glaciers and Climate Change, Lisse, Swets \& Zeitlinger.

Ohlschlager, J. (2000), Glacier Change on the Three Sisters Volcanoes, Oregon: 19002010, M.S. thesis, Portland State University, Portland, Oregon.

Oyler, J., Dobrowski, S., Ballantyne, A., Klene, A., and Running, S. (2015), artificial amplification of warming trends across the mountains of the western United States, Geophysical Research Letters, 42(1).

Paul, F., Machguth, H., and Kaab, A. (2005), On the impact of glacier albedo under conditions of extreme glacier melt: The summer of 2003 in the Alps, EARSeL eProceedings, 4(2), 139-149.

Paul F., and Haeberli, W. (2008), Spatial variability of glacier elevation changes in the Swiss Alps obtained from two digital elevation models, Geophysical Research Letters, 35(32).

Pellicciotti, F., Brock, B., Strasser, U., Burlando, P., Funk, M., and Corripio, J. (2005), An enhanced temperature-index glacier melt model including the shortwave radiation 
balance: Development and testing for Haut Glacier d'Arolla, Switzerland, Journal of Glaciology, 51(175), 573-587.

Pelto, M., (1993), Current behavior of glaciers in the North Cascades and effect on regional water supplies, Washington Geology, 21(2), 3-10.

Pelto, M. (2008a), Glacier annual balance measurement, forecasting climate correlations, North Cascades, Washington, 1984-2006, The Cryosphere, 2(1), 13-21.

Pelto, M. (2008b), Impact of Climate Change on North Cascade Alpine Glaciers, and Alpine Runoff, Northwest Science, 82(1), 65-75.

Pfeffer, W., Arendt, A., Bliss, A., Bolch, T., Cogley, J., Gardner, A., Hagen, J., Hock, R., Kaser, G., Kienholz, C., Miles, E., Moholdt, G., Molg, N., Paul, F., Radic, V., Rastner, P., Raup, B., Rich, J., and Sharp, M. (2014), The Randolph Glacier Inventory: a globally complete inventory of glaciers, Journal of Glaciology, 60(221), 537-552.

Post, A., Richardson, D., Tangborn, W., and Rosselot, F. (1971), Inventory of glaciers in the North Cascades, Washington, US Geological Society, 705-A.

PRISM Climate Group (2017), Historical Past (1985-1980), Oregon State University, Corvallis, OR, http://prism.oregonstate.edu, created 4 Feb 2004.

Radić, V., and Hock, R. (2011), Regionally differentiated contribution of mountain glaciers and ice caps to future sea-level rise, Nature Geoscience, 4(2), 91-94.

Radić, V., Hock, R., and Oerlemans, J. (2007), Volume-area scaling vs flowline modelling in glacier volume projections, Annals of glaciology, 46, 234-240.

Radić, V., and Hock, R. (2011), Regionally differentiated contribution of mountain glaciers and ice caps to future sea-level rise, Nature, 4(2), 1-4.

Radić, V., Bliss, A., Beedlow, A., Hock, R., Miles, E., and Graham, C. (2014), Regional and global projections of twenty-first century glacier mass changes in response to climate scenarios from global climate models, Climate Dynamics, 42(1-2), 37-58.

Ragettli, S., and Pellicciotti, F. (2012), Calibration of a physically based, spatially distributed hydrological model in a glacierized basin: On the use of knowledge from glaciometerological processes to constrain model parameters, Water Resources Research, 48(3).

Raymond, C. (1983), Deformation in the vicinity of ice divides, Journal of Glaciology, 29(103), 357-373.

Reiners, P., Ehlers, T., Mitchell, S., and Mongomery, D. (2003), Coupled spatial variations in precipitation and long-term erosion rates across the Washington Cascades, Nature, 426(6967), 645-647. 
Riahi, K., Rao, S., Krey, V., Cho, C., Chirkov, V., Fischer, G., Kinderman, G., Nakicenovic, N., and Rafaj, P. (2011), RCP 8.5 - A scenario of comparatively high greenhouse gas emissions, Climate Change, 109(1-2), 33-57.

Riedel, J., and Larrabee, M. (2011), North Cascades National Park Complex Glacier Mass Balance Monitoring Annual Report, Water Year 2009, Natural Resource Technical Report NPS/NCCN/NRTR-2011/483.

Riedel, J., and Larrabee, M. (2015), Mount Rainier National Park Glacier Mass balance Monitoring Annual Report, Water year 2011, Natural Resource Data Series NPS/NCCN/NRDS-2015/752.

Riedel, J., Wilson, S., Baccus, W., Larrabee, M., Fudge, T., and Fountain, A. (2015), Glacier status and contribution to streamflow in the Olympic Mountains, Washington, USA, Journal of Glaciology, 61(225), 8-16.

Riedel, J., Wener, J., and Bowerman, D. (2010), Long term monitoring of glaciers at Mount Rainier National Park: narrative and standard Natural Resource Report NPS/NCCN/NRR -2010/175. National Park Service, Fort Collins, Colorado.

Rivera, A., Benham, T., Casassa, G., Bamber, J., and Dowdeswell, D. (2007), Ice elevation and areal changes of glaciers from the Northern Patagonia Icefield, Chile, Global and Planetary Change, 59(1-4), 126-137.

Ruffner, J., (1985), Climates of the States, vol. 2, $3^{\text {rd }}$ ed, Gale Research Co., Detroit, Michigan.

Rupp, D., Abatzoglou, J., Hegewisch, K., and Mote, P. (2013), Evaluation of CIMP5 20 ${ }^{\text {th }}$ century climate simulations for the Pacific Northwest USA, Journal of Geophysical Research: Atmospheres, 118(19), 10,884-10,906.

Sisson, T., Robinson, J., and Swinney, D. (2011), Whole-edifice ice volume change A.D. 1970to 2007/2009 at Mount Rainier, Washington, based on LiDAR surveying, Geology, 39(7), 639-642.

Sitts, D., Fountain, A., and Hoffman, M. (2010), Twentieth Century Glacier Change on Mount Adams, Washington, USA, Northwest Science, 84(4), 378-385.

Stahl, K. and Moore, R. (2006), Influence of watershed glacier coverage on summer streamflow in British Columbia, Canada, Water Resources Research, 42(6).

Tangborn, W., Fountain, A., and Sikonia, W. (1990), Effect of area distribution with altitude on glacier mass balance- a comparison of North and South Klawatti glaciers, Washington State, U.S.A., Annals of Glaciology, 14, 278-282. 
Thackery, G., (2001), Extensive early and middle Wisconsin glaciation on the Western Olympic Peninsula, Washington, and the variability of Pacific moisture delivery to the northwestern United States, Quaternary Research, 55(3), 77-270.

Taylor, K., Stouffer R., and Meehl, G. (2012), An overview of CMIP5 and the experiment design. Bulletin of the American Meteorological Society, 93(4), 485-498.

USGS (2006), Shuttle Radar Topography Mission, Global Land Cover Facility, 3 Arc Second scene, University of Maryland, College Park, Maryland.

USDA Forest Service (1981), Alpine Lakes Area Land Management Plant (Report)

Wang, T., Hamann, A., Spittlehouse, D., and Murdock, T. (2012), Climate Was - Highresolution spatial climate data for Western North America, Journal of Applied Meteorology and Climatology, 51(1), 16-29.

Wang, Y., Leung, L., McGregor, J., Lee, D., Wang, W., Ding, Y., and Kimura, F. (2004), Regional climate modeling Progress Challenges, and Prospects, Journal of the Meteorological Society of Japan, 82(6), 1599-1628.

Weertman, J. (1964), The theory of glacier sliding, Journal of Glaciology, 5(39), 287-303.

van Vuuren, D., Edmonds, J., Kainuma, M., Riahi, K., Thomson, A., Hibbard, K., Hurtt, G., Kram, T., Krey, V., Lamarque, J., Masui, T., Meinshausen, M., Nakicenovic, N., Smith, S., Rose, S. (2011), The representative concentration pathways: An Overview, Climatic Change, 109(1-2), 5-31.

Zhao, L., Ding, R., and Moore, J. (2014), Glacier volume and area change by 2050 in high mountain Asia, Global and Planetary Change, 122, 197-207.

Zhou, Q., and Liu, X. (2004), Error analysis on grid-based slope and aspect algorithms, Photogrammetric Engineering and Remote Sensing, 70(8), 957-962. 


\section{Appendices}

\section{A. Detailed Model Description}

The regional glaciation model (RGM) is a high-resolution model that couples ice dynamics and a surface mass balance model to model many glaciers. Input data is relatively sparse, needing only a large-scale global climate model, gridded observations or reanalysis temperature and precipitation, a DEM, and bare earth DEM. In the following sections, the RGM will be discussed in detail.

\section{a. Melt Model}

Mass balance, in its most simple form, is the difference between snow accumulation and melt, and it is the drives glacier advance and retreat. Accumulation occurs in areas where temperature is at or below the threshold temperature, which is defined here as $0^{\circ} \mathrm{C}$. To calculate accumulation, we use

$$
\text { Accumulation }=N D * P * \frac{\rho_{w}}{\rho_{i}},
$$

Where $N D$ is the negative degree day value $\left({ }^{\circ} \mathrm{C}\right), \mathrm{P}$ is the precipitation $(\mathrm{m}), \rho_{\mathrm{w}}$ is the density of water $\left(1000 \mathrm{~kg} \mathrm{~m}^{-3}\right)$ and $\rho_{i}$ is the density of ice $\left(910 \mathrm{~kg} \mathrm{~m}^{-3}\right)$. Positive and negative degrees days are sums of the average monthly temperature in a given location based on a Gaussian distribution and will be discussed in detail later in this section. Areas of melt are where temperatures are greater than the threshold temperature. Melt requires satisfying the energy balance equation of radiation, sensible and latent heat flux, and heat conduction. For simplicity we focus on incoming shortwave and sensible heat, which typically represent most the heat balance in temperate conditions. To calculate melt rate, we use

$$
\begin{aligned}
& f_{s}=f_{m}+\left(a_{s} * I\right) \\
& f_{i}=f_{m}+\left(a_{i} * I\right)
\end{aligned}
$$

where $f_{s}$ and $f_{i}$ are the snow and ice melt rates $\left(\mathrm{mm}\right.$ month $\left.{ }^{-1}{ }^{\circ} \mathrm{C}^{-1}\right)$, respectively, $f_{m}$ is the bulk melt rate factor $\left(\mathrm{mm}\right.$ day $\left.{ }^{-1}{ }^{\circ} \mathrm{C}^{-1}\right), a_{s}$ and $a_{i}$ are the snow and ice $\left(\mathrm{m}^{2} \mathrm{~W}^{-1} \mathrm{~mm}\right.$ day ${ }^{-1}{ }^{\circ} \mathrm{C}^{-}$ $\left.{ }^{1}\right)$ melt rates respectively, and $l$ is the insolation $\left(\mathrm{W} \mathrm{m}^{-2}\right)$ at a given location. Based on the melt rates of snow and ice, the potential snow melt $\left(m_{s}\right)$ is estimated from

$$
\begin{gathered}
f_{\text {ratio }}=\frac{f_{i}}{f_{s}} \\
m_{s}=f_{s} * D D
\end{gathered}
$$




$$
m_{i}=\left(m_{s}-s\right) * f_{s} \quad s<m_{s}
$$

where $f_{\text {ratio }}$ is the ratio of potential snow melt to potential ice melt, $f_{i}$, is the ice melt, $f_{s}$ is the snow melt, (Equations (7.2) and (7.3)), $m_{s}$ is the total snow melt $(m), D D$ is the positive degree days $\left({ }^{\circ} \mathrm{C}\right)$ and $s$ is the total mass of snow on the surface. If the potential snow melt is greater than the amount of snow, then the remaining energy in $m_{s}$ will be used to melt ice $\left(m_{i}\right)$ which is proportional to the excess snow melt.

Changes in glacier mass are driven by winter accumulation of snow and ice loss via melt as a function of air temperature (Day-Degree model). Often monthly day degrees are too coarse in time to yield reasonable melt, disregarding day to day variation. For instance, there are areas where the mean monthly temperature is $0^{\circ} \mathrm{C}$, indicating no melt for that month in the model though positive degree days did occur during that time frame, and therefore the melt on those days is disregarded. However, monthly data is often the finest temporal resolution available. To improve prediction using monthly temperature and precipitation the method of Calov and Greve (2005) is employed. This method involved the use of an integrand also allows for day-degrees to be calculated analytically instead of as an approximation, increasing accuracy and decreasing processing time. Monthly estimates of degree-days from monthly PRISM surface air temperatures are found from

$$
\begin{gathered}
D D=\int_{0}^{A}\left[\frac{\sigma}{\sqrt{2 \pi}} e^{-\frac{T_{a c}^{2}}{2 \sigma^{2}}}+\frac{T_{a c}}{2} \operatorname{erfc}\left(-\frac{T_{a c}}{\sqrt{2} \sigma}\right)\right] d t, \\
\operatorname{erfc}(x)=\frac{2}{\sqrt{\pi}} \int_{x}^{\infty} e^{-x^{2}} d x,
\end{gathered}
$$

where $A$ is one month, $\sigma$ is the standard deviation of the air temperature over the annual cycle, and $\mathrm{T}_{\mathrm{ac}}$ is the annual temperature cycle, which is the PRISM and lapse rate corrected GCM temperature divided by $\sigma \sqrt{2}$, and $x$ is some gridded location. As previously noted, the locations where the integrand is negative (ND) are used to calculate the amount of snow fall (Equation (7.1).

In addition to seasonal temperature variation, seasonal variations in solar radiation can play a significant role in ice melt. Solar radiation at a location on the surface of the Earth is estimated from solar altitude and angle based on solar declination, latitude, and hour angle (Garnier and Ohmura, 1999) (Figure 7.2). Declination is the angle between the line joining the center of the Earth to the center of the Sun and Earth's equatorial plane, latitude is the angle of the line through some point on the surface of Earth and the closest pole, and hour angle is the placement of the sun at a given time, which varies due to the rotation of earth (Hussein and Albarqouni, 2010, Figure 7.2). The zenith angle is defined as the angle of the line from 


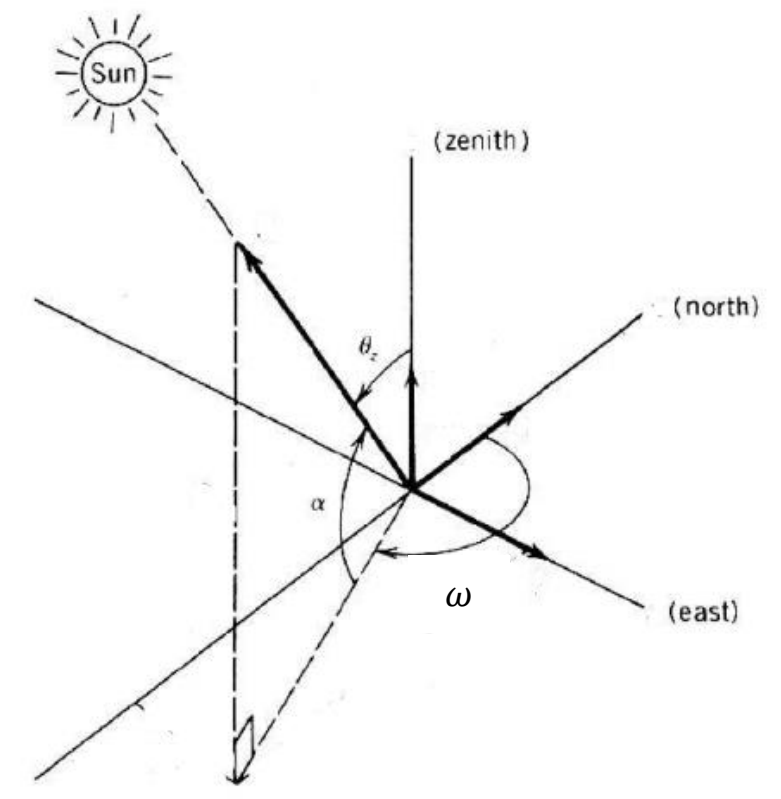

Figure 7.1: Illustration of the solar position angles needed to estimate the incidence angle. $\Theta_{z}$ is the zenith angle, $\alpha$ is the altitude angle $\left(90-\Theta_{z}\right)$, and $\omega$ is the solar azimuth angle measured from north through east.

a point on the earth's surface to the sun and from the zenith (Figure 7.1). The zenith angle is the complimentary to the altitude angle, $\alpha$, between horizontal and the line from the point to the sun (Figure 7.1). Solar azimuth $\omega$ is the angle of the horizontal projection of the line between the point and the sun, and the line from the point and north. The angle is defined by the clockwise sweep of the horizontal projection of the sun line from north (Figure 7.1)

Initially, the insolation model in the RGM employed a code to estimate the solar position and the incidence angle using the PyEphem package in Python. This package allowed for temporally varying solar position, which over a model run of 1000 years could potentially avoid error from a grid of incidence angles for a static solar position. However, this code was modified. Insolation is estimated based on solar intensity and angle, and topographic factors such as slope, aspect, shading and solar angle with

$$
I=\cos \theta_{z} *\left[I_{i} *\left(\cos \left(\theta_{z}\right) * \cos (\beta)+\sin \left(\theta_{z}\right) \sin (\beta) * \cos \left(\varphi_{\alpha}-\varphi_{A}\right)\right)\right]
$$

where $\theta_{z}$ is the angle between the solar ray and normal to the surface, $l_{i}$ is the downwelling short wave radiation over the entire region from CCSM4 (Gent et al., 2011)., $b$ is the surface slope from the horizon, $\varphi$ is the azimuth of the sun $(\alpha)$ or surface (A) from north through east. 


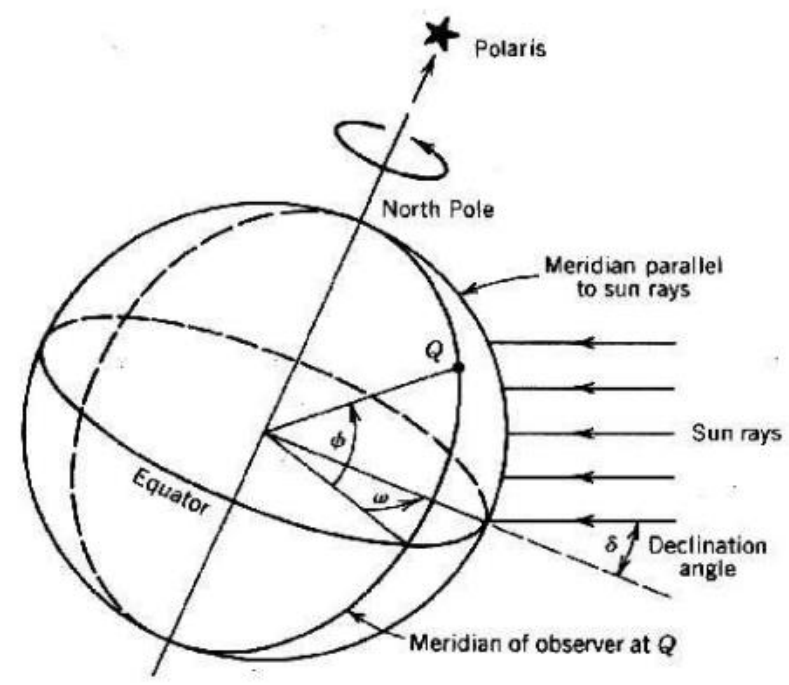

Figure 7.2: Illustration of various angles used to calculate solar position. Here, $\delta$ is the declination angle, $\phi$ is the latitude, and $\omega$ is the hour angle in degrees. Figure taken from Hussein and Albarqouni (2010).

\section{b. Climate}

Inputs of climate data that are accurate and have the appropriate spatial and temporal resolution are necessary for accurate mass balance estimates. The global climate model (GCM) is used to estimate temporal climate variations, and PRISM climate data is used to downscale climate data from the GCM, allowing for increased spatial resolution. I used the Community Climate System Model 4 (CCSM4) combined with the Regional Concentration Pathway (RCP) 8.5, 4.5, and 2.6 (Gent et al. 2011; van Vuuren et al., 2011). This GCM performs well in the Pacific Northwest compared to other GCMs, though it underestimates winter mean temperature and precipitation (Rupp et al., 2013; Figure 7.3). RCP 8.5 is chosen as a worst-case scenario with expected increasing $\mathrm{CO}_{2}$ "business-as-usual" radiative forcing by 2100 to $8.5 \mathrm{~W} \mathrm{~m}^{-2}$ (van Vurren et al., 2011; Riahi et al. 2011). RCP 4.5 is a middle of the road scenario, estimating $4.5 \mathrm{~W} \mathrm{~m}^{-}$ 2 by 2100 . RCP 2.6 is a best-case scenario where $\mathrm{CO}_{2}$ emissions are limited, estimating $<3.0 \mathrm{~W} \mathrm{~m}^{-2}$ by 2100 . To downscale air-temperature and precipitation from the GCM cell $\left(1^{\circ}\right.$, or $\left.\sim 100 \mathrm{~km}\right)$, several steps are taken. First, Parameter-elevation Regressions on Independent Slopes Model, a gridded climate dataset based on interpolation of weather stations with elevation and slope, is downscaled using a simple bilinear interpolation from $800 \mathrm{~m}$ resolution to $100 \mathrm{~m}$ resolution. A 20-year average (1981-2010) of the GCM and PRISM climate data is then calculated. For temperature, the deltas $(\Delta T)$ are 


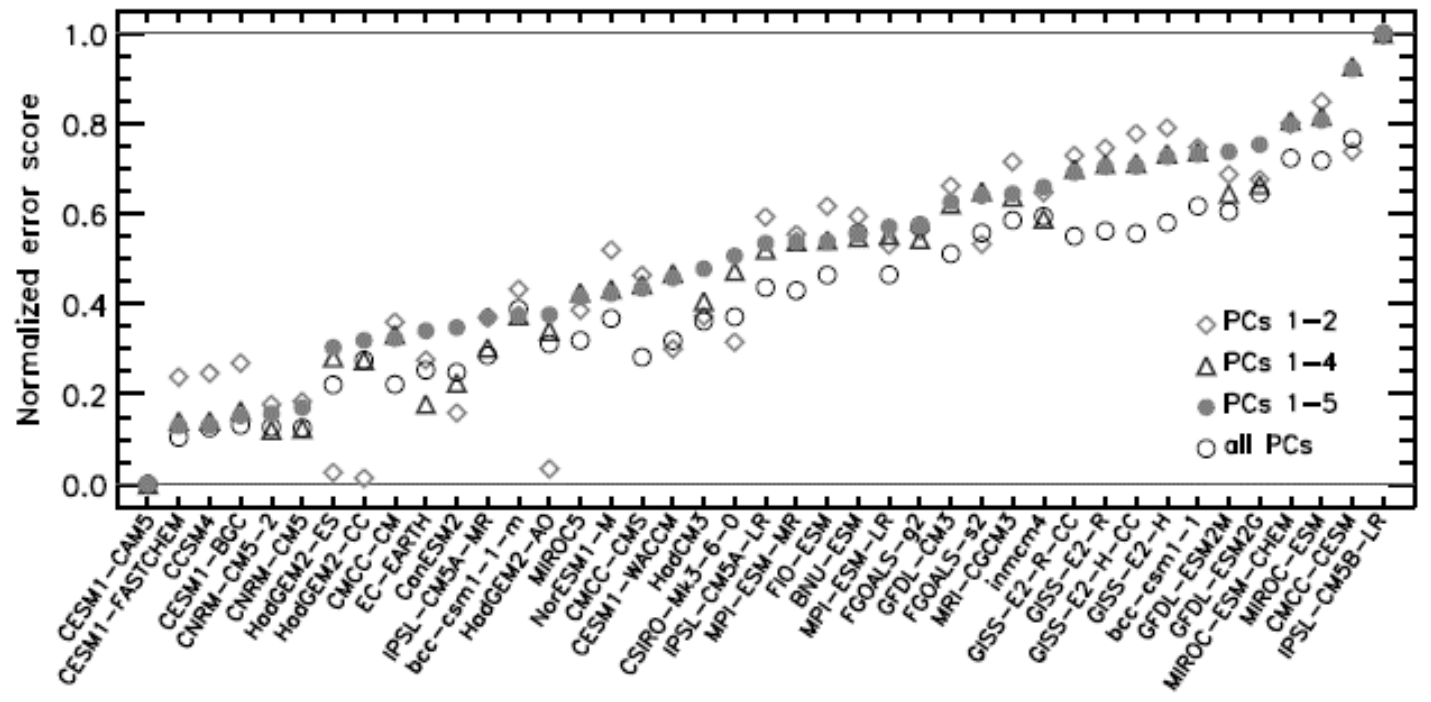

Figure 7.3: Figure from Rupp et al. (2014). Forty-one CMIP5 GCMs ranked according to normalized error score from empirical orthogonal function (EOF) analysis of 18 performance metrics. Ranking is based on the first five principal components (filled blue circles). The open symbols show the models' error scores using the first two, four, and all principle components. The nest coring model has a normalized error score of 0 .

calculated by subtracting the $20 \mathrm{GCM}$ year average $\left(T_{a v}\right)$ from the actual GCM value $T_{i}$ in a given year $i$, and the precipitation deltas $(\Delta P)$ the actual GCM value $\left(P_{i}\right)$ for a given year $i$ is divided by the $20 \mathrm{GCM}$ average $\left(P_{a v}\right)$ (Equations (7.10) and (7.11)).

$$
\begin{gathered}
\Delta T=T_{i}-T_{a v} \\
\Delta P=P_{i} / P_{a v}
\end{gathered}
$$

The temperature deltas are then added to the PRISM data and the precipitation deltas multiplied to give temporal climate variation. These values are then used to estimate glacier mass balance.

$$
\begin{gathered}
\delta T=\Delta H * \Gamma_{T} \\
\delta P=\Delta H * \Gamma_{P} \\
T_{\text {new }}=(T+\delta T)+\Delta T
\end{gathered}
$$




$$
P_{\text {new }}=(P+\delta P) * \Delta P
$$

As glaciers recede and advance the elevation of the modeled surface evolves and corrections to the climate data must be applied to account for these changes. This is done by estimating lapse rates for precipitation $\left(\Gamma_{p}, \mathrm{~mm} \mathrm{~m}^{-1}\right)$ and temperature $\left(\Gamma_{t},{ }^{\circ} \mathrm{C} \mathrm{m}^{-}\right.$ ${ }^{1}$ ) based on the original elevation of the Shuttle Radar Topography mission DEM (Farr et al., 2007) and the PRISM temperature and precipitation climate average (1981-2010) data using a linear regression. The additional elevation difference ( $\delta \mathrm{T} / \delta \mathrm{P})$ caused by growing/shrinking glaciers is then accounted for using the results of the regression and the change in glacier thickness $(\Delta H)$ for a given time step (Equations (7.12) and (7.13), and added to the PRISM values (Equations (7.14) and (7.15).

\begin{tabular}{|c|c|c|}
\hline 7 & 8 & 9 \\
\hline 4 & 5 & 6 \\
\hline 1 & 2 & 3 \\
\hline
\end{tabular}

Figure 7.4: Representation of a set of gridded cells in a DEM used to calculate the gradient in the $\mathrm{x}$ and $\mathrm{y}$ directions of a center cell $z_{i}$.

\section{c. Correction of the Solar Radiation Subroutine}

In the original version of the solar radiation subroutine, peak insolation was offset by $\sim 90^{p}$ azimuth to the north and caused inaccuracies in the estimate of glacier melt as well as great discrepancies in the placement of glaciers with aspect. To remedy this, Equation (7.9) was re-evaluated. The combination of gradient and aspect were producing erroneous surface aspect maps when compared to those produced in ArcGIS from the same DEM. The local gradient was initially calculated from a simple difference formula,

$$
\begin{aligned}
& d_{x}=\frac{\left(z_{8}-z_{2}\right)}{2 g} \\
& d_{y}=\frac{\left(z_{6}-z_{4}\right)}{2 g}
\end{aligned}
$$

where $g$ is the spatial resolution of the gridded DEM (100 meters) and the $z_{i}$ are cells of the DEM around a center cell $z_{5}$ (Figure 7.4). This produced noisy local gradients, and a $3^{\text {rd }}$ order finite difference formulation of gradient (Zhou and Liu, 2004), 


$$
\begin{aligned}
& d_{y}=\frac{\left(z_{7}-z_{1}+z_{8}-z_{2}+z_{9}-z_{3}\right)}{6 g} \\
& d_{x}=\frac{\left(z_{3}-z_{1}+z_{6}-z_{4}+z_{9}-z_{7}\right)}{6 g}
\end{aligned}
$$

was applied. This formulation of gradient allows for increased smoothing and therefore decreased sensitivity to DEM error at the cost of increased processing time (Zhou and Liu, 2004).

The aspect of the surface, $\varphi_{A}$, in radians was originally calculated with

$$
\varphi_{A}=\tan ^{-1}\left(\frac{d x}{d y}\right)
$$

where $d x$ is the gradient in the $x$ direction and $d y$ is the gradient in the $y$ direction. Slope with respect to the horizon, $\beta$, in radians is then calculated as the maximum gradient between $d x$ and $d y$ with

$$
\beta=\frac{\pi}{2}-\tan ^{-1}\left(d x^{2}+d y^{2}\right) .
$$

Surface slope $(\beta)$ and surface aspect $\left(\varphi_{A}\right)$ are pictured in Figure 7.1.

Through comparisons of an aspect map created from the model to an aspect map created in ArcMap from the same input DEM, aspect was then reformulated to

$$
\varphi_{A}=-1 * \tan ^{-1}\left(\frac{d y}{-d x}\right)
$$

A mapping, which is a function to overwrite the initial surface aspects from Equation (7.22) to the correct azimuth degrees, was applied following the methods of ArcMap, seen below

$$
\begin{array}{cc}
\varphi_{A}^{\prime}=\frac{\pi}{2}-\varphi_{A} & \text { if } S<0 \\
\varphi_{A}^{\prime}=2 \pi-\varphi_{A}+\frac{\pi}{2} & \text { if } S>\frac{\pi}{2} \\
\varphi_{A}^{\prime}=\frac{\pi}{2}-\varphi_{A} & \text { else }
\end{array}
$$

where $S$ is the solar elevation. This corrected the output from Equation (7.23) which lead to a correct aspect grid in the model.

The initial formulation for $\cos \theta_{i}$ was incorrect and was corrected to 


$$
\begin{gathered}
\cos \theta_{i}=\cos \beta \cos \theta_{z}+\sin \beta \sin \theta_{z} \cos \left(\varphi_{\alpha}-\varphi_{A}^{\prime}\right) \\
\cos \theta_{z}=\sin \delta \sin ^{\prime} \varphi_{A}+\cos \delta \cos \varphi^{\prime}{ }_{A} \cos \omega \\
I=I_{i} *\left(\sin \left(\theta_{z}\right) * \sin (\beta)+\cos \left(\theta_{z}\right) * \cos (\beta) * \cos \left(\varphi_{\alpha}-\varphi_{A}^{\prime}\right)\right) \\
I=\cos \theta_{z} *\left[I_{i} *\left(\cos \left(\theta_{z}\right) * \cos (\beta)+\sin \left(\theta_{z}\right) * \sin (\beta) * \cos \left(\varphi_{\alpha}-\varphi_{\prime A}\right)\right)\right]
\end{gathered}
$$

Based on Hock (1999), where $\delta$ is the declination, and $\omega$ is the hour angle, both in degrees. Also, because the solar insolation $l_{i}$ for the entire region is taken from the CCSM4 GCM, it is vertical, and does not agree with the actual location of the sun, Equation (7.25) must be modified by multiplying $\cos \theta_{z}$ to the incidence angle $\cos \theta_{i}$, which corrects the downwelling shortwave radiation from CCSM4, $I_{0}$, to the same position as the sun. Therefore we correct Equation (7.26) to Equation (7.27) with

\section{d. Ice Dynamics}

While mass balance estimated the total amount of ice entering and leaving the glacier, it does not capture the whole picture. Glaciers deform under the weight of the ice and flow. Additionally, a thick layer of water at the bed can cause the ice to move as one unit, or slide, further moving ice down slope into warmer temperatures (Cuffey and Patterson, 2010). The RGM required inputs of bare-surface and glaciated surface elevations, precipitation, temperature, solar radiation, and the standard deviation of the climate inputs from average to estimate flux divergence (7.28) and glacier sliding (7.29), and then to redistribute mass on the landscape using Glen's Flow law for ice deformation (Cuffey and Paterson, 2010),

$$
\begin{gathered}
Q=-\frac{2 A(\rho g)^{n}}{n+2}\left|\nabla_{x y} S\right|^{n-1} H^{n+2} \nabla_{x y} S+V_{s} H \\
V_{s}=-C(\rho g)^{m} H^{m}\left|\nabla_{x y} S\right|^{m-1} \nabla \mathrm{S}_{x y}
\end{gathered}
$$

where $\underline{H}$ is the ice thickness $(\mathrm{m}), Q$ is the volume discharge of ice per unit width $\left(\mathrm{m}^{2} \mathrm{yr}^{-2}\right.$, A is the softness parameter $\left(\mathrm{Ps}^{-3} \mathrm{yr}^{-1}\right), \rho$ is the ice density $\left(\mathrm{kg} \mathrm{m}^{-3}\right), g$ is the gravitational constant (9.81 $\left.\mathrm{m} \mathrm{s}^{-2}\right), n$ is Glen's flow law exponent (3), $\nabla S_{x, y}$ is the gradient of the surface in the $x$ and $y$ directions for a given raster cell, $V_{s}$ is the sliding velocity $\left(\mathrm{m} \mathrm{yr}^{-1}\right), C$ is the sliding law coefficient ( $\mathrm{m} \mathrm{yr}^{-1} \mathrm{~Pa}^{-\mathrm{m}}$ ), and $\mathrm{m}$ is the sliding exponent (1). The above equations follow the Shallow Ice Approximation and assume isothermal ice (Clarke et al., 2015). To approximate $\nabla s_{x, y}$, a finite-difference expression can be used over the surface elevation raster $S$, seen below, 


$$
\begin{aligned}
\nabla s_{x, y}=\omega *\{ & \frac{\Delta t}{(\Delta x)^{2}}\left[D_{i+\frac{1}{2}, j}^{k}\left(S_{i+1, j}^{k+1}-S_{i, j}^{k+1}\right)-D_{i-\frac{1}{2}, j}^{k}\left(S_{i, j}^{k+1}-S_{i-1, j}^{k+1}\right)\right] \\
& +\frac{\Delta t}{(\Delta y)^{2}}\left[D_{i, j+\frac{1}{2}}^{k}\left(S_{i, j+1}^{k+1}-S_{i, j}^{k+1}\right)-D_{i, j-\frac{1}{2}}^{k}\left(S_{i, j}^{k+1}-S_{i, j-}^{k+}\right.\right. \\
& +\left\{\frac { \Delta t } { ( \Delta x ) ^ { 2 } } \left[D_{i+\frac{1}{2}, j}^{k}\left(S_{i+1, j}^{k}-S_{i, j}^{k}\right)-D_{i-\frac{1}{2}, j}^{k}\left(S_{i, j}^{k}-S_{i-1, j}^{k}\right)\right.\right. \\
& +\frac{\Delta t}{(\Delta y)^{2}}\left[D_{i, j+\frac{1}{2}}^{k}\left(S_{i, j+1}^{k}-S_{i, j}^{k}\right)-D_{i, j-\frac{1}{2}}^{k}\left(S_{i, j}^{k}-S_{i, j-1}^{k}\right)\right] \\
& +\Delta t\left[\omega b_{i, j}^{k+1}+(1-\omega) b_{i, j}^{k}\right]
\end{aligned}
$$

where $k$ is the time step index, $\dot{b}$ is the surface mass balance rate, $D$ is a spatially and temporally varying ice volume diffusivity $\left(\mathrm{m}^{2} \mathrm{yr}^{-1}\right), S$ is the DEM elevation, $b$ is the annual average mass balance for a given time step, $i$ and $j$ are cell indexes that define a given location on a grid, and $\omega$ is a constant which determines the implicity of the equation. If $\omega=0$, the equation is fully explicit in the unknowns. If $\omega=1$, it is fully implicit. This equation also accounts for the cell indexing within the model. The model then calculates the ice dimensions at each time step of one year and the difference between the volume at the previous and current time steps. The ice thickness at any given location is then estimated based on the ice flux into and out of each cell. The elevation data is then updated at each time step to reflect these changes in ice thickness (7.31).

$$
\frac{\partial H}{\partial t}=-\nabla \mathrm{S}_{x y} \cdot Q+\dot{b}
$$




\section{B. Olympics Sensitivity Analysis and Justification}

In the past application of this model to British Columbia, topography has appeared to affect the location of ice. In that application there was a higher percentage of modeled ice area that occurred at higher elevations than is observed, as well as higher elevations with increasing continentality (Figure 7.5) (Clarke et al, 2015). This is because further inland the climate is drier and there is less moisture available for snow fall, causing glaciers to shift to cooler, higher elevation areas where precipitation is

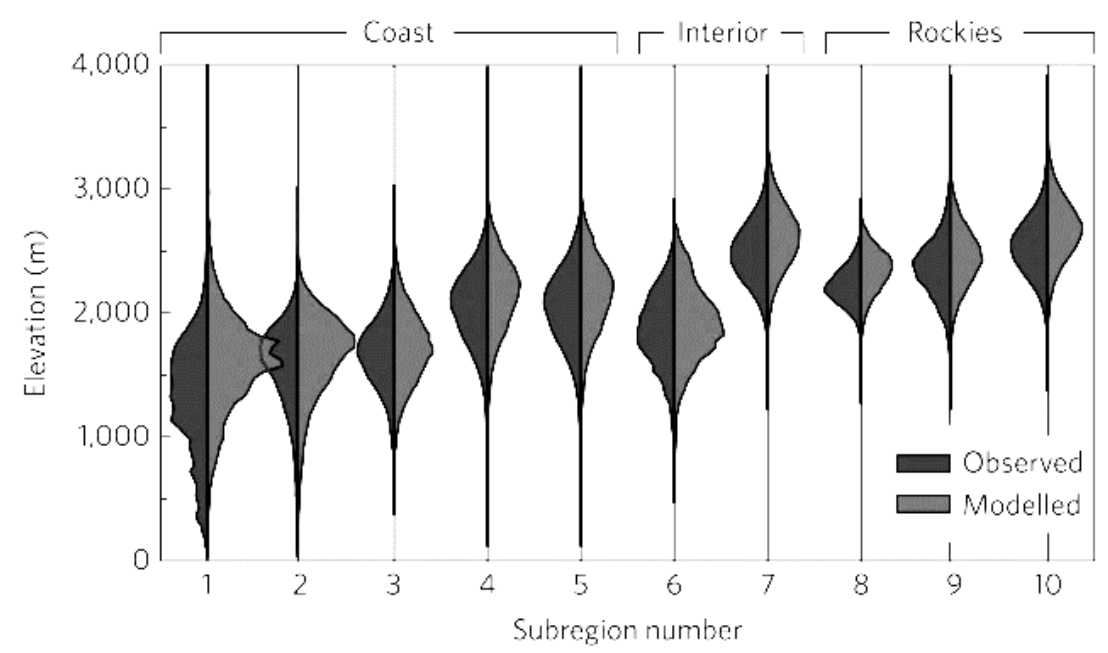

Figure 7.5: Hypsometric comparison of observed and modeled British Columbian glaciers. Subregion number refers to divisions in the previous study, moving from the coast inland. This image shows the larger amount of modeled ice area at higher elevations than observed, and the increasing elevations of the ice with continentality. Figure from Clarke et al., (2015).

greater. Similar hypsometric differences between modeled and observed ice have also been seen in the Olympic Mountains application of this model (Chapter 1.2). In the application to the Olympic Mountains a bias east-facing glaciers exists with a deficit other directions (Figure 7.6).

The application showed that errors in the PRISM precipitation data may be the cause for the locational misfit of the ice in that region (Figure 7.7). In a study just south of the Olympics region, the PRISM precipitation matches observed ground validation from the Olympic Mountain Experiment (Houze et al., 2017), but only through compensating errors of regions of overestimated precipitation and regions of underestimated precipitation (Currier et al., 2017).

To test whether model parameters (ice softness, density, sliding, and various melt model parameters) affected the placement of glaciers sensitivity analyses were conducted. In each test one of these parameters was changed $\pm 10 \%$ relative to the original value when the model was first received. Results of area and location area 


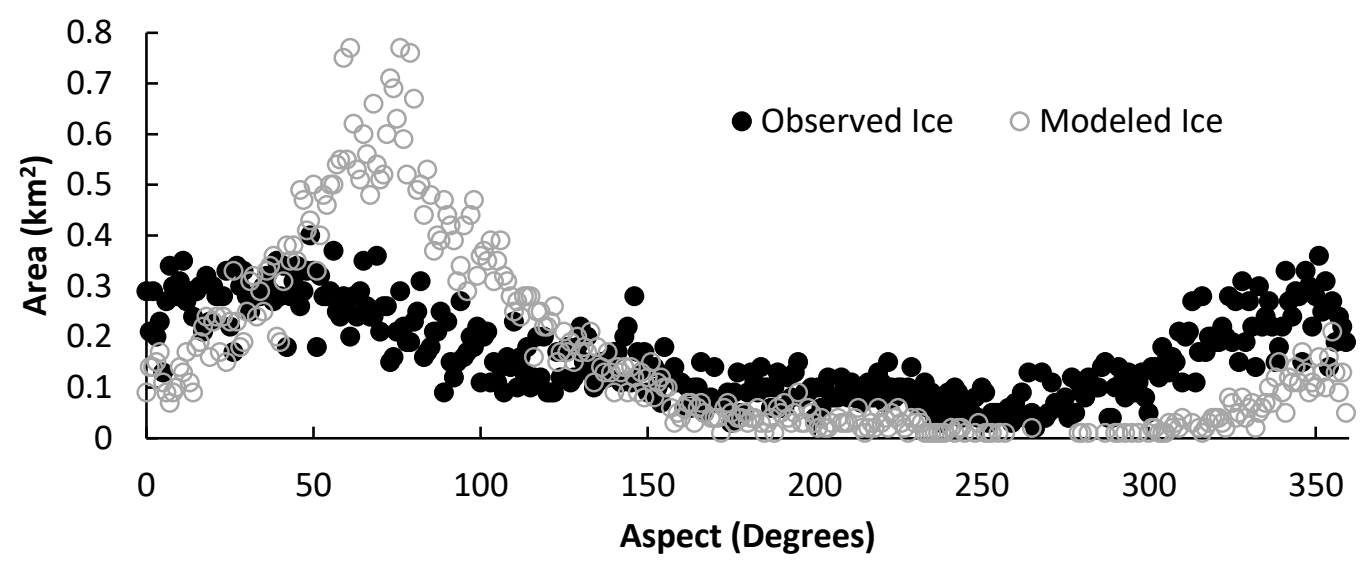

Figure 7.6: Comparisons of the distribution of modeled and observed ice area with aspect for an application of the Regional Glaciation Model in the Olympic Mountains before solar radiation subroutine corrections. A clear eastern trend in the observed ice exists, with the observed ice exhibiting a smoothed trend.

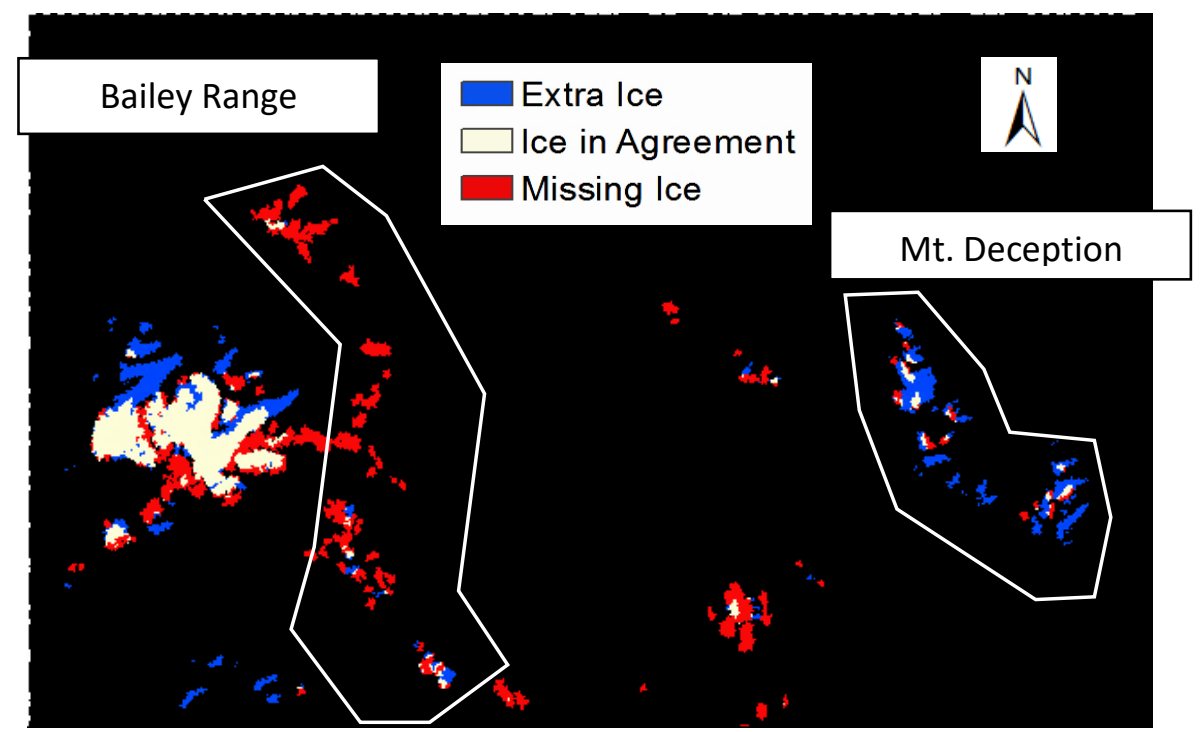

Figure 7.7: Location misfits for the Olympic Mountains application of the model, with the original model version before accounting for solar radiation, highlighting the locations of large bodies of extra and missing ice for the year 1970 with RCP 8.5. Areas of interest are bounded by white lines.

then compared to 1986 extents following the methods in Section 1.2.

The physical parameters (ice density, softness, and sliding) had very little $(<5 \%$ change in error) effect on glacier placement, whereas climate forcing parameters (ulk melt, snow/ice radiation) have a much greater effect (>20\% change in error) on ice area. 
Table 7.1: Comparison the distribution of ice from sensitivity analyses conducted on the Olympics to the original model parameters after the solar radiation subroutine corrections. The model that employs the original parameters (based on BC application values changed for Menounos's testing of updated model in the Olympics) RMSE for aspect, slope, and elevations values are normalized to observed area $\left(59.11 \mathrm{~km}^{2}\right)$ and have units of degrees, degrees, and meters, respectively. The original location misfit (missing, correctly modeled, and extra ice) are listed in $\mathrm{km}^{2}$. Corresponding RMSE values and location misfit categories for the sensitivity analyses are listed as fractions of the original error values.

\begin{tabular}{|c|c|c|c|c|c|c|c|c|}
\hline & & & \multicolumn{2}{|c|}{$\frac{\text { Softness }}{\left(\mathrm{Pa}^{-3} \mathrm{yr}^{-1}\right)}$} & \multicolumn{2}{|c|}{$\frac{\text { Sliding }}{\left(\mathrm{m} \mathrm{yr}^{-1}\right)}$} & \multicolumn{2}{|c|}{$\frac{\text { Density }}{\left(\mathrm{kg} \mathrm{m}^{-3}\right)}$} \\
\hline & \multicolumn{2}{|c|}{$\begin{array}{c}\text { Original } \\
\text { Parameters }\end{array}$} & $\begin{array}{c}6.82 \mathrm{E}- \\
17\end{array}$ & $\begin{array}{c}8.33 \mathrm{E}- \\
17\end{array}$ & $1.08 \mathrm{E}-4$ & $1.32 \mathrm{E}-4$ & 819 & 1001 \\
\hline Aspect RMSE & \multicolumn{2}{|c|}{0.33} & $9 \%$ & $10 \%$ & $11 \%$ & $6 \%$ & $81 \%$ & $-32 \%$ \\
\hline Slope RMSE & \multicolumn{2}{|c|}{0.37} & $2 \%$ & $-1 \%$ & $4 \%$ & $-2 \%$ & $82 \%$ & $-45 \%$ \\
\hline $\begin{array}{l}\text { Elevation } \\
\text { RMSE }\end{array}$ & \multicolumn{2}{|c|}{0.12} & $4 \%$ & $2 \%$ & $5 \%$ & $<-1 \%$ & $-25 \%$ & $-43 \%$ \\
\hline Missing Ice & \multicolumn{2}{|c|}{21.65} & $1 \%$ & $1 \%$ & $<1 \%$ & $2 \%$ & $12 \%$ & $21 \%$ \\
\hline $\begin{array}{l}\text { Correct } \\
\text { Modeled }\end{array}$ & \multicolumn{2}{|c|}{37.46} & $-17 \%$ & $-1 \%$ & $<-1 \%$ & $-1 \%$ & $6 \%$ & $-13 \%$ \\
\hline Extra Ice & \multicolumn{2}{|c|}{126.22} & $1 \%$ & $-1 \%$ & $2 \%$ & $5 \%$ & $27 \%$ & $-34 \%$ \\
\hline Modeled Area & \multicolumn{2}{|c|}{163.68} & $1 \%$ & $-1 \%$ & $2 \%$ & $4 \%$ & $22 \%$ & $-33 \%$ \\
\hline Ice Area Diff. & \multicolumn{2}{|c|}{104.57} & $1 \%$ & $-1 \%$ & $3 \%$ & $6 \%$ & $34 \%$ & $-52 \%$ \\
\hline $\begin{array}{l}\text { Percent } \\
\text { Modeled }\end{array}$ & \multicolumn{2}{|c|}{$277 \%$} & $278 \%$ & $275 \%$ & $281 \%$ & $287 \%$ & $338 \%$ & $185 \%$ \\
\hline $\begin{array}{l}\text { Correct } \\
\text { Location }\end{array}$ & \multicolumn{2}{|c|}{$63 \%$} & $63 \%$ & $63 \%$ & $63 \%$ & $62 \%$ & $67 \%$ & $55 \%$ \\
\hline Present & \multicolumn{2}{|c|}{44} & 44 & 44 & 44 & 42 & 53 & 38 \\
\hline \multirow[t]{3}{*}{ Absent } & & 30 & 30 & 30 & 32 & 21 & 36 \\
\hline & \multicolumn{2}{|c|}{$\begin{array}{c}\text { Bulk Melt } \\
\left(\mathrm{mm} \text { day }^{-1}{ }^{\circ} \mathrm{C}^{-1}\right)\end{array}$} & \multicolumn{2}{|c|}{$\begin{array}{l}\text { Snow Radiation } \\
\left(\mathrm{m}^{2} \mathrm{~W}^{-1} \mathrm{~mm}\right. \\
\left.\text { day }^{-1}{ }^{\circ} \mathrm{C}^{-1}\right)\end{array}$} & \multicolumn{2}{|c|}{$\begin{array}{l}\text { Ice Radiation } \\
\left(\mathrm{m}^{2} \mathrm{~W}^{-1} \mathrm{~mm}\right. \\
\left.\text { day }^{-1}{ }^{\circ} \mathrm{C}^{-1}\right)\end{array}$} & \multicolumn{2}{|c|}{$\begin{array}{l}\text { Solar Angle } \\
\text { (UTC) }\end{array}$} \\
\hline & $1.20 \mathrm{E}-3$ & $9.90 \mathrm{E}-4$ & $9.2 \mathrm{E}-6$ & $1.12 \mathrm{E}-5$ & $2.25 \mathrm{E}-2$ & $2.75 \mathrm{E}-2$ & $\begin{array}{c}\text { 08:00:0 } \\
0\end{array}$ & $\begin{array}{c}12: 00: 0 \\
0\end{array}$ \\
\hline Aspect RMSE & $16 \%$ & $41 \%$ & $75 \%$ & $-5 \%$ & $-69 \%$ & $4 \%$ & $-82 \%$ & $-85 \%$ \\
\hline Slope RMSE & $-24 \%$ & $36 \%$ & $22 \%$ & $-16 \%$ & $-66 \%$ & $-5 \%$ & $-76 \%$ & $-75 \%$ \\
\hline $\begin{array}{l}\text { Elevation } \\
\text { RMSE }\end{array}$ & $-25 \%$ & $40 \%$ & $24 \%$ & $-14 \%$ & $-64 \%$ & $-3 \%$ & $-75 \%$ & $-73 \%$ \\
\hline Missing Ice & $12 \%$ & $-20 \%$ & $-18 \%$ & $10 \%$ & $81 \%$ & $3 \%$ & $51 \%$ & $48 \%$ \\
\hline $\begin{array}{l}\text { Correct } \\
\text { Modeled }\end{array}$ & $6 \%$ & $6 \%$ & $4 \%$ & $-6 \%$ & $-47 \%$ & $-2 \%$ & $-30 \%$ & $-29 \%$ \\
\hline Extra Ice & $-20 \%$ & $27 \%$ & $15 \%$ & $-12 \%$ & $-87 \%$ & $-4 \%$ & $-76 \%$ & $80 \%$ \\
\hline Modeled Area & $35 \%$ & $22 \%$ & $13 \%$ & $-10 \%$ & $-78 \%$ & $-4 \%$ & $-65 \%$ & $-69 \%$ \\
\hline Ice Area Diff. & $\begin{array}{c}- \\
34.85\end{array}$ & $34 \%$ & $20 \%$ & $-16 \%$ & $-122 \%$ & $-6 \%$ & $-127 \%$ & $-107 \%$ \\
\hline $\begin{array}{l}\text { Percent } \\
\text { Modeled }\end{array}$ & $67 \%$ & $277 \%$ & $312 \%$ & $248 \%$ & $31 \%$ & $267 \%$ & $96 \%$ & $87 \%$ \\
\hline $\begin{array}{l}\text { Correct } \\
\text { Location }\end{array}$ & $49 \%$ & $63 \%$ & $66 \%$ & $59 \%$ & $33 \%$ & $62 \%$ & $44 \%$ & $45 \%$ \\
\hline Present & 40 & 44 & 47 & 42 & 21 & 42 & 23 & 19 \\
\hline Absent & 34 & 30 & 27 & 32 & 53 & 32 & 51 & 55 \\
\hline
\end{tabular}




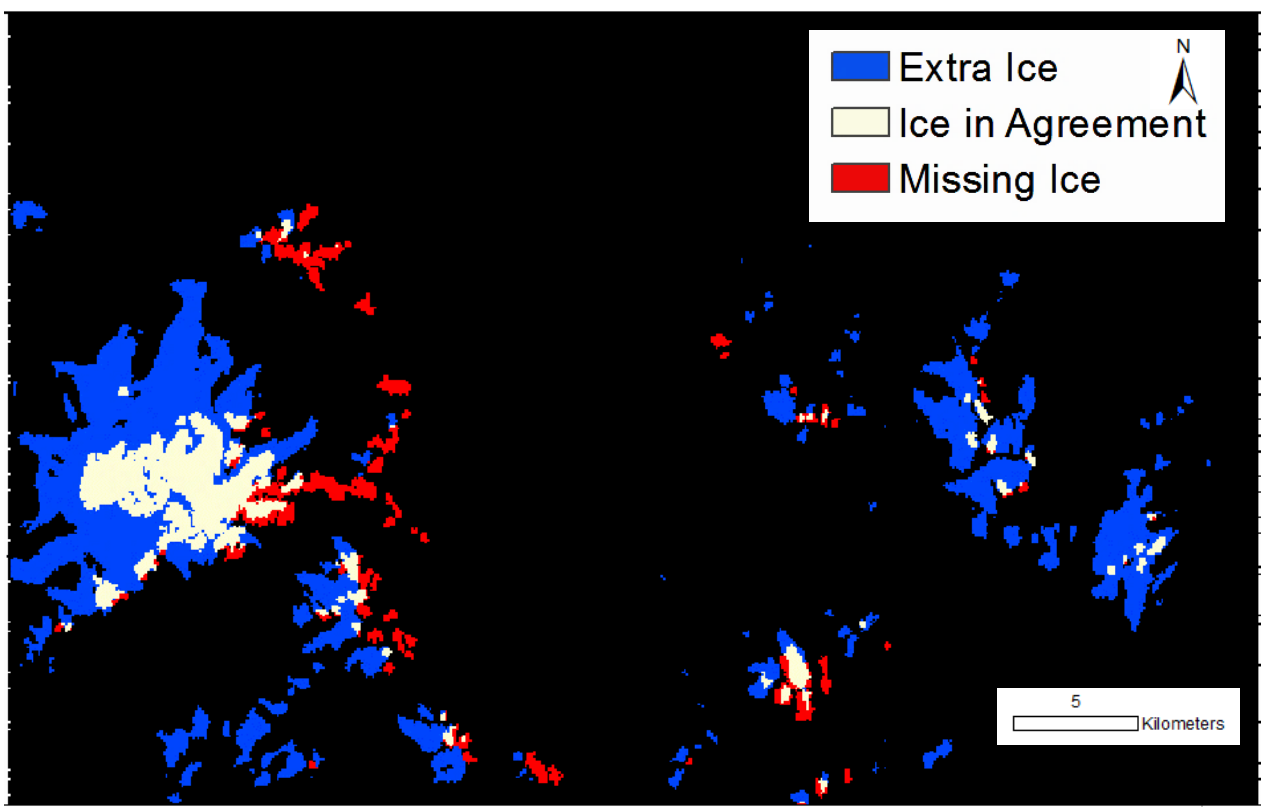

Figure 7.8: The distribution of modeled ice in the Olympics after the application of the modified solar radiation code compared to observed 1970 ice extents.

Density had large effects on the total glacier area but the range limits are outside of the accepted range for ice density of $830-917 \mathrm{~kg} \mathrm{~m}^{-3}$ (Cuffey and Paterson,2010). A later attempt to tune density within the accepted range does not cause a large difference in the model fit, so density will not be used as a tuning parameter. Ice softness and sliding had negligible effects on glacier area or topographic distribution. The bulk melt factor, radiation parameters for ice and snow, and solar time (the monthly time the solar position is estimated to calculated solar radiation for that month) exert moderate controls over the amount of melt ice experiences. Because these parameters are theoretical constants and not well constrained they are good tuning parameters for the RGM.

Using these methods, I found that the original parameters produced large aspect error for all model runs relative to other topographic error (elevation and slope), and that tuning the physical and climate forcing parameters did little to fix the problem. Most modeled ice appeared to be northeast to east facing, showing a clear model bias (Figure 7.7). It was also this finding that led to my conclusion that the solar radiation method in the RGM needed correcting. Solar angle time greatly affects the glacier distribution of ice, lowering aspect RMSE by $82-85 \%$ of the initial error $( \pm 0.33$ normalized RMSE), suggesting that while topography partially controls which slopes ice accumulates, peak solar radiation has the largest control. Additionally, extra ice was also greatly reduced by changing the solar time. However, it is at the cost of increased missing glaciers. 
After modifying the code, sensitivity analyses were again applied to determine the effect of tuning various parameters. The results of these analyses are summarized in Table 7.1. While there is an initial increase in aspect error for the original model parameters and that tuning the physical parameters does little to change that. However, aspect error can be lowered by choosing solar times later in the day where shading is less. It is also apparent from Figure 7.8 that this increase in aspect error is from extra modeled ice rather than a bias in aspect. 


\section{North Cascades Sensitivity Analyses}

After the application in the Olympics, the RGM was then applied to the North Cascades. The modeled distribution of glaciers in the North Cascades with the original

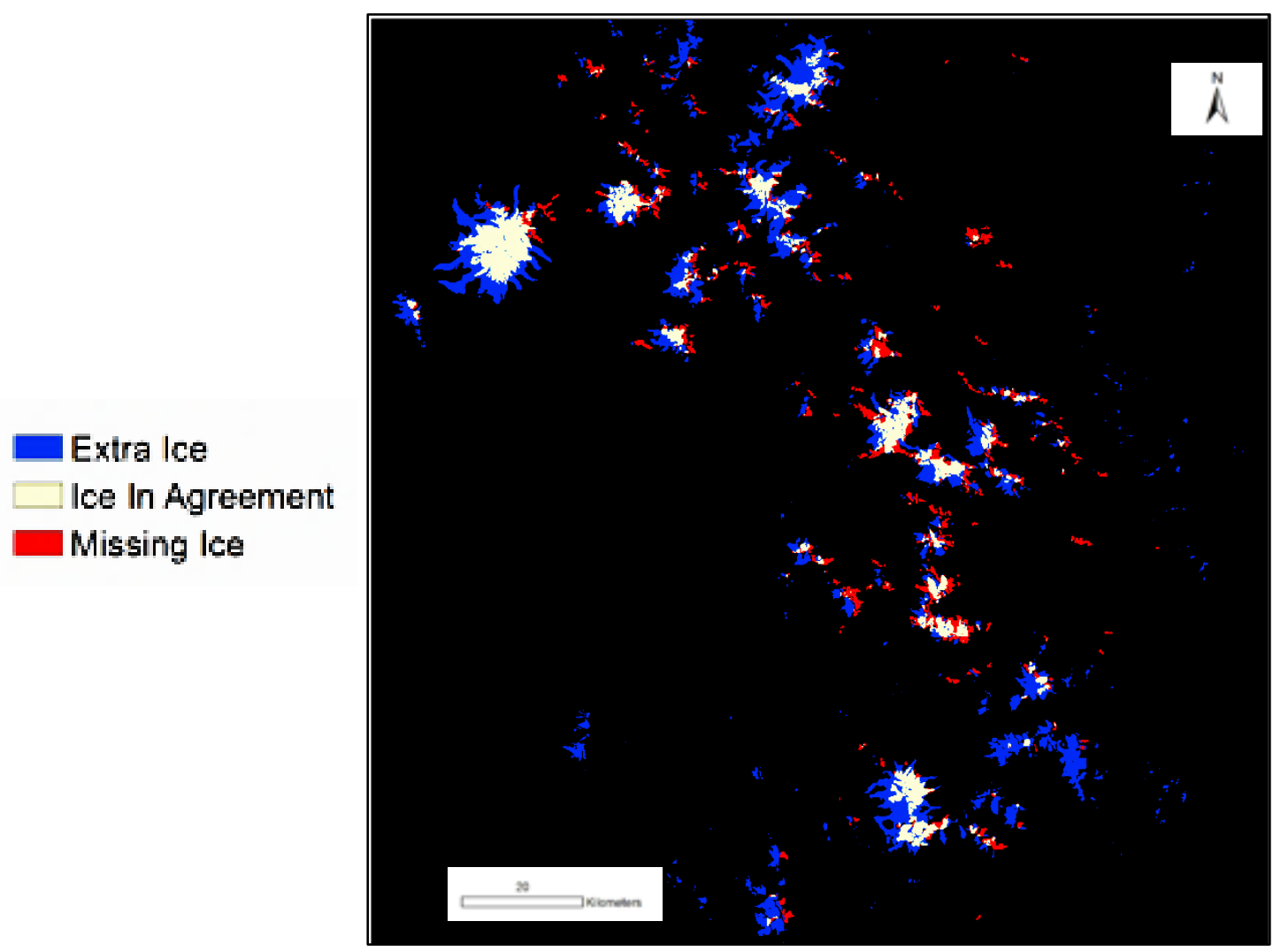

Figure 7.9: Location Misfit of the North Cascades.

parameters was compared to the observed 1970 extents is poor (Figure 7.9). Modeled extra ice appears to have a slight western bias, but this is likely due to the initial choice of solar time, 10 AM PDT, which causes minimum insolation to be found to the NW. Additionally, the central region of the North Cascades has less modeled ice than observed relative to the southern and northern regions, possibility due to increased sheltering from major storms by the higher surrounding peaks to the north and south (Mass, 2010). However, the missing glaciers over the entire region could be due to an underestimation PRISM precipitation due to the complex terrain and limited observational data, or a lack of snow redistribution due to wind and avalanching that is not considered in the model. An attempt to better reduce the error of misplaced of ice, sensitivity analyses were conducted for the North Cascades (Table 7.2). 
Table 7.2: Complete summary of sensitivity analyses conducted in the North Cascades using the RGM. Statistics are made in reference to the 1970 glacier outlines from the 1:24000 USGS topographic maps (USGS, 1998). Original RMSE values are normalized to observed area $\left(349.97 \mathrm{~km}^{2}\right)$ and location misfit (missing, correctly modeled, and extra ice) are listed in $\mathrm{km}^{2}$, and corresponding RMSE values and location misfit categories are listed as fractions of the original values. Correct refers to modeled ice that matches observed extents.

\begin{tabular}{|c|c|c|c|c|c|c|c|c|}
\hline & & & \multicolumn{2}{|c|}{$\frac{\text { Softness }}{\left(\mathrm{Pa}^{-3} \mathrm{yr}^{-1}\right)}$} & \multicolumn{2}{|c|}{$\frac{\text { Sliding }}{\left(\mathrm{m} \mathrm{yr}^{-1}\right)}$} & \multicolumn{2}{|c|}{$\frac{\text { Density }}{\left(\mathrm{kg} \mathrm{m}^{-3}\right)}$} \\
\hline & \multicolumn{2}{|c|}{$\begin{array}{c}\text { Original } \\
\text { Parameters }\end{array}$} & $\begin{array}{c}6.82 \mathrm{E}- \\
17 \\
\end{array}$ & $8.33 \mathrm{E}-17$ & $1.08 \mathrm{E}-4$ & $1.32 \mathrm{E}-4$ & 819 & 1001 \\
\hline Aspect RMSE & \multicolumn{2}{|c|}{0.24} & $1 \%$ & $0 \%$ & $2 \%$ & $-1 \%$ & $52 \%$ & $-30 \%$ \\
\hline Slope RMSE & \multicolumn{2}{|c|}{0.14} & $2 \%$ & $-1 \%$ & $3 \%$ & $-3 \%$ & $99 \%$ & $-64 \%$ \\
\hline $\begin{array}{l}\text { Elevation } \\
\text { RMSE }\end{array}$ & \multicolumn{2}{|c|}{0.061} & $2 \%$ & $-1 \%$ & $3 \%$ & $-3 \%$ & $100 \%$ & $-62 \%$ \\
\hline Missing Ice & \multicolumn{2}{|c|}{144.85} & $0 \%$ & $0 \%$ & $-1 \%$ & $1 \%$ & $0 \%$ & $21 \%$ \\
\hline Correct & \multicolumn{2}{|c|}{205.12} & $0 \%$ & $0 \%$ & $1 \%$ & $-1 \%$ & $15 \%$ & $-15 \%$ \\
\hline Extra Ice & \multicolumn{2}{|c|}{401.59} & $1 \%$ & $0 \%$ & $1 \%$ & $-1 \%$ & $56 \%$ & $35 \%$ \\
\hline $\begin{array}{l}\text { Modeled } \\
\text { Area }\end{array}$ & \multicolumn{2}{|c|}{606.71} & $1 \%$ & $0 \%$ & $1 \%$ & $-1 \%$ & $42 \%$ & $-28 \%$ \\
\hline Ice Area Diff. & \multicolumn{2}{|c|}{256.74} & $2 \%$ & $-1 \%$ & $3 \%$ & $-3 \%$ & $99 \%$ & $-65 \%$ \\
\hline $\begin{array}{l}\text { Percent } \\
\text { Modeled }\end{array}$ & \multicolumn{2}{|c|}{$173 \%$} & $175 \%$ & $173 \%$ & $171 \%$ & $171 \%$ & $246 \%$ & $125 \%$ \\
\hline $\begin{array}{l}\text { Correct } \\
\text { Location }\end{array}$ & \multicolumn{2}{|c|}{$59 \%$} & $59 \%$ & $59 \%$ & $58 \%$ & $58 \%$ & $67 \%$ & $50 \%$ \\
\hline Present & \multirow{2}{*}{\multicolumn{2}{|c|}{$\begin{array}{l}134 \\
139\end{array}$}} & 135 & 134 & 134 & 134 & 172 & 112 \\
\hline \multirow[t]{4}{*}{ Absent } & & & 138 & 139 & 139 & 139 & 101 & 161 \\
\hline & \multicolumn{2}{|c|}{ Bulk Melt } & \multicolumn{2}{|c|}{$\underline{\text { Snow Radiation }}$} & \multicolumn{2}{|c|}{ Ice Radiation } & \multicolumn{2}{|c|}{$\underline{\text { Solar Time }}$} \\
\hline & \multicolumn{2}{|c|}{$\left(\mathrm{mm} \operatorname{day}^{-1}{ }^{\circ} \mathrm{C}^{-1}\right)$} & \multicolumn{2}{|c|}{$\begin{array}{c}\left(\mathrm{m}^{2} \mathrm{~W}^{-1} \mathrm{~mm}\right. \\
\left.\mathrm{day}^{-1}{ }^{\circ} \mathrm{C}^{-1}\right)\end{array}$} & \multicolumn{2}{|c|}{$\begin{array}{c}\left(\mathrm{m}^{2} \mathrm{~W}^{-1} \mathrm{~mm}\right. \\
\left.\mathrm{day}^{-1}{ }^{\circ} \mathrm{C}^{-1}\right)\end{array}$} & \multicolumn{2}{|c|}{ (UTC) } \\
\hline & $1.20 \mathrm{E}-3$ & $\begin{array}{c}9.90 \mathrm{E} \\
-4\end{array}$ & $9.2 \mathrm{E}-6$ & $1.12 \mathrm{E}-5$ & $2.25 \mathrm{E}-2$ & $2.75 \mathrm{E}-2$ & $\begin{array}{c}\text { 08:00: } \\
00\end{array}$ & $\begin{array}{c}12: 00: 0 \\
0\end{array}$ \\
\hline Aspect RMSE & $-20 \%$ & $31 \%$ & $-10 \%$ & $12 \%$ & $3 \%$ & $-3 \%$ & $-64 \%$ & $-71 \%$ \\
\hline Slope RMSE & $-38 \%$ & $55 \%$ & $-22 \%$ & $87 \%$ & $7 \%$ & $-6 \%$ & $-30 \%$ & $-25 \%$ \\
\hline $\begin{array}{l}\text { Elevation } \\
\text { RMSE }\end{array}$ & $-39 \%$ & $57 \%$ & $-21 \%$ & $25 \%$ & $6 \%$ & $-5 \%$ & $-29 \%$ & $-28 \%$ \\
\hline Missing Ice & $10 \%$ & $-11 \%$ & $10 \%$ & $-8 \%$ & $-2 \%$ & $2 \%$ & $49 \%$ & $44 \%$ \\
\hline Correct & $-7 \%$ & $8 \%$ & $-6 \%$ & $6 \%$ & $1 \%$ & $-1 \%$ & $-37 \%$ & $-33 \%$ \\
\hline Extra Ice & $-46 \%$ & $31 \%$ & $-11 \%$ & $13 \%$ & $4 \%$ & $-3 \%$ & $-81 \%$ & $-81 \%$ \\
\hline $\begin{array}{l}\text { Modeled } \\
\text { Area }\end{array}$ & $-33 \%$ & $23 \%$ & $-9 \%$ & $11 \%$ & $3 \%$ & $-3 \%$ & $-66 \%$ & $-66 \%$ \\
\hline Ice Area Diff. & $-26 \%$ & $55 \%$ & $-22 \%$ & $26 \%$ & $7 \%$ & $-6 \%$ & $\overline{101 \%}$ & $-156 \%$ \\
\hline $\begin{array}{l}\text { Correct } \\
\text { location }\end{array}$ & $116 \%$ & $214 \%$ & $157 \%$ & $192 \%$ & $178 \%$ & $169 \%$ & $59 \%$ & $59 \%$ \\
\hline $\begin{array}{l}\text { Percent } \\
\text { Modeled }\end{array}$ & $54 \%$ & $63 \%$ & $55 \%$ & $62 \%$ & $59 \%$ & $58 \%$ & $37 \%$ & $39 \%$ \\
\hline Present & 120 & 157 & 129 & 141 & 135 & 133 & 75 & 160 \\
\hline Absent & 153 & 116 & 144 & 132 & 273 & 140 & 198 & 167 \\
\hline
\end{tabular}


Results were comparable to the Olympics sensitivity analyses. Physical parameters with exception of density, which is well constrained for temperate ice, had little effect on the distribution of ice, geographically or topographically. Forcing parameters had moderate effects, and solar time had the largest effect, particularly on the aspect error. This reinforces my conclusion that aspect bias is due to the choice in solar time, and that additional location errors are likely due to errors in PRISM. 


\section{Circular Statistics Methods}

The error in azimuth dependency cannot be adequately examined using traditional statistical methods due to its circular nature $\left(0^{0}=360^{\circ}\right)$. Therefore a von Mises Distribution, which is the circular equivalent to the normal distribution, is employed instead. Only two parameters are needed for this distribution: a mean direction $\bar{\theta}$ and a concentration parameter $\mathrm{k}$. The concentration parameter is a measure of the strength of the mean direction. If $\mathrm{k}$ is zero, the glaciers are uniformly distributed in all directions. If $\mathrm{k}$ is large, then many glaciers face in the mean direction. The concentration parameter is difficult to determine directly, and instead is estimated from $\bar{R}$, the mean resultant vector length. To calculate $\bar{R}$, the mean direction is first estimated by finding the northing $\left(X_{i}\right)$ and easting $\left(Y_{i}\right)$ of the aspect with

$$
\begin{aligned}
X_{i} & =\cos \theta_{i} \\
Y_{i} & =\sin \theta_{i}
\end{aligned}
$$

where $\theta$ is in radians and $i$ is some cell, and then calculated with

$$
\bar{\theta}=\tan ^{-1}\left(\sum_{i=1}^{n} Y_{i} / \sum_{i=1}^{n} X_{i}\right)
$$

$\bar{R}$ can be found with

$$
\bar{R}=\frac{\sqrt{\left(\sum_{i=1}^{n} \cos \theta_{i}\right)^{2}+\left(\sum_{i=1}^{n} \sin \theta_{i}\right)^{2}}}{n}
$$

where $\mathrm{n}$ is the number of measurements (raster cells that contain ice). The concertation parameters can then be looked up in a table based on the calculated $\bar{R}$ (Davis, 2002)

Using Table A.10 in Davis (2002) and assuming a confidence value $(\alpha)$ of 0.05 , the critical test statistics can be estimated. Because the sample size of each misfit population is large, the largest degrees of freedom value in the table, $n=50$, is used to estimate the test statistic of 0.24 . Therefore, if the concentration parameter is greater than or equal to 0.24 , the ice population will be significantly concentration in the calculated mean direction (Davis, 2002).

To test the equality of the mean directions of two populations, a confidence interval of $\pm 5 \%$ was estimated around some ice population's mean direction. If the mean direction of one of the other populations falls within that range, the two 
populations have the same directional trend. Otherwise, it is unlikely that they share the same trend. To create the confidence interval, the standard error is calculated with

$$
s_{e}=1 / \sqrt{n \bar{R} \kappa}
$$

and then, by assuming the error is normally distributed, the confidence interval will be

$$
\bar{\theta} \pm z_{\alpha} s_{e}
$$

where $z_{\alpha}$ is the $z$ value for $\alpha$ of $0.05,1.9$

The Watson-Williams test was then used to compare the overall distribution of two populations (Kanji, 2006). To do this a pooled resultant length $\left(R_{p}\right)$, which similar to the mean resultant length vector but describes two sets of data rather than one, was calculated with

$$
R_{p}=\sqrt{\left(\sum \cos \theta_{1}+\sum \cos \theta_{2}\right)^{2}+\left(\sum \sin \theta_{1}+\sum \sin \theta_{2}\right)^{2}}
$$

where 1 and 2 refer to a specific population. A pooled $\mathrm{k}$ is then estimated with

$$
\bar{R}_{p}=\frac{R_{1}+R_{2}}{N}
$$

where $R=\bar{R} * n$ and $\mathrm{N}=\mathrm{n}+\mathrm{m}$, where $\mathrm{n}$ and $\mathrm{m}$ are the number of observations in each population. I estimate the critical value (250.10) for $\alpha$ of 0.05 using Table A.3 in Davis (2002). The test statistics is then calculated with

$$
F_{1, N-2}=\left(1+\frac{3}{8 \kappa}\right) \frac{(N-2)\left(R_{1}+R_{2}-R_{p}\right)}{\left(N-R_{1}+R_{2}\right)}
$$

If the calculated test statistic is equal to or exceeds the critical value, then it is likely that the two populations have different distributions. 


\section{E. Final Model Climate Analyses, RCP 8.5 and 2.6 and Seasonal Trends for RCP 4.5}

The distribution of glacier area with climate was examined for each RCP in the final version of the RGM, which involves the recalibration of the model parameters to reduce extra ice and the addition of the precipitation mask over missing glaciers. The multiplier is chosen based on values determined in the steady state analyses to replace missing glaciers with correctly modeled, and then perform best with the full climate model. The multipliers were determined to be $x 2$ For all RCPs. Overall, the presented trends in glacier distribution with climate are in agreement with each other, and most differences are inconsequential. Missing glaciers are found in lower precipitations and higher summer temperatures that correctly modeled glaciers, though no clear difference can be seen in other seasons (Figure 7.10, Figure 7.11, and Figure 7.12).

Overall, missing glaciers appear to be disturbed in summer temperatures between 6-13 ${ }^{\circ} \mathrm{C}$ and winter precipitations between $200-500 \mathrm{~mm}$, whereas correctly modeled glaciers found in similar temperature range, but at precipitations up to $800 \mathrm{~m}$ (Figure 7.15 and Figure 7.16). This is likely because correctly modeled glaciers are found on high peaks where conditions are favorable to increased snow fall (higher precipitation, lower temperatures) (Figure 7.13 and Figure 7.14). 

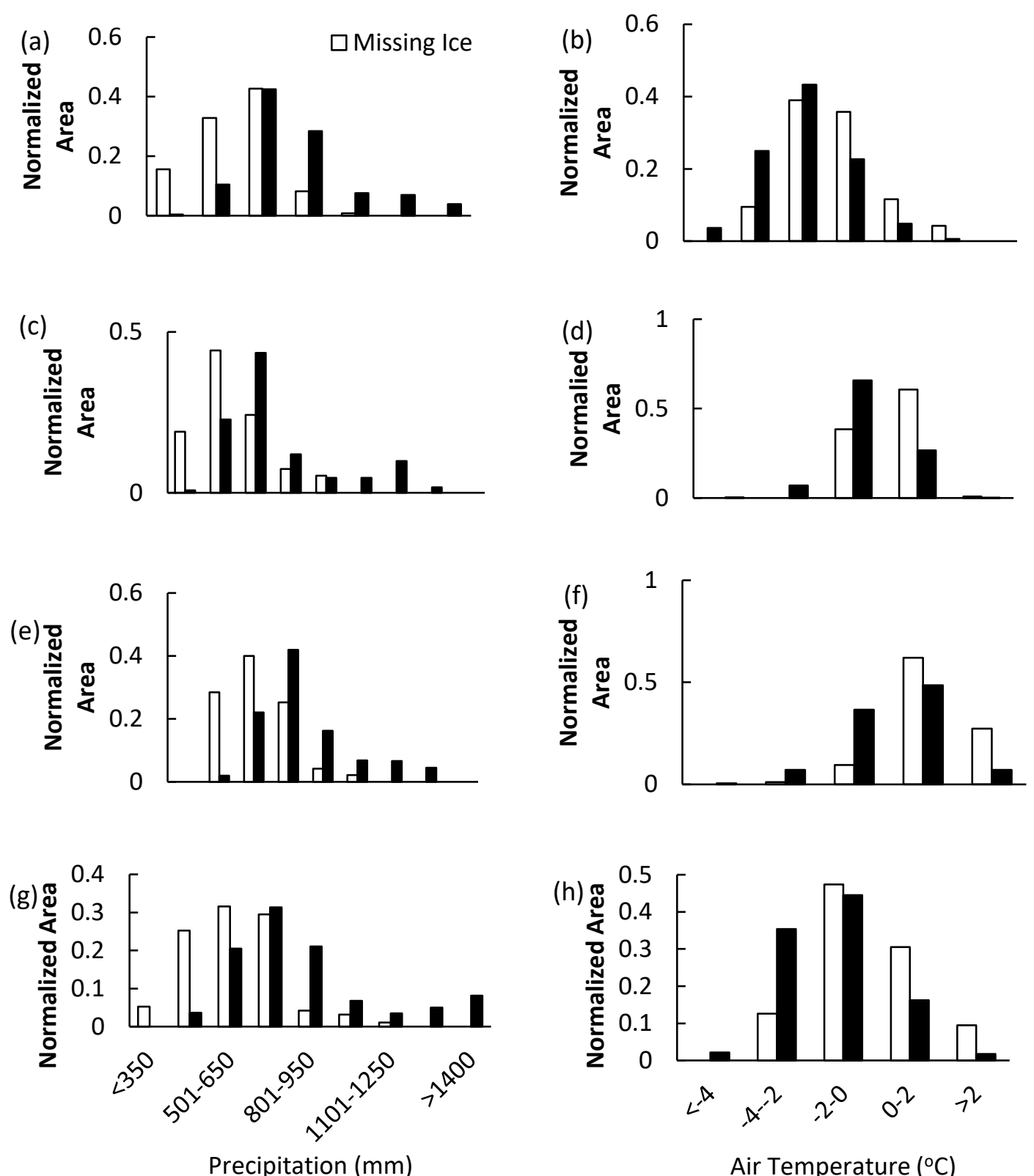

Air Temperature $\left({ }^{\circ} \mathrm{C}\right)$

Figure 7.10: Comparison of missing and correctly modeled glacier distributions from the application of the final model, where parameters are adjusted to minimize extra ice and a precipitation mask is added, to the North Cascades using RCP 4.5, with (a) winter precipitation and (b) winter temperature, (c) summer precipitation, (d) summer temperature, (e) spring precipitation, (f) spring temperature, (g) fall precipitation, (h) fall temperature. All precipitation graphics are over the same interval, using $200 \mathrm{~mm}$ bin intervals. Temperature is similar, using $2{ }^{\circ} \mathrm{C}$ bin intervals. Missing glaciers are normalized to an area of $61.37 \mathrm{~km}^{2}$, and correctly modeled ice to $288.6 \mathrm{~km}^{2}$ 


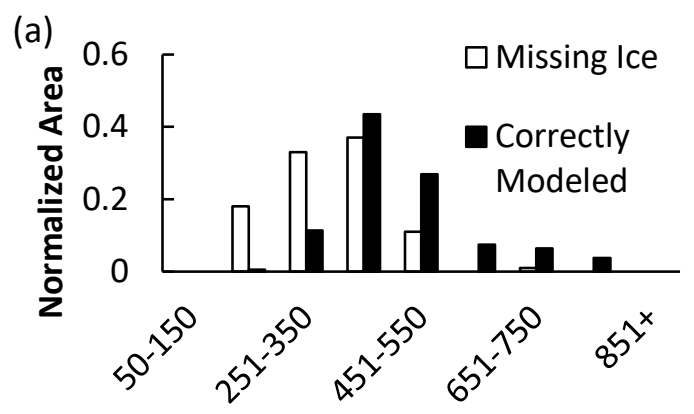

(b)
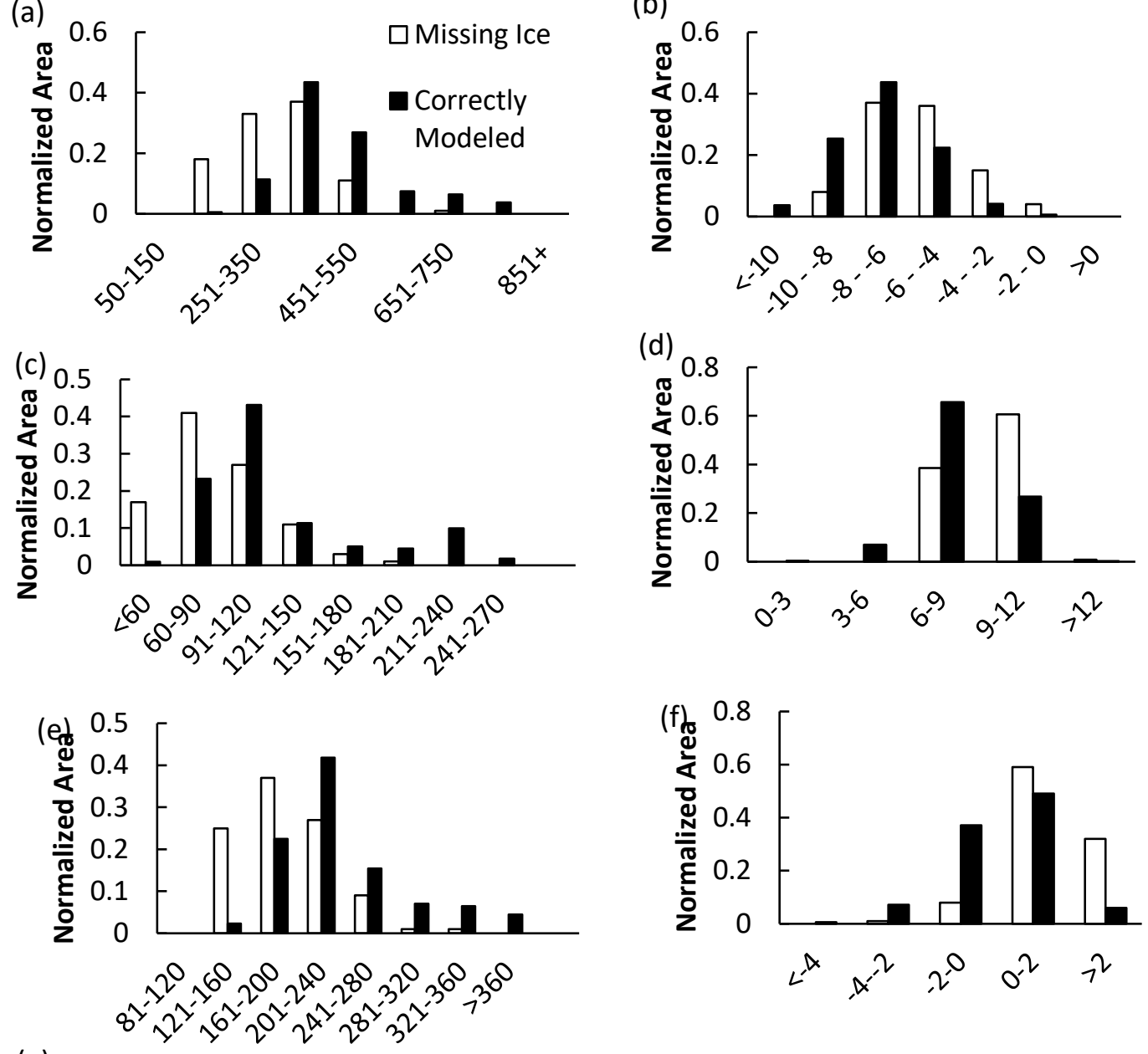

(g)
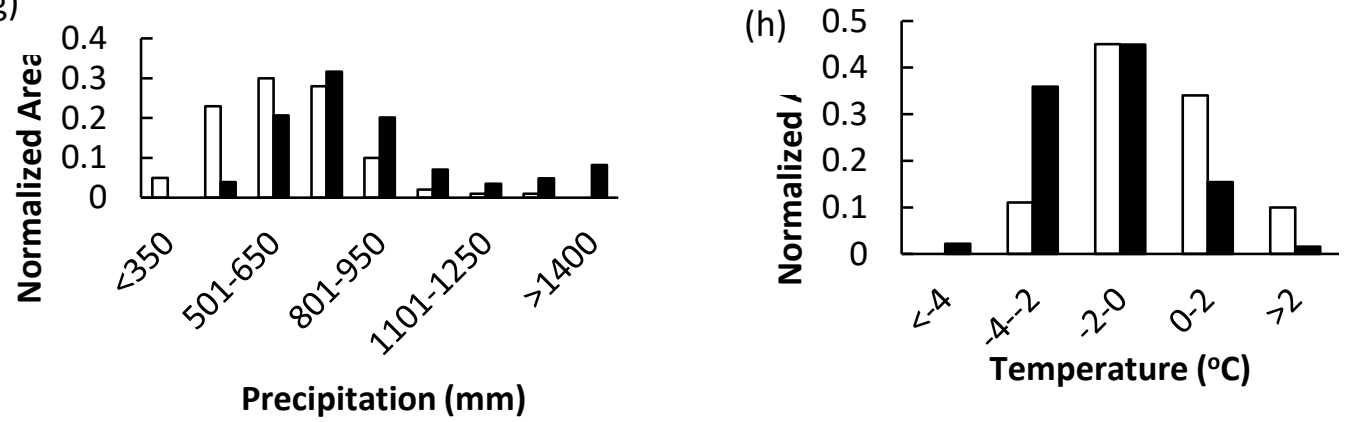

Figure 7.11: Comparison of all missing and correctly modeled glaciers from the application of the final model, where parameters are adjusted to minimize extra ice and a precipitation mask is added, to the North Cascades, using RCP, 2.6 over (a) winter precipitation (bin intervals of 100 $\mathrm{mm}$ ) (b) winter temperature (intervals of $2^{\circ} \mathrm{C}$ ), (c) summer precipitation (intervals of $30 \mathrm{~mm}$ ), (d) summer temperature (intervals of $3^{\circ} \mathrm{C}$ ), and (e) spring precipitation (intervals of $40 \mathrm{~mm}$ ), (f) spring temperature (intervals of $2^{\circ} \mathrm{C}$ ), (g) fall precipitation (intervals of $150 \mathrm{~mm}$ ), (h) fall temperature (intervals of $2^{\circ} \mathrm{C}$ ). Missing glaciers are normalized to an area of $59.44 \mathrm{~km}^{2}$, and correctly modeled glaciers to $290.53 \mathrm{~km}^{2}$. 

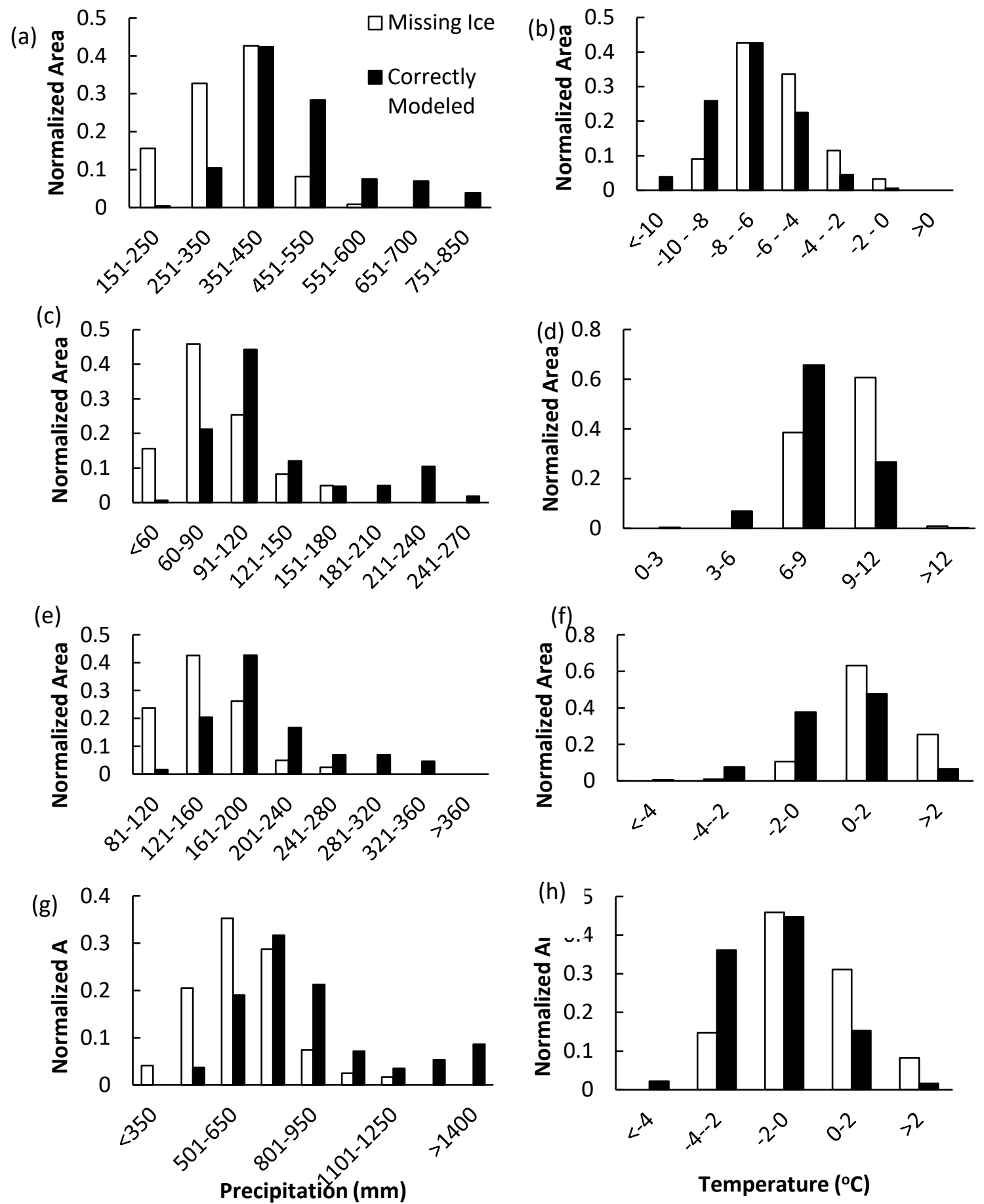

Figure 7.12: Comparison of missing and correctly modeled glaciers from the application of the final model, where parameters are adjusted to minimize extra ice and a precipitation mask is added, to the North Cascades, using RCP 8.5, over (a) winter precipitation (bin intervals of 100 $\mathrm{mm}$ ) (b) winter temperature (intervals of $2^{\circ} \mathrm{C}$ ), (c) summer precipitation (intervals of $30 \mathrm{~mm}$ ), (d) summer temperature (intervals of $3^{\circ} \mathrm{C}$ ), and (e) spring precipitation (intervals of $40 \mathrm{~mm}$ ), (f) spring temperature (intervals of $2^{\circ} \mathrm{C}$ ), (g) fall precipitation (intervals of $150 \mathrm{~mm}$ ), (h) fall. 


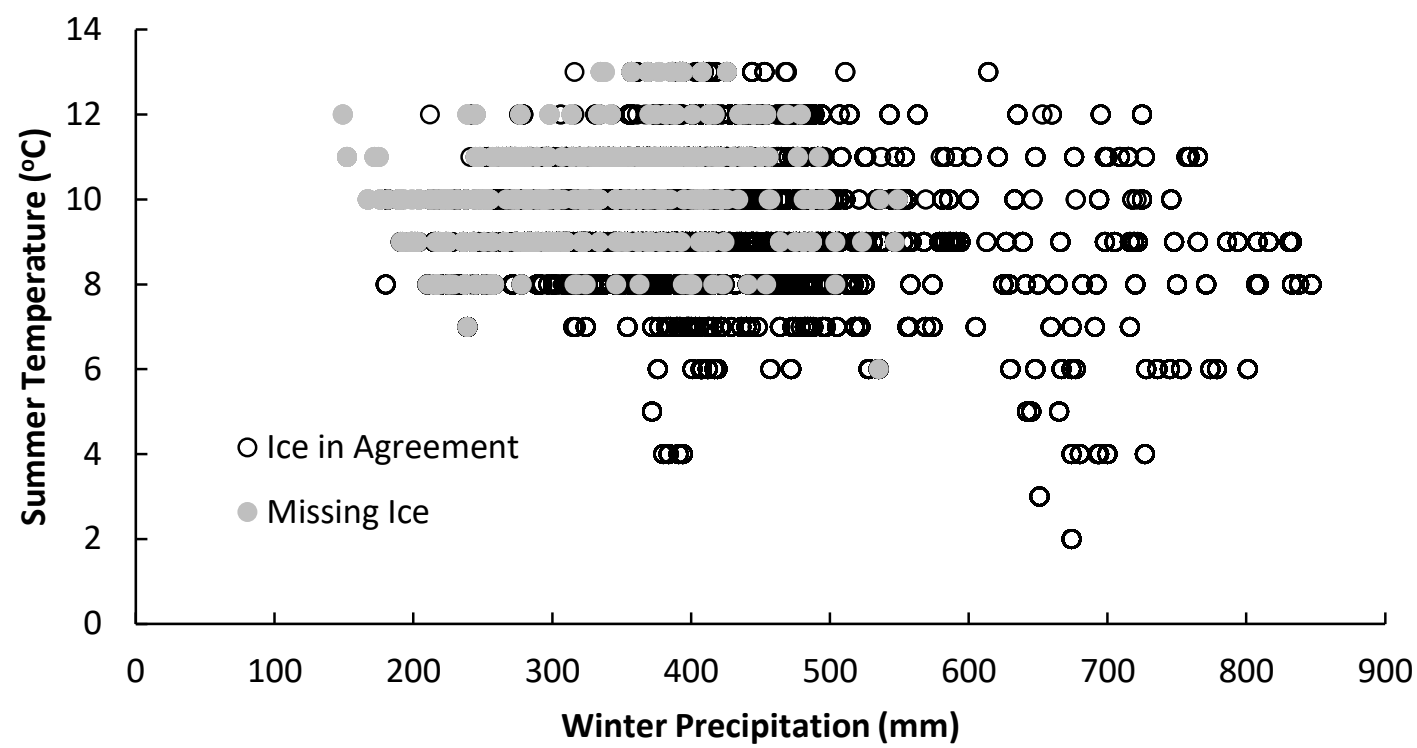

Figure 7.13: Comparison of the distribution of correctly modeled and missing glaciers with both temperature and precipitation for the application of the final model, where parameters are adjusted to minimize extra ice and a precipitation mask is added, to the North Cascades using RCP 2.6.

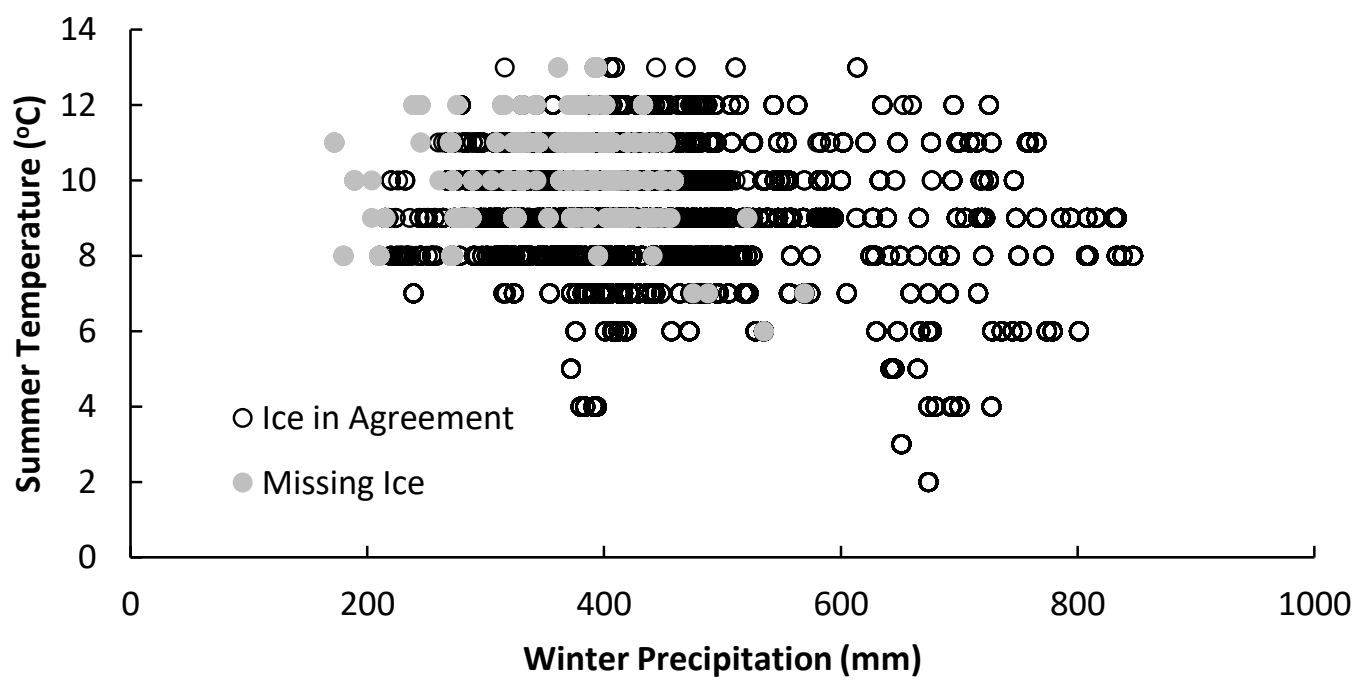

Figure 7.14: Comparison of the distribution of correctly modeled and missing glaciers with both temperature and precipitation in the application of the final model, where parameters are adjusted to minimize extra ice and a precipitation mask is added, to the North Cascades, using RCP 8.5. 

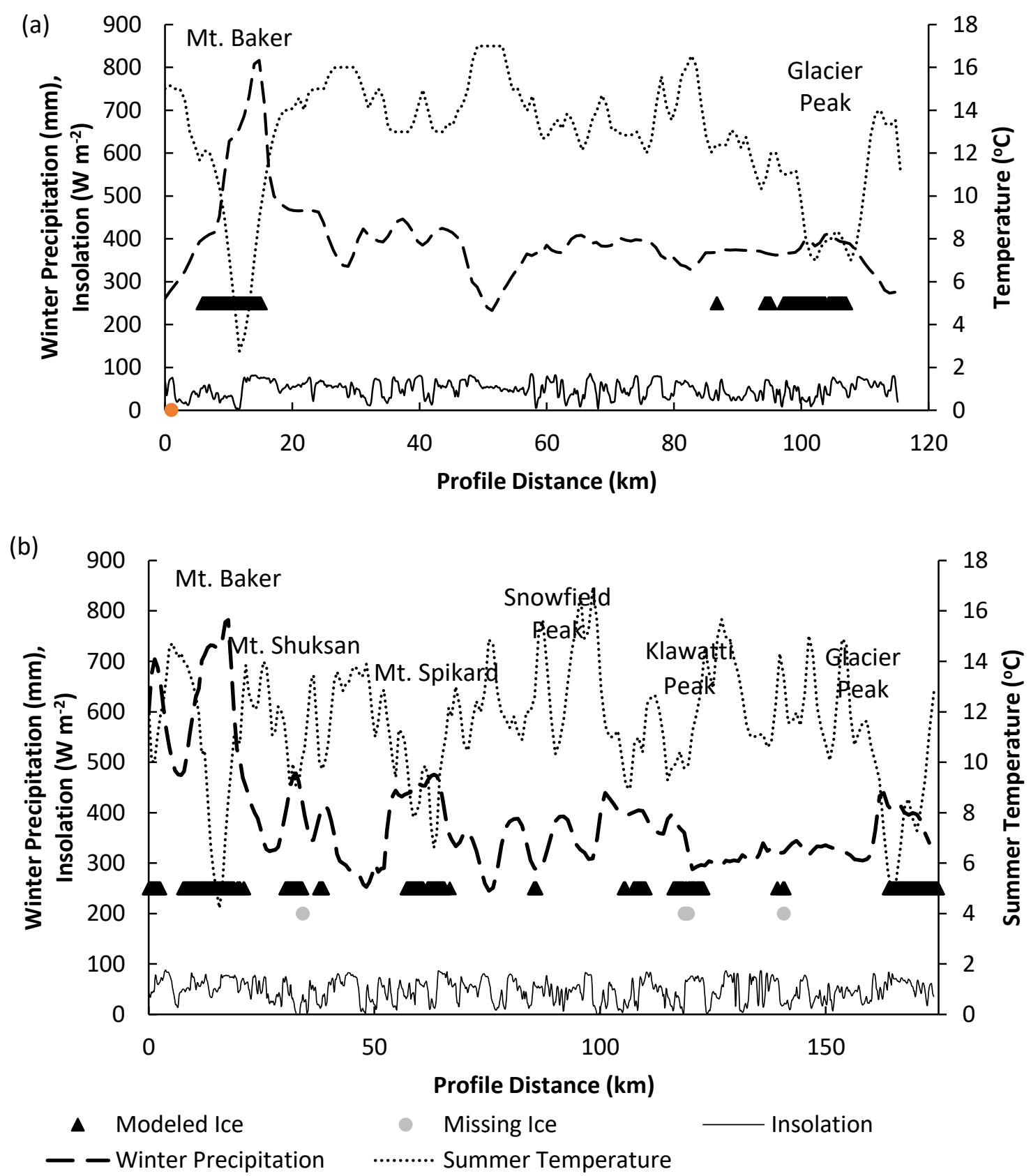

Figure 7.15: Distribution of temperature, precipitation, and solar radiation over modeled ice and missing observed ice from the application of the final model, where parameters are adjusted to minimize extra ice and a precipitation mask is added, to the North Cascades using RCP 2.6, where climate data is based on averages from 1961-1970 and ice extent data is based on the 1:24000 outlines from the USGS topographic maps (USGS, 1998) for the year 1970. a) shows the c limate data over the straight profile between Mt. Baker and Glacier Peak and b) shows the bent profile that goes through several other major peaks besides Mt. Baker and Glacier Peak. The profiles are defined in Figure 3.2. 

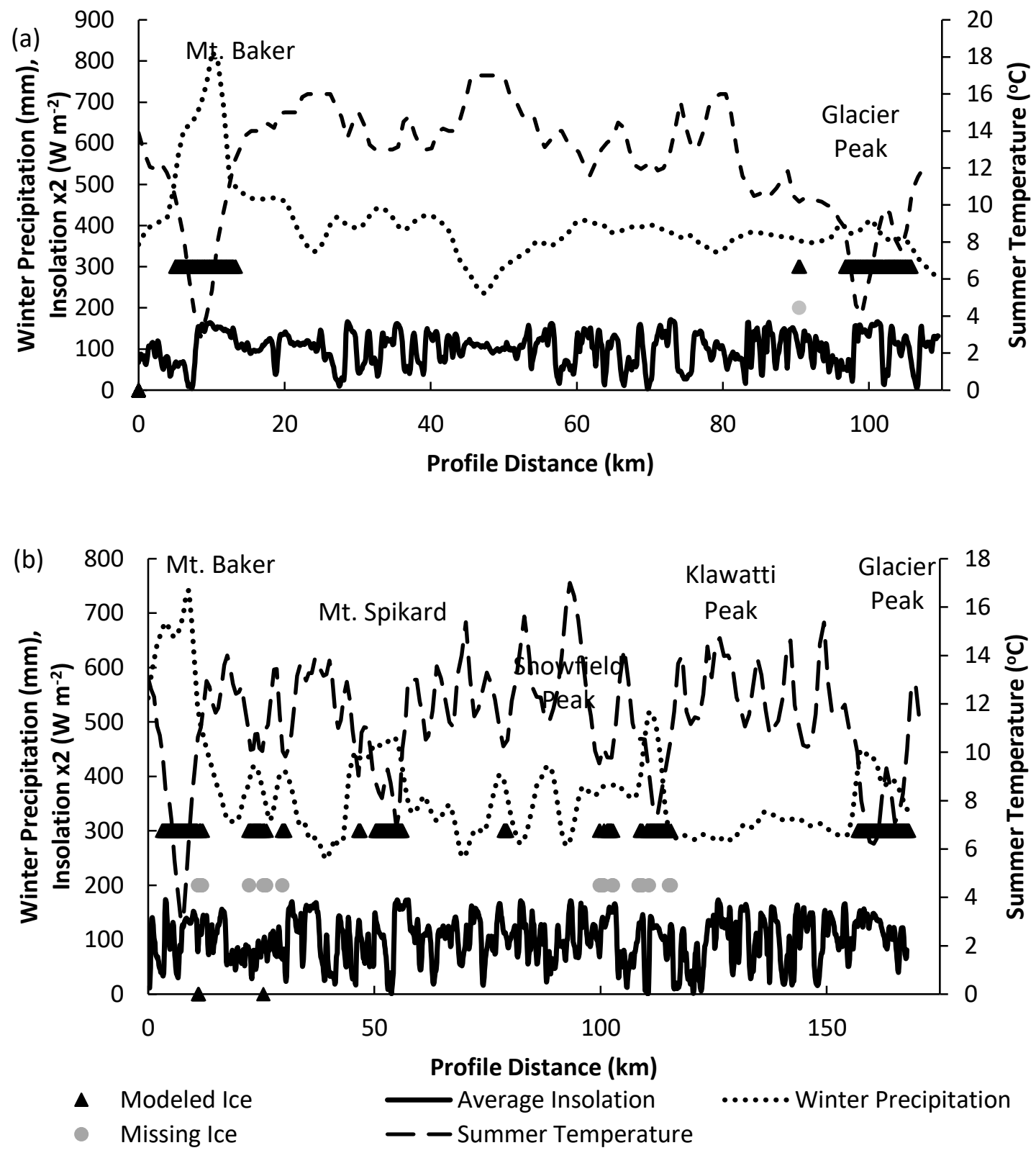

Figure 7.16: Distribution of temperature, precipitation, and solar radiation over modeled ice and missing observed ice from the application of the final model, where parameters are adjusted to minimize extra ice and a precipitation mask is added, to the North Cascades using RCP 8.5, where climate data is based on averages from 1961-1970 and ice extent data is based on the 1:24000 outlines from the USGS topographic maps (USGS, 1998) for the year 1970. a) shows the climate data over the straight profile between Mt. Baker and Glacier Peak and $b$ ) shows the bent profile that goes through several other major peaks besides $\mathrm{Mt}$. Baker and Glacier Peak. The extent of the profiles can be seen in Figure 3.2. 


\section{F. Future Projections}

While not included in the main text, each RCP's effect on future glacier area and distribution with topography was examined. The main difference between the RCP scenarios is the magnitude of the glacier retreat (Figure 7 and Table 7.3) and strength of topographic dependence, though the relationships remain the same (Figure 7. and Figure 7.). Initially, aspect is northeastern for all scenarios but, by 2075 , the distribution of glaciers with aspect appears to have no clear trends for RCP 2.6 and 8.5, whereas a strong trend to the SW and SE occur in RCP 4.5 before returning to a NE bias in 2098 when the glaciers advanced (Figure 7. and Figure 7.). The lack of aspect dependence in the model might be due to the precipitation mask or the choice of solar time near solar noon, overriding the strength of topography on glacier placement. Climatic and topographic analyses using RCP 2.6 and 8.5 are similar to those presented for RCP 4.5 future projections (Figure 7., Figure 7., Figure 7., Figure 7., and Figure 7.). Glacier response to RCP 2.6 shows less favorability of the distribution with local climate. In terms of retreat and distribution with topography, RCP 2.6's 2100 glacier distribution with elevation appear to match RCP

Table 7.3: Summary of retreat rates $\left(\mathrm{km}^{2} \mathrm{yr}^{-1}\right)$ and the estimated year of glacier disappearance for the for all RCP scenarios in application of the final model, where parameters are adjusted to minimize extra ice and a precipitation mask is added, to the North Cascades us. The retreat rate was calculated by fitting a linear regression between 1970 to 2100 , or 2075 to 2100 , and the disappearance year from extrapolation of the retreat rate.

1970-2100

2075-2100

\begin{tabular}{lcc|cc} 
& Retreat Rate & Disappearance Year & Retreat Rate & Disappearance Year \\
\cline { 2 - 5 } RCP 2.6 & -1.6 & 2193 & -1.3 & 2216 \\
RCP 4.5 & -2.3 & 2129 & +4.5 & -- \\
RCP 8.5 & -2.5 & 2093 & -0.12 & 2237
\end{tabular}

8.5's 2050 distribution and RCP 4.5's 2025 distribution, possibly indicating that RCP 2.6 is predicting glacier area loss almost five decades behind RCP 8.5, and The below images are additional comparisons of the predicted future retreat of ice for various RCP scenarios. 
(a)

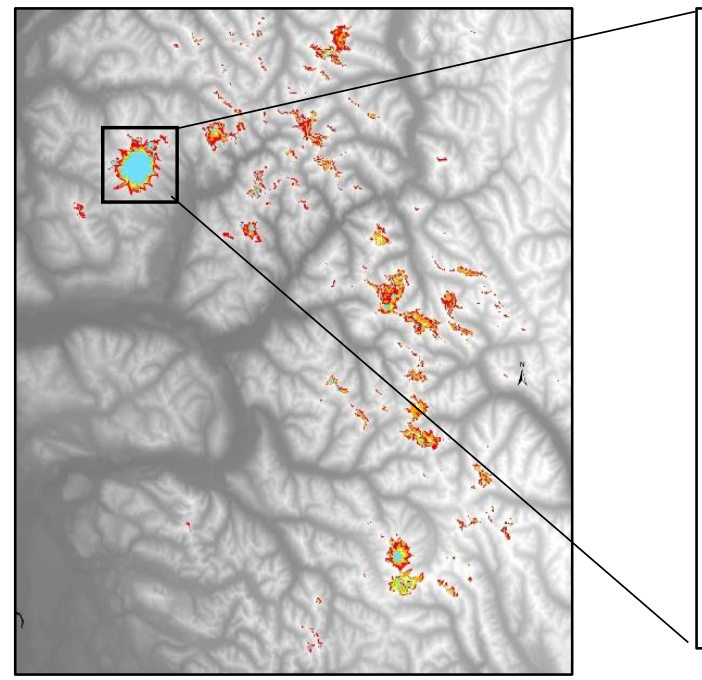

(b)

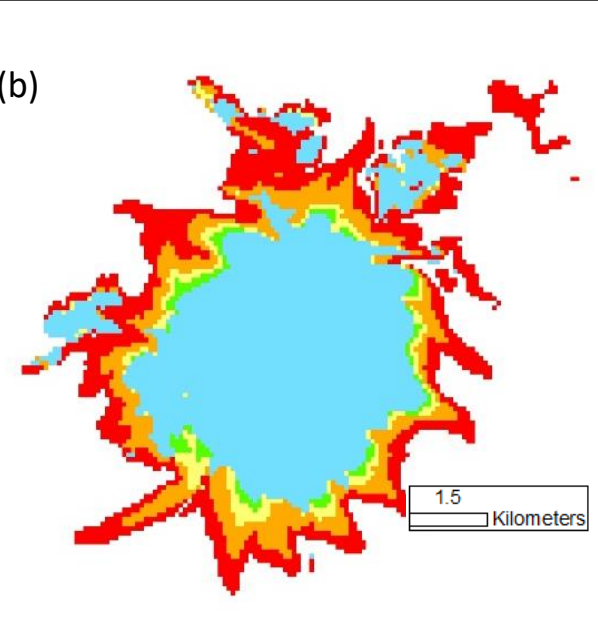

Figure 7.17: Change in ice extents over time in the North Cascades as predicted by the final model where parameters are chosen to minimize extra ice before the addition of the precipitation mask, (a) shows the entire model domain, and (b) shows Mt. Baker for the precipitation mask model using RCP 4.5. Red indicates the glacier extents from 2000, orange those from 2025, yellow 2050, green 2075, and blue 21000

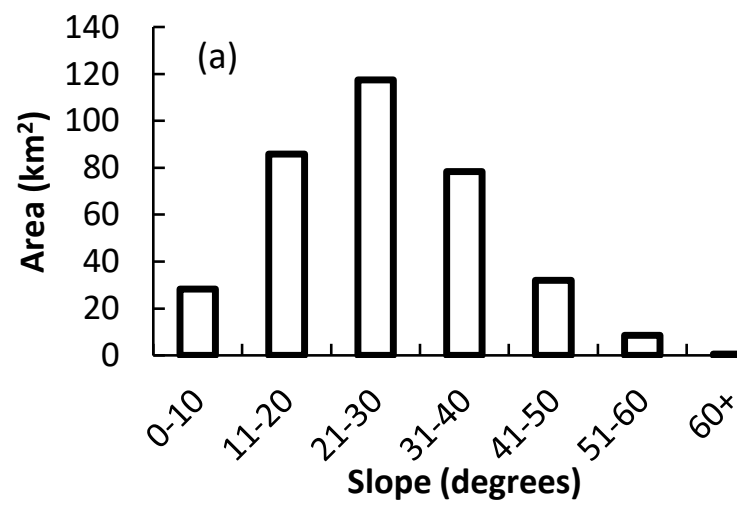

Figure 7.18: Distribution of glaciers with slope for the precipitation mask model employing application of the final model, where parameters are adjusted to minimize extra ice and a precipitation mask is added, to the North Cascades using RCP 4.5. Left graphics represent 2000 , right represent 2075. Data is binned in intervals of $10^{\circ}$ 
(a)
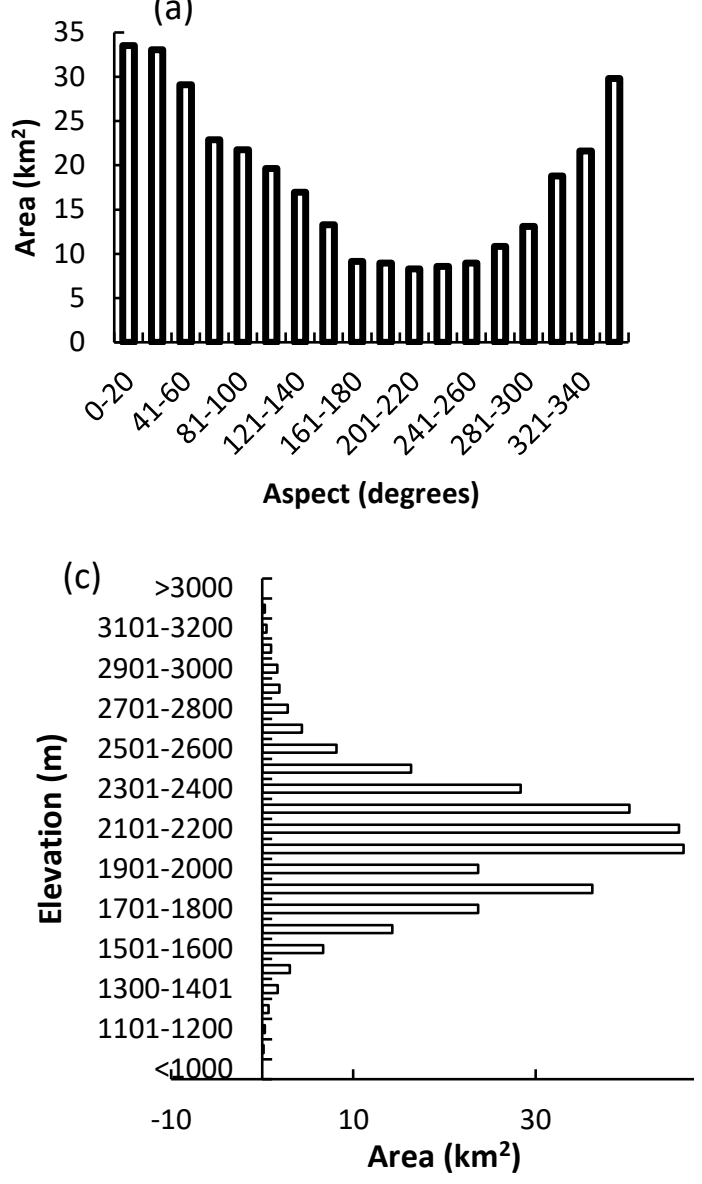
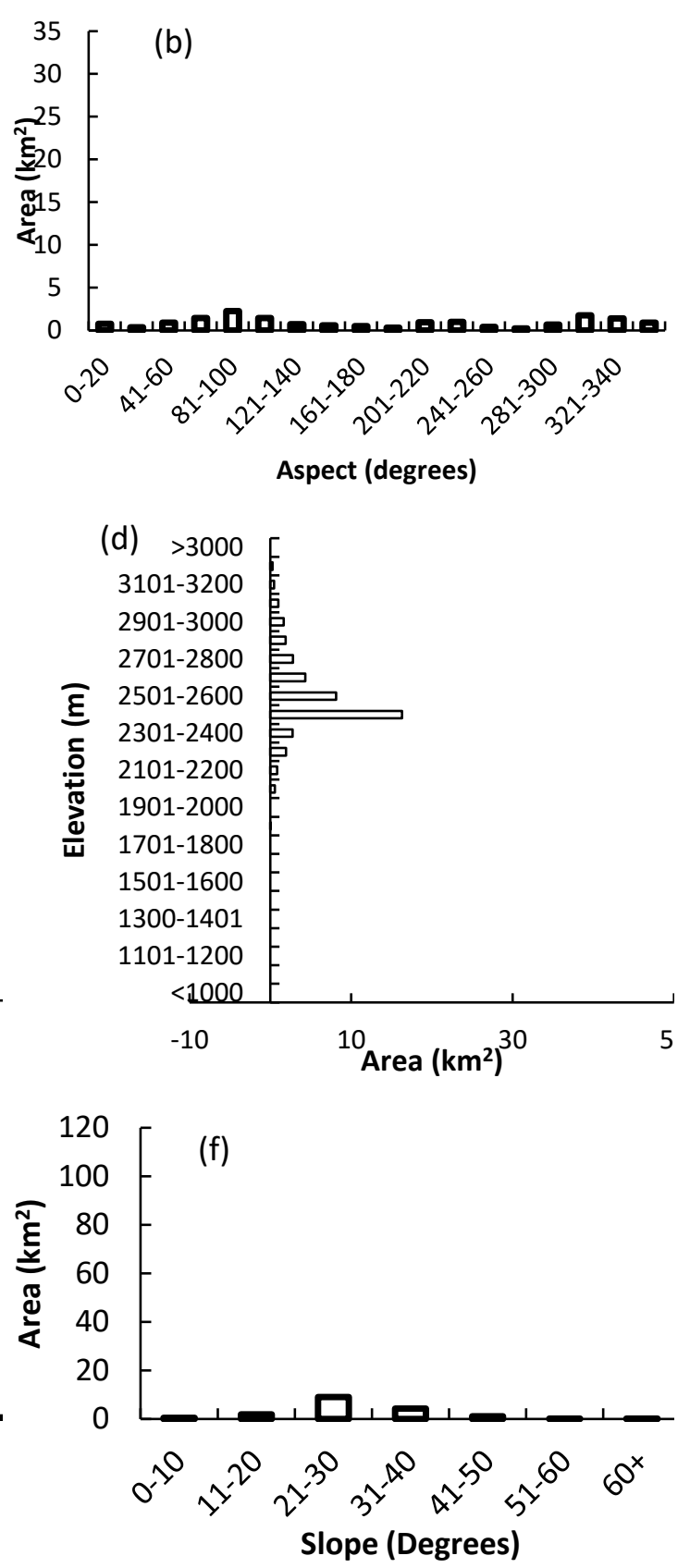

Figure 7.19: Change in glacier distribution with topography over time with the application of the final model, where parameters are adjusted to minimize extra ice and a precipitation mask is added, to the North Cascades using RCP 8.5. Left columns are from the year 2000, the right are from 2100. The first row shows the distribution of glaciers with aspect, the second the shows the distribution with Elevation, and the thirds the distribution with slope. Aspect is classified in $30^{\circ}$ intervals beginning at $0^{\circ}$, slope is classified in $10^{\circ}$ intervals beginning at $0^{\circ}$, and elevation is classified in intervals of $100 \mathrm{~m}$ beginning at $400 \mathrm{~m}$. 

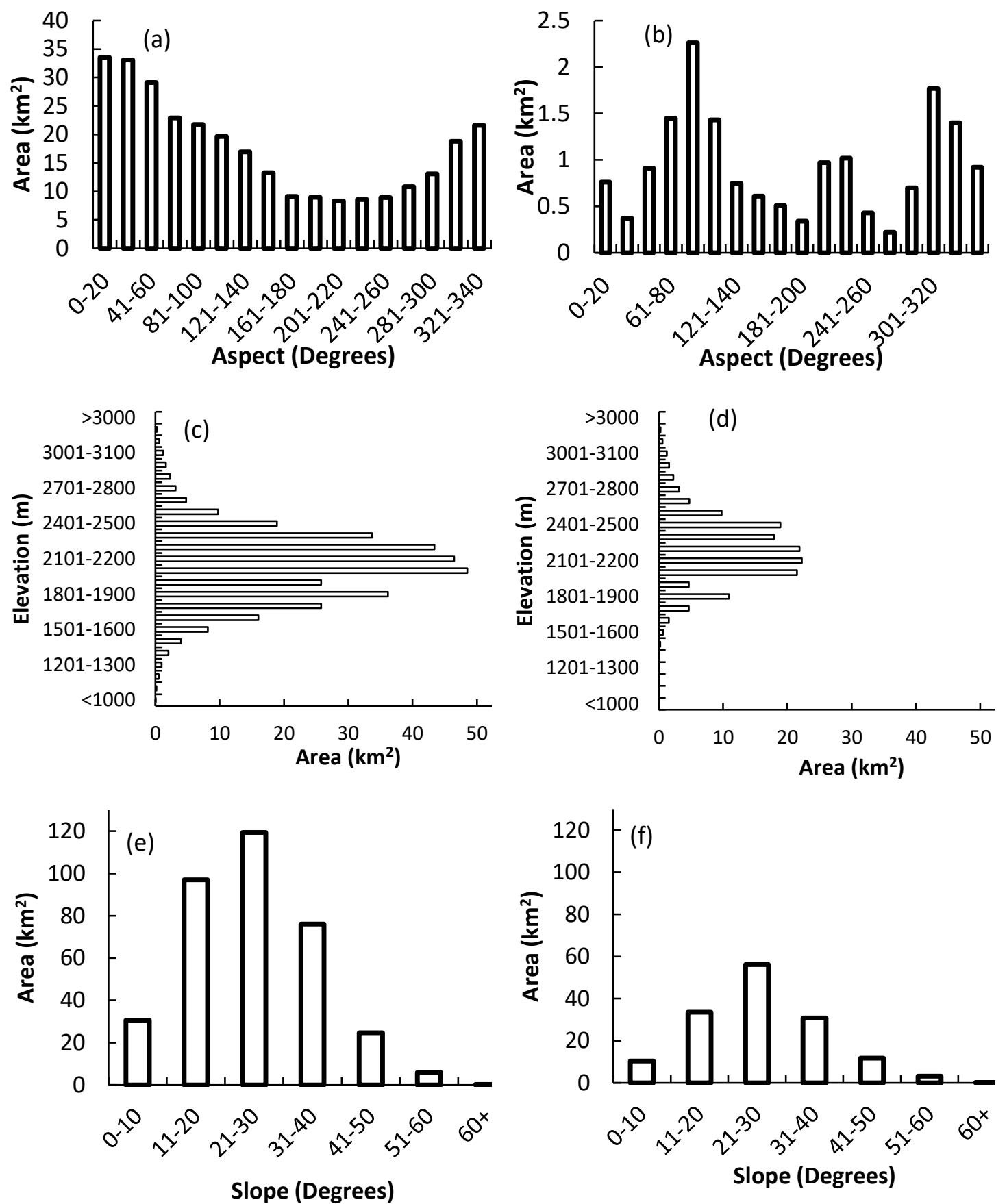

Figure 7.20: Change in glacier distribution with topography over time with the application of the final model, where parameters are adjusted to minimize extra ice and a precipitation mask is added, to the North Cascades using RCP 2.6. The first row shows the distribution of glaciers with aspect, the second the shows the distribution with Elevation, and the thirds the distribution with slope. Aspect is classified in $30^{\circ}$ intervals beginning at $0^{\circ}$, slope is classified in $10^{\circ}$ intervals beginning at $0^{\circ}$, and elevation is classified in intervals of $100 \mathrm{~m}$ beginning at $400 \mathrm{~m}$. Left graphics are from the year 2000 , the right are from 2100 . 

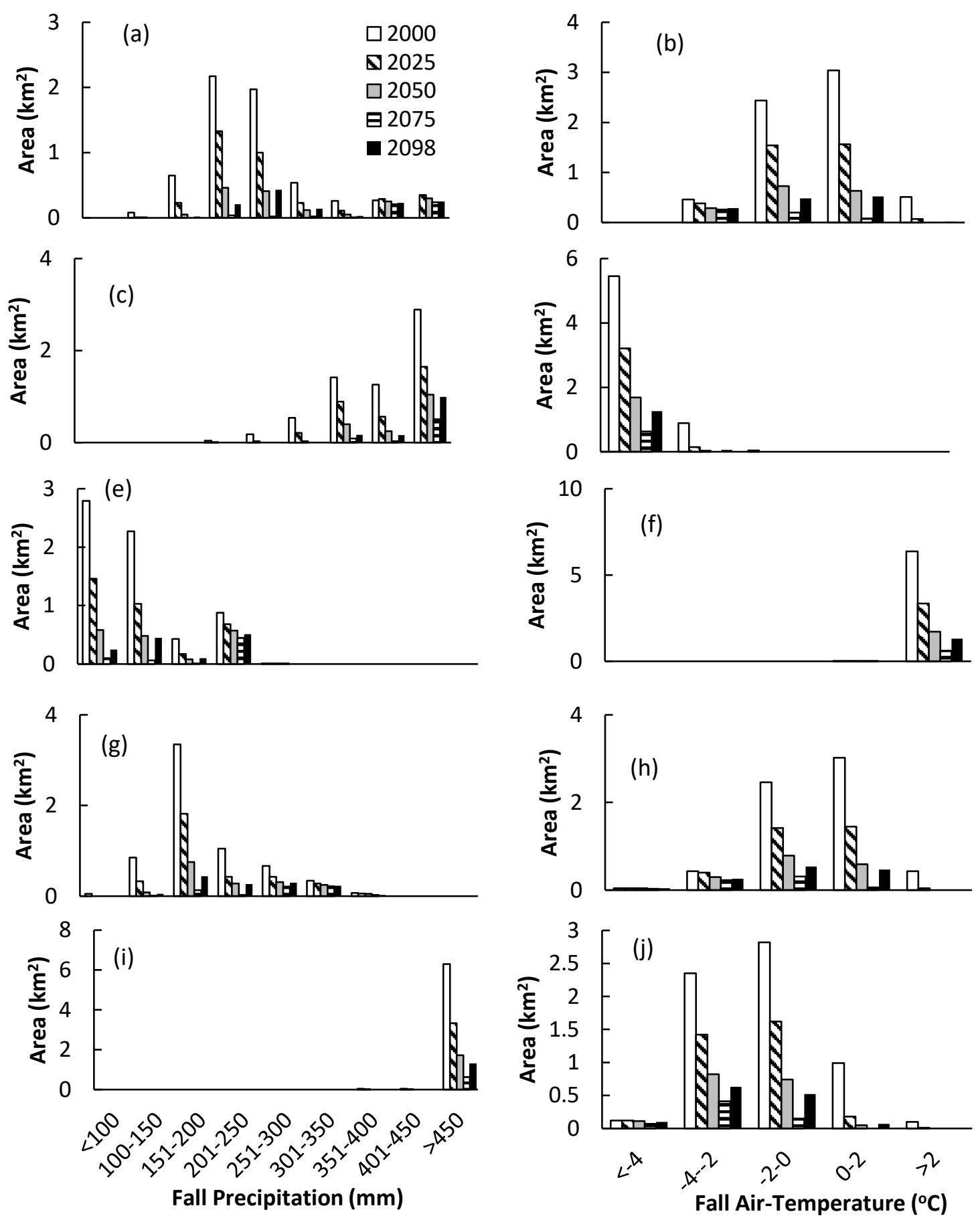

Figure 7.21: Distribution of future projections of glaciers in the application of the final model, where parameters are adjusted to minimize extra ice and a precipitation mask is added, to the North Cascades using RCP 4.5 with a) annual precipitation, (b) annual air temperature, (c) winter precipitation, (d) winter air temperature, (e) summer precipitation, (f) summer temperature, (g) spring precipitation, (h) spring temperature, (i) fall precipitation, (j) fall temperature. Precipitation in binned in intervals of $50 \mathrm{~mm}$, and temperature in intervals of $2^{\circ} \mathrm{C}$. 

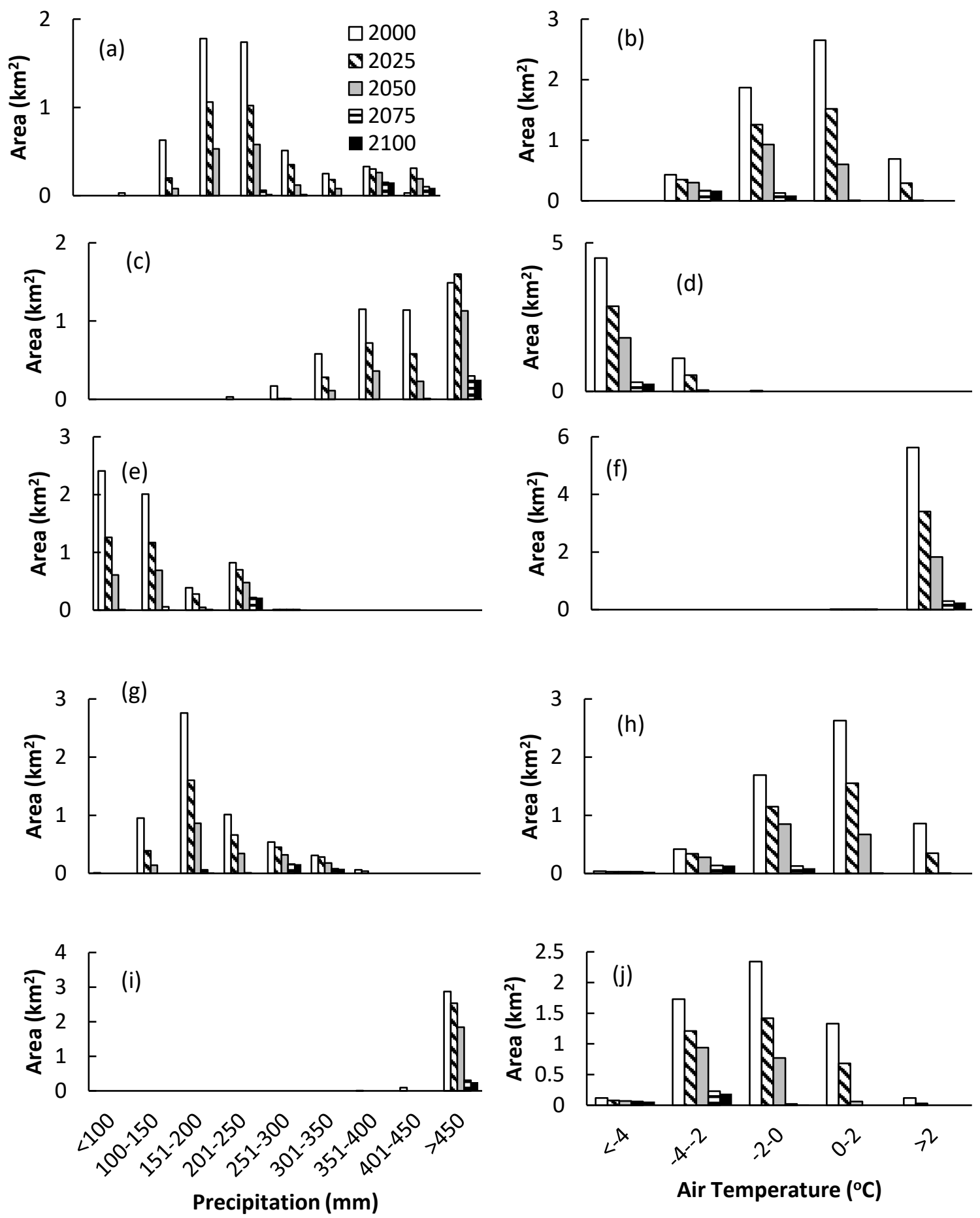

Figure 7.22: Distribution of future projections of glaciers in the application of the final model, where parameters are adjusted to minimize extra ice and a precipitation mask is added, to the North Cascades using RCP 8.5 with a) annual precipitation, (b) annual air temperature, (c) winter precipitation, (d) winter air temperature, (e) summer precipitation, (f) summer temperature, (g) spring precipitation, (h) spring temperature, (i) fall precipitation, and (j) fall temperature. Precipitation in binned in intervals of $50 \mathrm{~mm}$, and temperature in intervals of $2^{\circ} \mathrm{C}$. 

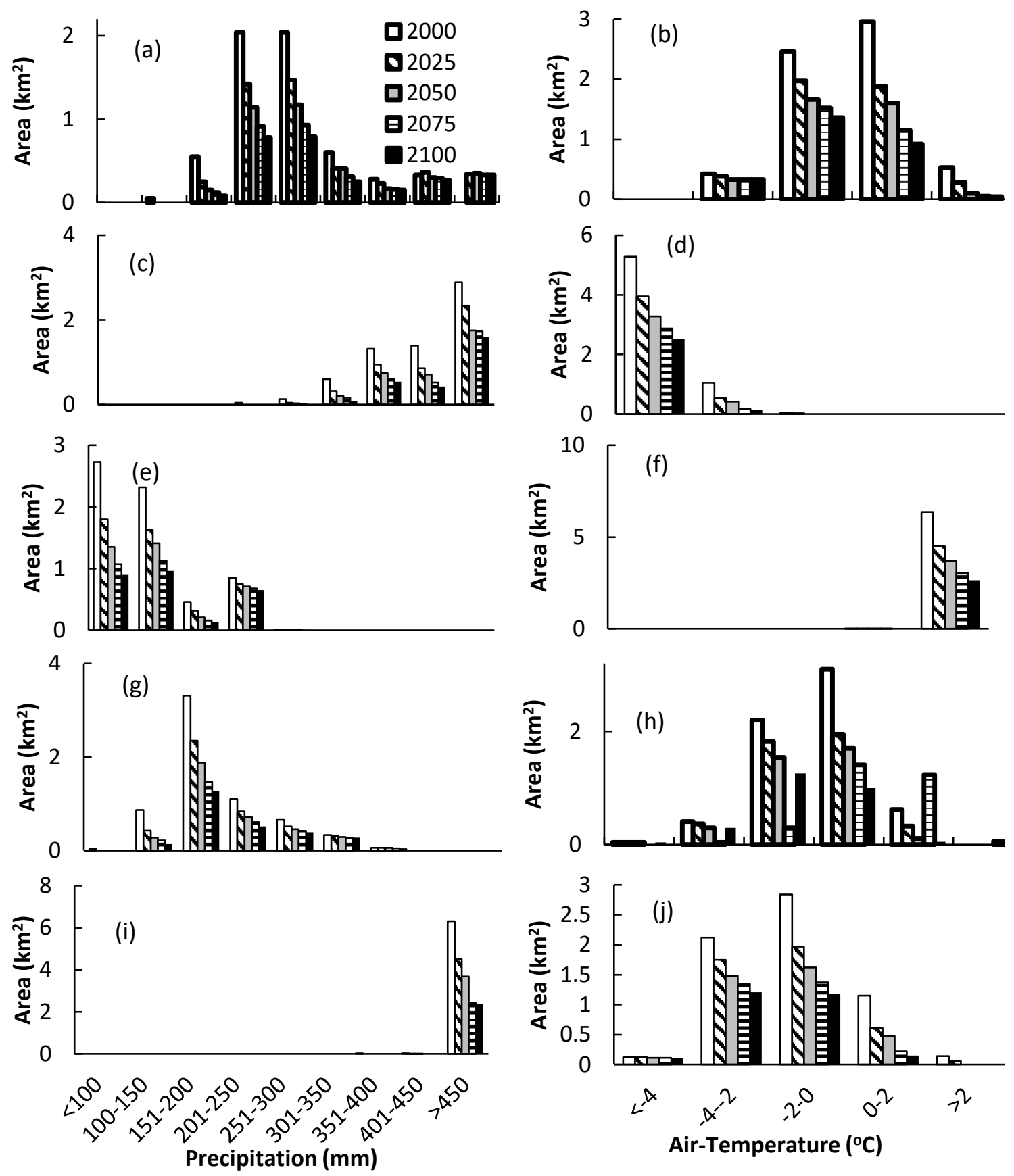

Figure 7.3: Distribution of future projections of glaciers in the application of the final model, where parameters are adjusted to minimize extra ice and a precipitation mask is added, to the North Cascades using RCP 2.6 with a) annual precipitation, (b) annual air temperature, (c) winter precipitation, (d) winter air temperature, (e) summer precipitation, (f) summer temperature, (g) spring precipitation, $(\mathrm{h})$ spring temperature, (i) fall precipitation, and (j) fall temperature. Precipitation is binned in intervals of $50 \mathrm{~mm}$, and temperature in intervals of $2^{\circ} \mathrm{C}$ 